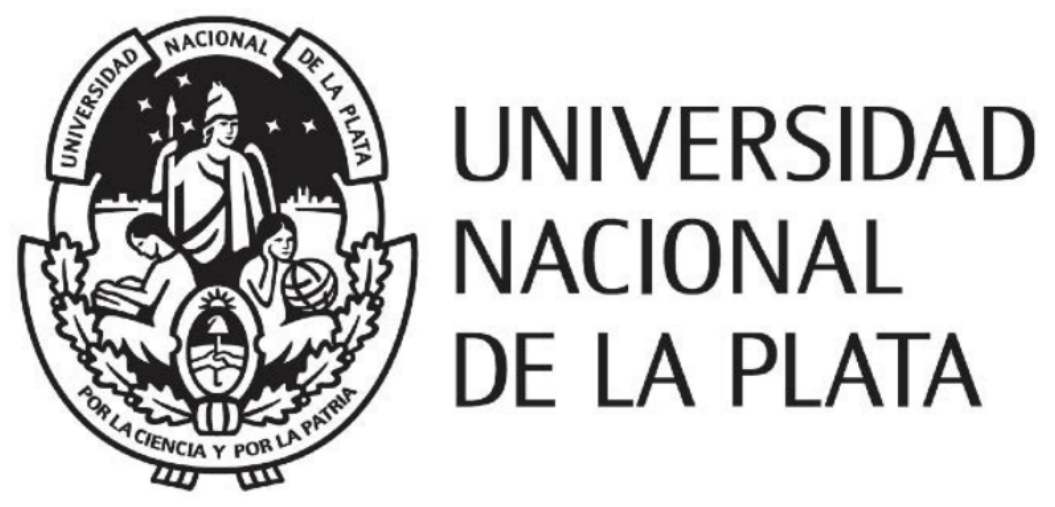

Facultad de Informática

\title{
Gestión de notificaciones en dispositivos móviles de chicos/as en edad escolar
}

Trabajo de tesis para obtener el grado de Magíster en Ingeniería del Software

Tesista: Julián Enrique Castro Olivera

Director: Dr. Gustavo Rossi

CoDirector: Dr. Andrés Rodríguez

La Plata, Septiembre del 2020 


\section{RESUMEN}

Las nuevas tecnologías traen aparejadas muchas ventajas a nuestras vidas, pero también grandes desafíos. Los teléfonos celulares, cada vez con más potencia computacional, se convirtieron en herramientas fundamentales para tareas del día a día. Sin embargo, también se transformaron en una fuente de distracciones de alta demanda. El uso de celulares en las aulas es una realidad, y si bien se debate entre prohibiciones y permisividades, surge la necesidad de analizar la situación con el objetivo de aportar a la problemática de la distracción que los mismos generan. Las notificaciones que llegan al celular, generadas por distintas fuentes, pueden ser inoportunas y atraer la atención de los niños y niñas. En esta tesis se realiza un análisis de la situación actual en los entornos educativos utilizando técnicas centradas en el humano, con el fin de identificar puntos de dolor y oportunidades de mejora. Con esta base y teniendo en cuenta tecnologías actuales orientadas a la gestión de la atención, se plantea una solución holística, teniendo en cuenta distintos momentos del día escolar.

\section{ABSTRACT}

New technologies bring many advantages to our lives, but also great challenges. Cell phones, with increasing computational power, became essential tools for day-to-day tasks. However, they also became a source of high-demand distractions. The use of cell phones in classrooms is a reality, and although there is a debate between prohibitions and permissiveness, the need arises to analyze the situation with the aim of contributing to the problem of the distraction that they generate. Notifications that reach the cell phone, generated by different sources, can be inconvenient and attract the attention of children. In this thesis an analysis of the current situation in educational environments is carried out using human-centered techniques, in order to identify pain points and opportunities for improvement. With this base and taking into account current technologies oriented to the management of attention, a holistic solution is proposed, taking into account different moments of the school day. 


\section{AGRADECIMIENTOS}

"Al Dr Rossi por privilegio de tener su apoyo y ofrecerse para ser el Director de mi trabajo de Tesis"

"A Andres Rodriguez, persona fundamental en la realización de la tesis mediante su apoyo incondicional, excelente predisposición, revisiones, consejos y motivación que me ha brindado todo el empuje e inspiración necesarias para terminar el presente trabajo en plena pandemia histórica para toda la humanidad. Andrés es de esos tutores que no se encuentran fácil y que todos necesitamos para poder cumplir nuestras metas académicas con conocimiento de calidad. ¡Voy a estar agradecido siempre Andrés! Y la verdad no alcanzan las palabras para expresarlo.

"A Javier Bazzocco por todo su apoyo y motivación para poder terminar mi última materia de la Maestría, Bases de Datos, por su guía y orientación por donde encaminar la tesis y por su GRAN aporte de haberme recomendado a Andrés Rodriguez."

"A mi querido compañero, excelente profesional del diseño y buen hombre señorón Pachu Strauss, que con sus genialidades hizo brillar las pantallas del prototipo, comprometiéndose con buenas causas desinteresadamente, con el fin de aportar al bien, en este mundo lleno de desafíos. ¡Infinitas gracias Pachu! Pusiste luz donde antes había oscuridad y dibujos de ingeniero." 


\section{INDICE}

CAPÍTULO 1: INTRODUCCIÓN 9

1.1 Contexto de la tesis $\quad 9$

$\begin{array}{ll}1.2 \text { Objetivo de la tesis } & 10\end{array}$

1.3 Contribuciones 11

1.4 Organización de la tesis $\quad 11$

CAPÍTULO 2: ESTADO DE LA CUESTIÓN

2.1 Marco teórico 13

2.1.1 Introducción al concepto de atención 13

2.1.2 Gestión de la competencia de estímulos digitales en la escuela 14

2.2 Trabajos relacionados $\quad 15$

2.2.1 Entornos Inteligentes de Aprendizaje $\quad 15$

2.2.2 Estudios de campo teléfono celular en las aulas $\quad 19$

2.3 Gestión de la atención: tecnologías para la optimización del uso de notificaciones y la atención $\quad 22$

2.3.1 Auditorium Mobile Classroom Service (AMCS) 22

2.3.2 Notificaciones móviles para fomentar la práctica reflectiva en Meta-Learning 24

2.3.3 Computación móvil anticipatoria 30

CAPÍTULO 3: DESCRIPCIÓN DEL PROBLEMA

3.1 Marco de trabajo empleado 35

3.1.1 Ingeniería de software centrada en las personas 35

3.1.2 Design thinking $\quad 37$

3.2 Empatizar y definir $\quad 40$

3.2.1 Representación de los actores por medio de Personas $\quad 40$

3.2.2 Journey Map $\quad 43$

3.2.3 Componentes del Journey Map: 44

3.2.4 Fases del Journey Map $\quad 45$

CAPÍTULO 4: SOLUCIÓN PROPUESTA

4.1 Aprender jugando $\quad 51$

4.1.1 Entrenando planificación y memoria de trabajo a niños/as de tercer grado 53

4.1.2 Gamification en la educación y la economía de la atención 59

4.1.3 Componentes esenciales en el diseño de juegos $\quad 60$

4.2 Concentrate: un juego para ayudar a la concentración 61

4.2.1 Historia del juego (Storytelling) $\quad 62$

4.2.2 Reglas básicas del juego 63

4.2.3 Journey Map del Alumno/a 64

4.2.4 Concentrate: flujo del alumno $\quad 65$ 
4.2.5 Journey Map del Maestro/a

4.2.6 Concentrate: flujo del Maestro/a $\quad 71$

4.2.7 Funcionalidades futuras $\quad 74$

4.2.8 Modos en que puede entrar el juego dependiendo del contexto del alumno/a: 74

$\begin{array}{ll}\text { 4.3 Testear, validar, continuar testeando } & 75\end{array}$

4.4 El método de inspección como herramienta alternativa de testeo 76

4.5 Inspección con heurísticas específicas para aplicaciones móviles educativas basadas en gamificación $\quad 79$

CAPÍTULO 5: CONCLUSIONES

$\begin{array}{ll}5.1 \text { Conclusiones generales } & 89\end{array}$

$\begin{array}{ll}5.2 \text { Trabajos futuros } & 91\end{array}$

$\begin{array}{ll}\text { Bilbiografía } & 93\end{array}$

$\begin{array}{lr}\text { Apéndices } & 97\end{array}$

$\begin{array}{ll}\text { Entrevistas } & 97\end{array}$

Maestra $1 \quad 97$

Maestra $2 \quad 99$

Maestra $3 \quad 100$

Padre $1 \quad 102$

Journey Map Alumno $\quad 104$

Concentrate: Journey Map Alumna/o 106

$\begin{array}{ll}\text { Concentrate: Journey map Maestro/a } & 107\end{array}$ 


\section{Tabla de figuras}

$\begin{array}{lr}\text { Figura 1: Wandering Platform [11] } & 18\end{array}$

Figura 2: Recolectando y presentando evidencia [13] 21

Figura 3: material educativo personalizado [14] 23

Figura 4: Notificaciones con reflexiones y preguntas [15] 25

Figura 5 - Menú principal de la app English Practice [16] 28

Figura 6 - Notificación en la app English Practice [16] 28

Figura 7 - Notificación de nuevo comentario y de nuevo mensaje [16] 28

Figura 8: Fases clave de la computación anticipatoria [17] 31

Figura 9: Proceso de design thinking idealizado y en la realidad [30] 38

Figura 10 - Ciclo de DT a utilizar [30] 38

Figura 11: Alumno/a Persona $\quad 43$

Figura 12: Journey Map - Descripción de los momentos previos a la escuela 46

Figura 13: Journey Map - Durante la jornada escolar 47

Figura 14: Journey Map - Posterior a la jornada escolar 48

Figura 15: Matemarote: Si el avioncito es amarillo y va en dirección izquierda, se debe 54 presionar la tecla A. [25]

Figura 16: Matemarote: Si el avioncito es amarillo y va en dirección derecha, se debe 54 presionar la tecla L.[25]

Figura 17: Matemarote: Si el avioncito es rojo y va en dirección izquierda, se debe 54 presionar la tecla L. [25]

Figura 18: Matemarote: Si el avioncito es rojo y va en dirección derecha, se debe 54 presionar la tecla A. [25]

Figura 19: The number race: muestra de pantalla de comparación [23]

Figura 20: The number race: muestra de pantalla de comparación con dificultad mas 55 alta [23] 
Figura 21: The number race: muestra de pantalla de tablero [23]

Figura 22: Words matter: juego de sílabas [24]

Figura 23: Words matter: juego de sílabas [24]

Figura 24: Concentrate: inicio de sesión

Figura 25: Concentrate: ¡Brodie!

Figura 26: Concentrate: Journey Map del alumno/a

Figura 27: Concentrate: bienvenida al juego

Figura 28: Concentrate: selección método autenticación

Figura 29: Concentrate: bienvenida al alumno/a

Figura 30: Concentrate: presentación del profesor Qwad 66

Figura 31: Concentrate: selección de personaje

Figura 32: Concentrate: personaje listo para la misión

Figura 33: Concentrate: inicio de misión

Figura 34: Concentrate: alumno accede a notificación 67

Figura 35: Concentrate: alerta de la situación por el profesor Qwad (Strike 1)

Figura 36: Concentrate: Strike 2

Figura 37: Concentrate: alerta de la situación por el profesor Qwad (Strike 2)

Figura 38: Concentrate: pregunta para recuperar puntos

Figura 39: Concentrate: respuesta del alumno/a para recuperar puntos

Figura 40: Concentrate: resumen de las preguntas y respuestas

Figura 41: Concentrate: selección de tipo de accesorio

Figura 42: Concentrate: selección de sombrero

Figura 43: Concentrate: vista previa del accesorio vestido por Brodie 
Figura 45: Concentrate: Journey Map de la maestra/o $\quad 71$

$\begin{array}{ll}\text { Figura 46: Concentrate: inicio de sesión } & 72\end{array}$

Figura 47: Concentrate: selección de método de autenticación 72

Figura 48: Concentrate: pantalla principal $\quad 72$

Figura 49: Concentrate: acceso a listado de alumnos desde la clase 73

$\begin{array}{ll}\text { Figura 50: Concentrate: listado de alumnos } & 73\end{array}$

Figura 51: Concentrate: gráfico de barras de cantidad de distracciones por alumno 73

$\begin{array}{ll}\text { Figura 52: Concentrate: pantalla escuela } & 74\end{array}$

Figura 53: Concentrate: pantalla listado de alumnos $\quad 74$

$\begin{array}{ll}\text { Figura 54: Concentrate: detalle del alumno/a } & 74\end{array}$

Figura 55: Educational Computer Games Evaluation Issues 80

Figura 56: Evaluación de Concentrate, Rol de Alumno, Heurísticas Área Educacional de 81 Omar 2010

Figura 57: Evaluación con Heurísticas de Jugabilidad del framework de Omar2010 82

Figura 58: Resultado de inspección en heurísticas de motivación intrínseca 84

Figura 59: Resultado de Inspección con Heurísticas de Motivación Extrínseca 86

Figura 60: Inspección con Heurísticas dependientes del Contexto 87 


\section{CAPÍTULO 1: INTRODUCCIÓN}

Se presenta en este capítulo el contexto de la tesis (sección 1.1), su objetivo (sección 1.2), la visión general de la tesis (sección 1.3)

\subsection{Contexto de la tesis}

En la era de la información, los smartphones o teléfonos inteligentes se han vuelto una herramienta esencial en el día a día de las personas. Si bien nacieron con el objetivo de la comunicación como fin primero, el aumento de la capacidad de procesamiento de los mismos y el aumento de ancho de banda disponible para el uso de internet, hicieron que este tipo de dispositivos lleve a cabo cada vez más funciones, para las cuales en otros tiempos, era necesaria una computadora de escritorio. Adicionalmente la portabilidad y la amplia gama de modelos y precios facilitaron la accesibilidad a los smartphones. Esto posibilita que las personas tengan uno o más celulares a su alcance, incluyendo los niños desde edades muy tempranas, trayendo una serie de aspectos positivos, pero también de desafíos en distintos frentes, entre los cuales se encuentra el educativo. Según un estudio realizado por el Foro de generaciones interactivas, "en la Argentina, la mitad de los niños de 9 años posee su propio celular y este número aumenta al $89 \%$ entre los jóvenes de 10 a 18 años, superando a los demás países estudiados para este segmento etario. El $54 \%$ de los encuestados obtuvo su teléfono móvil antes de los 12 años."[33] Así como pueden ser una herramienta poderosa para la búsqueda de información y material escolar, las aplicaciones, redes sociales y juegos son fuentes de distracción. Incluso mientras estas aplicaciones no están siendo utilizadas, continúan en actividad, generando comunicaciones en forma de notificaciones, convirtiéndolas en objetivo de los niños/as en horario escolar. Por lo tanto, puede tener consecuencias en el proceso cognitivo de aprendizaje en sus distintas instancias, debido a la competencia por la atención que se produce entre las notificaciones y el docente.

El psicólogo experto en neuropsicología, Marcos Jofré opina que "es difícil que los contenidos escolares puedan competir con velocidad, movimiento, colorido con lo que pasa con la pantalla" [1] , señaló. Por esta razón para el psicólogo se empiezan a ver, con más frecuencia en los primeros años de la escuela, dificultades severas para concentrarse, permanecer allí y desarrollar autodisciplina.

Roxana Morduchowicz, doctora en Comunicación por la Universidad de París y consultora de la UNESCO en temas de educación y tecnologías opina que "Existe el preconcepto y el prejuicio de que, por presencia de pantallas, baja el rendimiento escolar o se reprueban más exámenes", .Internet y la tecnología podrían potenciar el aprendizaje, el tema es cómo se usen" [2]. 
Los smartphones estarán cada vez más presentes y disponibles desde edades muy tempranas, y como se ve en las opiniones de los expertos, también abre oportunidades de colaborar en el proceso de aprendizaje. Para lograr el aprovechamiento de estas tecnologías, evitando los potenciales aspectos negativos, como por ejemplo la competencia por un recurso limitado como es la atención, actualmente existen distintas corrientes de investigación en las que se analizan y proponen distintas soluciones para gestionar de manera automática fuentes de distracción, más específicamente las notificaciones, basadas en el aprendizaje y predicción del comportamiento del usuario.

\subsection{Objetivo de la tesis}

El propósito de la tesis es caracterizar y modelar requerimientos de software para la gestión de notificaciones en dispositivos móviles utilizados por chicos/as en edad de escuela primaria, teniendo en cuenta el tiempo, lugar y un objetivo concreto, con el fin de dar soporte al proceso de aprendizaje como aporte fundamental.

Los niños/as en edad escolar, que poseen un smartphone, lo llevan en distintos momentos a lo largo del día, incluyendo fuera del horario escolar. Es decir, podemos dividir su día en tres momentos principales: antes de la escuela, durante la escuela y posterior a la escuela. Las notificaciones se originan en cualquiera de estos momentos y su impacto varía según la actividad que está desarrollando el niño.

¿Qué problemas generan las mismas en cuanto a la captura de la atención del niño/a en distintos momentos del día? ¿Existen oportunidades de utilizarlas para favorecer la atención en temas de interés para la educación? El presente trabajo identificará los posibles escenarios de interrupción de la atención por medio de la elaboración del Journey Map ${ }^{1}$ del alumno/a con el objetivo de detectar los denominados puntos de dolor causados por las notificaciones e identificar oportunidades donde las mismas pueden tener un impacto positivo en el proceso de aprendizaje.

Actualmente existen distintas líneas de investigación que indagan sobre modelos predictivos / anticipativos, tal como lo denomina la publicación Computación Móvil Anticipatoria: encuesta del estado del arte y desafíos de investigación [18] en un sentido amplio, buscando aprender del comportamiento recurrente del usuario con respecto a las notificaciones y a partir de allí gestionar las mismas colaborando con la administración del recurso limitado que tenemos los seres humanos denominado atención. Utilizando distintas técnicas estadísticas e inteligencia artificial plantean mejoras en la interacción entre las notificaciones y sus receptores.

¿En qué consiste la propuesta del presente trabajo en relación a las líneas de investigación existentes? Se propondrá la caracterización de un modelo de gestión de notificaciones que

\footnotetext{
1“Visualización del proceso que una persona recorre para poder lograr un objetivo." [20]
} 
contemple no solo el comportamiento del usuario con respecto a las notificaciones sino también el contexto y el objetivo prioritario del niño en edad escolar en línea con aportar herramientas al proceso de aprendizaje.

¿Cómo se estimará el aporte / impacto de la presente propuesta en el proceso de aprendizaje de los niños/as en edad escolar?

Por medio de la utilización de prototipos que plantearán aspectos del modelo propuesto, se podrá obtener las impresiones iniciales de cómo resultaría la interacción del mismo con los niños/as en los distintos momentos de su día escolar. Con la observación y opiniones se genera una retroalimentación que servirá para ir mejorando el modelo propuesto, que luego serán procesada e incorporada a futuras iteraciones.

\subsection{Contribuciones}

Las principales contribuciones del presente trabajo son:

- Marco conceptual de análisis y diseño de la propuesta: el presente trabajo utiliza un marco conceptual de análisis que complementa el enfoque tradicional de la Ingeniería del Software. Utilizando principios de la Ingeniería del Software Centrada en el Humano, se pone foco en las necesidades de las personas intervinientes en el ecosistema escolar. Mediante técnicas de Design thinking, el esquema de trabajo se centra en lograr empatizar y así obtener los mejores hallazgos para luego, diseñar una solución integral que no solo se enfoque en el alumno/a, sino también en las personas que interactúan con ellos y ellas.

- Prueba de concepto o prototipo de la aplicación: con el objetivo de obtener una primera aproximación de la solución propuesta, se construirá un prototipo que permitirá tener las primeras impresiones de manera interactiva.

\subsection{Organización de la tesis}

En el Capítulo 2 se realiza una introducción al concepto de atención, teniendo como principal foco el escenario escolar, las distracciones y los distintos desafíos que se plantean en las aulas. También se analizan distintas propuestas actuales de cómo realizar el abordaje del problema mediante distintas tecnologías y casos de uso.

En el Capítulo 3 se describe y analiza el problema específico de las distintas situaciones que se generan en el día de un niño/a durante su día escolar, utilizando técnicas de relevamiento y diseño centradas en el humano como Design Thinking. Se identifican puntos de dolor y oportunidades de mejora, para luego ser abordados por la solución propuesta. 
En el Capítulo 4, tomando como base los puntos de dolor y oportunidades identificadas en el capítulo 3 , se propone una solución de software que aporte a la problemática planteada de la atención en clase.

Finalmente el el Capítulo 5 se procede a dar el cierre del presente trabajo, elaborando las sconclusiones, proponiendo trabajos futuros y continuidad de la temática desarrollada. 


\section{CAPÍTULO 2: ESTADO DE LA CUESTIÓN}

\subsection{Marco teórico}

\subsubsection{Introducción al concepto de atención}

Uno de los principales aspectos del proceso cognitivo sobre el cual se investigarán modelos de mejoras en las notificaciones es la atención. Según Warren W Tylor, en la publicación Cognitive Neuroscience and Psychotherapy Network Principles for a Unified Theory, "La atención es un término funcionalmente equivalente en el cual estamos plenamente conscientes de lo que atendemos y en gran medida inconscientes de lo que no atendemos." [3]

La British Medical Bulletin hace referencia a una publicación de James Williams, escritor de Los principios de la psicología, donde se de define la atención como "la toma de posesión por parte de la mente, en forma clara y vívida, de uno de lo que parecen varios objetos o líneas de pensamiento simultáneamente posibles. La focalización, la concentración, de la conciencia son de su esencia. Implica retirarse de algunas cosas para tratar con otras de manera efectiva, y es una condición que tiene un verdadero opuesto en el estado confuso, aturdido y disperso." [4]

El estar siempre conectados por medio de dispositivos celulares que generan estímulos provenientes de distintas fuentes y orígenes, ocasiona que nuestra atención esté en constante competencia, requiriendo que nuestro cerebro priorice y decida qué notificación ver primero que otra y cuál ignorar, es decir, no puede atender todas al mismo tiempo. Como comenta Fabricio Ballarini, Biólogo investigador del Conicet "Tomar conciencia de que no podemos dividir nuestra atención; dejar un porcentaje para el camino y otro para la pantalla del celular puede alterar la conducta al manejar un automóvil" [5]. Es decir, la atención es un recurso limitado.

Adicionalmente explica un aspecto de gran relevancia con respecto al presente trabajo: "Existen evidencias científicas de que las tareas auditivas interfieren menos con las tareas visuales, que las visuales o auditivas lo hacen entre sí. Escuchar música en el automóvil posiblemente distraiga menos que mirar una pantalla de GPS." [5]. Llevado al ambiente educativo, esto podría traducirse a un escenario escolar en el cual la maestra está dictando clases mientras a los alumnos les llegan notificaciones generadas por los distintas aplicaciones instaladas en el teléfono celular, iluminando la pantalla. En este caso, la competencia por la atención se dará entre ambos estímulos, poniendo en riesgo el proceso cognitivo. 


\subsubsection{Gestión de la competencia de estímulos digitales en la escuela}

En la actualidad, distintos enfoques son aplicados a la problemática de la pérdida de atención en las escuelas que intentan solucionar la distracción generada por los teléfonos celulares con distintos grados de restricciones, algunos de los cuales son:

Prohibición: consiste en prohibir que los niños menores a 15 utilicen teléfonos celulares, tablets y smartwatches durante la jornada escolar, incluyendo la hora del almuerzo, tal como especifica el comunicado del poder legislativo francés [6]. Debido a la preocupación del gobierno francés por la dependencia y distracción generada por los teléfonos celulares. Esta ley impulsada por el presidente Macrón, extiende la prohibición vigente a recreos y horarios de comidas. Los niños deben mantenerlos apagados o guardados en sus lockers. Adicionalmente existen algunas excepciones para niños con capacidades diferentes.

Utilización de acuerdo con el criterio de la escuela con sugerencia a la prohibición: existen países en los cuales la utilización de los teléfonos celulares en la escuela está supeditado al criterio de los docentes de la misma. Es decir, permitir o no utilizarlos y en qué momentos del día escolar es decisión del/la director/a. Un ejemplo de este caso es Inglaterra. En una nota publicada por la BBC, el ministro de educación de dicho país, Nick Gibb opina que los teléfonos deben ser prohibidos en las escuelas: "Si bien esto es claramente un asunto del director, mi opinión es que las escuelas deberían prohibir que sus alumnos traigan teléfonos inteligentes a la escuela o al aula" [7]. Existen opiniones a favor y en contra de esta postura, para una de las cuales es esperable que los niños/as deben ser enseñados a limitar la cantidad de tiempo que pasan online.

El Departamento para la Educación de el Reino Unido publicó el texto "Educación de relaciones, relaciones y educación sexual y educación de la salud. Orientación para los órganos de gobierno, propietarios, directores, principales, equipos de liderazgo senior y maestros" [8] donde el gobierno propone una serie de lineamientos en cómo llevar a cabo la implementación del uso de los teléfonos celulares en las escuelas. En sus párrafos cita distintos aspectos a tener en cuenta com ser:

- "Los niños y los jóvenes están creciendo en un mundo cada vez más complejo y viven sus vidas indistintamente tanto en línea como fuera de línea."

- Si bien esto representa "muchas oportunidades positivas y exitantes" también conlleva "riesgos y desafíos".

- "Los alumnos deben ser enseñados acerca de los beneficios de balancear el tiempo en línea y fuera de línea" 
Así mismo, el ministro resalta que: "Asegurarse que los niños/as pueden regular el uso de los teléfonos celulares y redes sociales por sus propios medios se está convirtiendo en una habilidad incrementalmente importante que deben aprender".

\subsection{Trabajos relacionados}

Un grupo de investigadores de la Universidad de Ionan, Grecia publicó un estudio en la European Journal of Engineering Research and Science titulado "¿Smartphones en las escuelas? Sì, ¿porqué no?” [9] cuyo principal objetivo es explorar los factores potenciales para hacer que los dispositivos de comunicación modernos, como los teléfonos móviles y las tabletas, sean adecuados para el aprendizaje en las escuelas, teniendo en cuenta las posibles ventajas o desventajas.

En los últimos años se realizaron grandes avances en las tecnologías que posibilitaron el acceso personas de distintas edades y recursos económicos, incluyendo adultos así como a niños en temprana edad. Esto genera distintos escenarios en los cuales la relación de los niños y niñas con dispositivos como los teléfonos celulares vayan influyendo en su desarrollo cognitivo entre otros aspectos, tal como menciona la publicacion "niños y niñas de la actualidad nacen y crecen en un período de destacados avances tecnológicos, familiarizados con el lenguaje de las computadoras, videojuegos e internet como si fuera un lenguaje nativo / lengua madre. Esto genera que sus habilidades, actitudes y aspiraciones reflejan el ambiente en el cual se desarrollan. Sus estructuras cognitivas son paralelas, no secuenciales y tienen preferencias de aprendizaje para las cuales la educación tradicional no está preparada, generando aburrimiento."[9]

La velocidad con la que se dieron los avances tecnológicos, permitiendo tener en la palma de la mano (por ej por medio de un teléfono celular) una computadora capaz de convertirse en un centro de entretenimiento, pasando por una herramienta de investigación de información y hasta generación de material multimedia, plantea desafíos en la relación maestro alumno/a, desde un punto de vista pedagógico. Es de gran importancia lograr que se generen las condiciones no solo de adaptación a la tecnología actual, sino a nuevas formas de enseñanza y aprendizaje que permitan obtener las ventajas de la innovación sin descuidar los potenciales aspectos negativos de la misma.

\subsubsection{Entornos Inteligentes de Aprendizaje}

Teniendo en cuenta estos nuevos escenarios, existen propuestas que abarcan los aspectos mencionados como por ejemplo los Entornos de Aprendizaje Inteligentes o Smart Learning Environments (SLE). La investigación hace referencia a los SLE, comentando que "Nuevos 
ambientes de aprendizaje, también Ilamados "Smart Learning Environments", reflejan una nueva pedagogía en la era digital y subrayan la significancia del diseño e instrucción tecnológica para apoyar, facilitar, potenciar y mejorar el aprendizaje. SLEs son enriquecidos con contenido digital adecuados en el contexto de problemas del mundo real y son adaptables, efectivos, eficientes, disfrutables y comprometen a los aprendices y educadores",

Según la definición de J. Michael Spector, investigador del Departamento de Learning Technologies de la universidad de North Texas, un SLE es aquel que tiene varias de las siguientes características [10]:

- Conocimiento: acceso a información pertinente y la habilidad de agregar o modificar información

- Soporte a las tareas: la habilidad de realizar una tarea y proveer al alumno (learner) con herramientas e información necesaria para realizar la tarea.

- Sensitividad del alumno (learner): habilidad de mantener y hacer uso del perfil del alumno, así como proveer de soporte y conocimiento apropiado.

- Sensibilidad al contexto: habilidad de reconocer situaciones específicas, incluyendo aquellas en las que el alumno podría necesitar asistencia.

- Reflexión y realimentación: habilidad de criticar una solución o rendimiento y/o proveer retroalimentación significativa y a tiempo al alumno basado en su progreso, su perfil y la tarea de aprendizaje a la mano.

Si bien SLE no es una tecnología en particular, provee un marco de trabajo en el cual se definen con mayor nivel de especificidad las características previamente descritas en base a las cuales se continúan llevando a cabo distintas líneas de investigación. El docente, la tecnología y el alumno son las piezas fundamentales de dicho marco.

Una de las características destacadas de los SLE es que tienen la capacidad de adaptarse a las necesidades de los alumnos, de manera personalizada de acuerdo a sus necesidades, ritmos de aprendizaje. También brindan las herramientas para incentivar a los docentes a encontrar la mejor manera de orientar y motivar a los alumnos incluyendo a aquellos con capacidades diferentes.

Esto es clave para lograr alumnos comprometidos y entusiasmados en obtener conocimientos, aprendiendo por motivación propia y no por presiones externas como sucede en los modelos de enseñanza actuales. Tal como cita el artículo "El problema para los maestros es que los alumnos no pueden prestar atención. Actualmente el problema no es que los estudiantes no pueden prestar atención, sino que eligen no prestar atención" [10].

Planteadas las condiciones que se deben cumplir para generar un ambiente de aprendizaje en donde la tecnología cumple un papel importante como parte de un ecosistema, es posible pensar en el aporte positivo de los teléfonos móviles o smartphone en el proceso pedagógico escolar. Tal es el caso de la investigadora Hagit Meishar-Tal, quien en su publicación "Teaching 
Sustainability via Smartphone-Enhanced Experiential Learning in a Botanical Garden" realiza un estudio en el cual tiene como objetivo evaluar [11]:

- La satisfacción general de los estudiantes y los docentes con el proyecto

- La percepción de los estudiantes de la contribución del proyecto a su aprendizaje

- La percepción de los estudiantes de la contribución del smartphone al proceso de aprendizaje

- La calidad de los resultados del aprendizaje

Para lograr dichos objetivos, existen una serie de conocimientos que el docente debe obtener para lograr que la experiencia sea satisfactoria. La publicación hace mención a los siguientes ítems basados en P.Mishra \& M. Koehler "Technological pedagogical content knowledge: A framework for teacher knowledge" [12]:

- Conocimientos de la tecnología: en el caso de estudio de la publicación, hace referencia a la correcta utilización de los smartphones y su potencial para la enseñanza.

- Conocimientos de Pedagogía: en el caso de estudio de la publicación, hace referencia al aprendizaje experimental.

- Conocimientos del contenido que se enseñará: en el caso de estudio de la publicación, hace referencia a la sustentabilidad.

Dadas las características de los smartphones que los convierten en una potencial fuente de distracción, la investigación identifica un desafío a la hora de llevar a la práctica la actividad propuesta: "Sin embargo la combinación de aprendizaje experimental y tecnología móvil posee un desafío singular. La integración de aprendizaje experimental y las tecnologías móviles en una actividad que debe llevarse a cabo de forma tal que el uso de tecnologías móviles no impedirán la aventura experimental. Eso es, se debe evitar la situación en la cual los alumnos reciben información de sus dispositivos móviles en lugar de la experiencia de campo" [12].

Con el objetivo de guiar a los alumnos en el aprendizaje, el proyecto creó una herramienta denominada The Wandering platform la cual está disponible vía web y los alumnos acceden mediante sus smartphones. El campo de estudio (Jardín Botánico) está dividido en estaciones, las cuales poseen un código QR (también se puede utilizar el GPS del smartphone) que podrá ser escaneado por los alumnos mediante la utilización de la Wandering platform y la cámara de fotos del smartphone. Una vez realizado el escaneo, los alumnos recibirán una tarea práctica a que deberán realizar y podrán responder la misma de diferentes maneras:

- Preguntas cerradas

- Preguntas abiertas

- Subir imágenes 


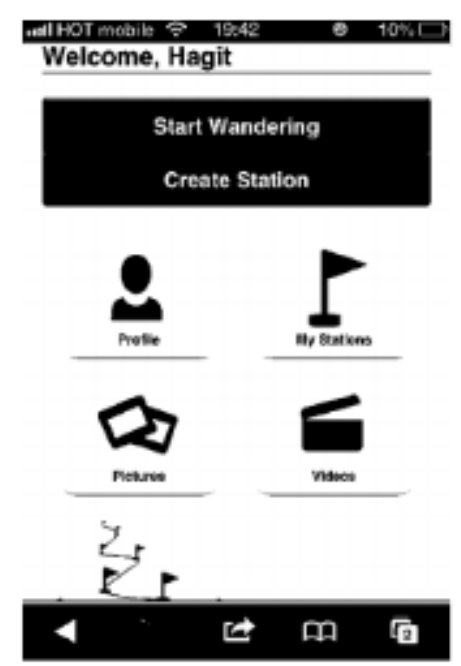

Figura 1: Wandering Platform [11]

Cabe destacar que uno de los requerimientos de la actividad, fue que las actividades asignadas a los alumnos pudiesen ser llevadas a cabo de manera independiente y sin necesidad de la intervención de los docentes, mediante el escaneo de códigos QR y la interacción con la aplicación Wandering platform.

\section{Resultados obtenidos de la actividad}

Luego de la finalización de la actividad, se le realizó una serie de preguntas a los alumnos, las cuales permitieron obtener los siguientes hallazgos:

"Las respuestas mostraron que los estudiantes pensaron que el taller contribuyó al desarrollo de las habilidades de pensamiento.. Sin embargo, enfatizaron que esto se logró no debido al uso del teléfono celular sino a la planificación de actividades de aprendizaje."[11]

"Se les preguntó a los estudiantes si recomendarían que sus amigos participen en un taller similar en el futuro. Seis de los alumnos respondieron negativamente y ocho afirmativamente. Cuando se les preguntó si pensaban que utilizarían el conocimiento que habían adquirido en el taller para impartir sus clases, tres respondieron negativamente y once afirmativamente."

"Los hallazgos implican que para algunos de los estudiantes la necesidad de usar el teléfono móvil para el aprendizaje experiencial no fue lo suficientemente convincente. No pudieron captar las ventajas de usar los teléfonos inteligentes en los jardines botánicos."[11]

“..los estudiantes no calificaron la contribución del uso de teléfonos celulares en el jardín botánico como alta en ningún indicador. Percibieron el teléfono inteligente como una contribución de mediana a fuerte al documentar los hallazgos y acceder a las instrucciones y una contribución muy pequeña a la orientación en el jardín y la medición de los fenómenos."[11] 
"(Los estudiantes) Percibieron el teléfono inteligente como una contribución de mediana a fuerte al documentar los hallazgos y acceder a las instrucciones y una contribución muy pequeña a la orientación en el jardín y la medición de los fenómenos. Por implicación, las contribuciones potenciales del teléfono celular al aprendizaje experiencial significativo no se utilizaron completamente en esta actividad"[11]

Analizando los resultados del estudio de campo, poniendo foco en la utilización de teléfonos celulares se observa que si bien los estudiantes, el uso de los mismos no logro optimizarse debido a distintos factores como por ejemplo:

La señal del teléfono celular tuvo dificultades técnicas y por momentos complicó el acceso a la Wonder platform.

La utilización del teléfono celular, si bien tuvo una participación relevante para el acceso a la Wonder platform con el objetivo de obtener las instrucciones de las actividades, no se hizo énfasis en "el uso de las capacidades de los teléfonos celulares para el aprendizaje como herramientas de investigación, medición y documentación fue subestimado. No se enseñaron aplicaciones útiles y no se instruyó a los estudiantes para desarrollar actividades que usarían el teléfono como un auxiliar en el aprendizaje experiencial".[11]

\subsubsection{Estudios de campo teléfono celular en las aulas}

La universidad de Nottingham, Gran Bretaña, llevó un estudio en el año 2008 acerca del uso del celular en las escuelas. Si bien tiene más de diez años de antigüedad, cabe destacar que al momento de llevarse a cabo, el $91 \%$ de los niños y niñas de 12 años poseía un smartphones con características tales como: reloj, calendario, juegos, reproductor de música, conexión Bluetooth, acceso a Internet y cámara de alta calidad, así como las funciones estándar de llamadas de voz y mensajes cortos. Uno de los resultados de la investigación identificó formas importantes en las cuales los smartphones pueden dar apoyo al aprendizaje.

Las actividades se llevaron a cabo de 331 estudiantes de tres escuelas diferentes y los docentes seleccionaron las actividades definidas por el equipo de investigación de la Universidad y se las extendieron a los alumnos [13].

En las escuelas estaban vigentes políticas de prohibición de utilización de teléfonos celulares. Con algunas particularidades, como por ejemplo: en la escuela A estaba permitido el uso responsable, es decir, si los alumnos tenían la necesidad de realizar o recibir alguna llamada importante como por ejemplo relacionadas a enfermedad de familiares. También en algunos casos, si los alumnos están escuchando música en hora libres, o haciendo tareas relacionadas a tareas escolares, también. 
Es decir, a pesar de las políticas de prohibición, algunos maestros tienen sus opiniones que expresan su visión acerca del uso de celulares en la escuela:

Maestros de escuela A:

- "Existe una política general, pero dentro de esa política puede haber bolsas de innovación donde las personas intentan usar los teléfonos móviles como un medio educativo herramienta dentro del aula." [13].

- "Como sociedad necesitamos generar una fuente continua de buenos ingenieros y científicos y para hacer eso obviamente tenemos que comprometernos con ellos dentro de la escuela secundaria para asegurar que los números se mantengan en el nivel A y más allá ... Creo que cualquier cosa que ayude a entusiasmar a los estudiantes con ciencias en el aula tiene que ser positivo" [13].

Luego de realizar las actividades, se hizo una encuesta del uso que le dieron los alumnos a los smartphones durante las mismas, las cuales fueron [13]:

- Utilización de la cámara: $96 \%$

- Aplicaciones de video: $22 \%$

- Transferencia de datos: $10 \%$

- Transferencia de datos a otros (compañeros) por Bluetooth: 7\%

También mediante la observación se registraron los siguientes usos [13]:

1. Experimentos de tiempo con cronómetro

2. Aparatos fotográficos y resultados de experimentos para informes

3. Fotografiando el desarrollo de modelos de diseño para eportfolios

4. Fotografiar textos / pizarras para su futura revisión

5. Material de proyecto de bluetoothing entre miembros del grupo

6. Recibir SMS y recordatorios por correo electrónico de los maestros

7. Sincronizar calendario / calendario y configurar recordatorios

8. Conexión remota a la plataforma de aprendizaje escolar

9. Grabar a un maestro que lee un poema para su revisión

10. Acceder a sitios de revisión en Internet

11. Crear películas narrativas cortas

12. Descargar y escuchar podcasts en idiomas extranjeros

13. Iniciar sesión en el sistema de correo electrónico de la escuela.

14. Usando GPS para identificar ubicaciones

15. Transferencia de archivos entre la escuela y el hogar

Algo a destacar es cómo las distintas actividades realizadas impactaron en la percepción del uso de los smartphones. Es decir, previo a las actividades, existían muchas dudas acerca de 
sus beneficios. Tanto en el momento del estudio, como en la actualidad los estudiantes utilizan los smartphones con fines de esparcimiento y sociales (redes sociales). Puede sonar sorprendente, pero es probable que los mismos alumnos no estén del todo conscientes de los beneficios que puede brindarles a la hora del aprendizaje. Un hallazgo del estudio de la universidad de Nottingham fue que previo a las actividades solo el $12 \%$ de los estudiantes pensaba que los mismos podrían ser utilizados con actividades de aprendizajes específicas. Luego de la experiencia propuesta por el proyecto de investigación, el porcentaje subió a 42\% [13].

Una de las escuelas, la B, tenía una plataforma web en la cual se encontraban los recursos y tareas asignadas a los alumnos. Ellos las podían descargar desde cualquier ubicación geográfica con acceso a internet. Un ejemplo son los trabajos de campo, en los cuales los alumnos pudieron por ejemplo tomar fotos y subirlas a la plataforma como parte de sus trabajos (Figura 2).
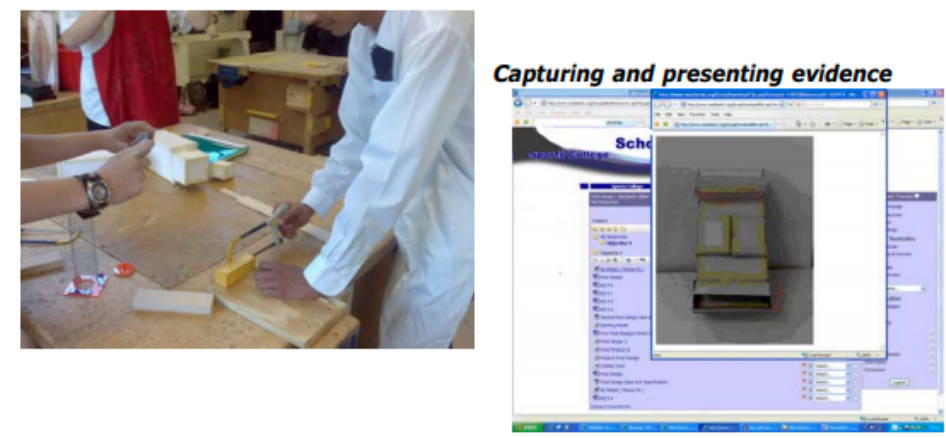

Figura 2: Recolectando y presentando evidencia [13]

Tal como se viene planteando en el presente trabajo, la distracción es un riesgo que está muy presente en la visión de los docentes y autoridades escolares a la hora de decidir acerca de las políticas de uso del celular. Por lo tanto, es importante abarcar esta temática tal como lo expresó un alumno durante la investigación llevada a cabo: "Los maestros deben estar capacitados para poder ver estos teléfonos como dispositivos de aprendizaje en lugar de una distracción" [13].

Si bien, tal como se describió en los dos casos presentados, tanto las posturas en contra como a favor del uso del celular en las escuelas y asignaturas tienen varios desafíos, algunos de ellos incluso en común: evitar las distracciones que generan interferencias en el proceso de aprendizaje. Las notificaciones, son una de las potenciales fuentes generadoras de distracciones. Es necesario por lo tanto, abordar la temática que afecta tanto a niños como adultos. 


\subsection{Gestión de la atención: tecnologías para la optimización del uso de notificaciones y la atención}

Existen en la actualidad distintas líneas de investigación que abordan el desafío de la gestión de la atención ante el escenario en el cual, los teléfonos móviles reciben notificaciones de distintas fuentes, distrayéndonos de las tareas en curso. Eso sucede en distintos ambientes y escenarios, incluyendo el educativo. Si bien existen estudios y aplicaciones específicas en el área de la educación, la presente sección también cita casos que si bien no están directamente relacionados con el proceso de aprendizaje, pueden también ser tomados en cuenta como posibles soluciones a la problemática de la interrupción de la atención.

\subsubsection{Auditorium Mobile Classroom Service (AMCS)}

Existe una gran cantidad de estímulos que pueden distraer a los alumnos durante las clases. Desde la apertura de una ventana del aula, hasta mensajes de texto, notificaciones y cualquier acción que ilumine la pantalla del teléfono celular logran interrumpir la atención hacia la actividad educativa en curso. Un ejemplo claro es el momento en donde el o la docente está exponiendo un tema. Tal como cita la publicación AMCS (Auditorium Mobile Classroom Service) - to ARS with Learning Questions, Push notifications, and extensive Means of evaluation [14] , Los alumnos durante este tiempo, los estudiantes deben lograr la "hazaña" de mantener la atención durante 90 minutos, estar atentos, seguir el contenido mediado, analizarlo, ponerlo en contexto y lo más complejo: ignorar distracciones al proceso de aprendizaje. Luego continúa " $Y$ aunque hace tiempo que está claro que, con la ayuda de Internet,hay fuentes adicionales de información disponibles que cubren el espacio de aprendizaje a través de las salas de conferencias, se están utilizando teléfonos inteligentes, computadoras portátiles y tabletas a menudo no se usan de manera rentable, sino que distraen, ya que ofrecen oportunidades para interactuar con otras cosas."

ACMS es un entorno desarrollado por especialistas en psicología y la Facultad de informática de la Universidad Técnica de Dresden, Alemania, que permite la participación de la clase o auditorio por medio de sus dispositivos móviles como smartphones, tablets, laptops. Es utilizado como canal de comunicación con los alumnos y permite focalizar en las necesidades individuales de los mismos durante la clase.

Previo al inicio de la clase, los docentes crean un evento en ACMS, indicando las características del mismo, como ser número de alumnos, tiempo de la clase. Luego, el docente puede configurar distintas funcionalidades como por ejemplo:

Preguntas para los alumnos antes, durante y posterior a la clase.

- Envió de las lecturas por adelantado 
- Asignaturas de aprendizaje por medio de múltiple y single choice

- Mensajes con contenido diferente a alumnos seleccionados

- Métricas de la clase

- Oportunidad a los alumnos de realizar preguntas

\section{Mensajes a los dispositivos móviles de los alumnos}

Previo a la clase, se motiva y orienta la atención de los alumnos hacia los tópicos que se desarrollarán en clase, como se observa en la Figura 3. Durante la clase, cada alumno tiene la opción de seguir el material que está siendo presentado, así como volver hacia atrás en el caso que lo necesite, contestar un set de preguntas y respuestas y obtener una devolución (feedback) de su proceso de aprendizaje. Estas son algunas de las funcionalidades disponibles en la plataforma que colaboran con la gestión de la atención, incluyendo la utilización de mensajes individualizados.

Tal como cita la publicación, "el objetivo de los mensajes es apoyar a los estudiantes en la regulación de la atención y el logro del objetivo de la clase (indicaciones metacognitivas). Esto se realiza por medio de notificaciones del tipo "push", dependiendo de los objetivos individuales y estratégicos durante la clase. Además, los mensajes son enviados para ayudar a los estudiantes a llenar los vacíos de conocimiento (indicaciones positivas)." [14] Por ejemplo, estudiantes que tienen dificultades en una tarea de aprendizaje al principio se les envía notas en diapositivas, explicaciones con mayor detalle, etc. De la mano de las notificaciones con información adicional, genera condiciones propicias para debates entre los alumnos y generar un intercambio positivo de argumentos durante la clase.
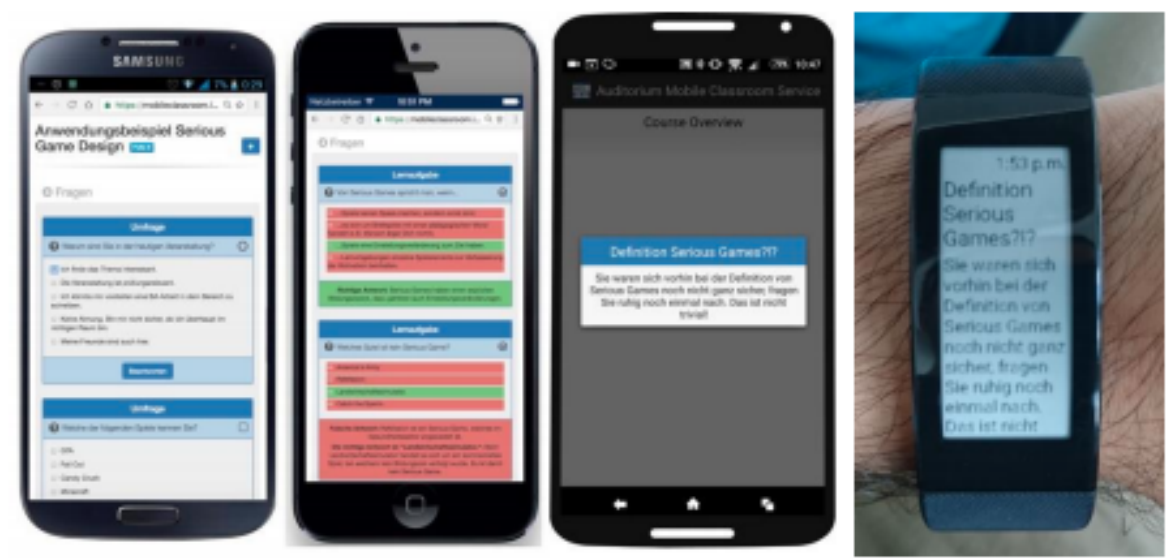

Abb. 2: Studierendenbefragung, Lernaufgaben, Prompts auf dem Smartphone und einer Smartwatch in AMCS (Beispiele aus der Vorlesung ${ }_{n}$ Serious Games")

Figura 3: material educativo personalizado [14]

\section{Resultados de la investigación de la clase utilizando ACMS}


Luego de llevar a cabo la experiencia, se realizó una evaluación acerca de cómo se sintieron los alumnos con la utilización de la plataforma ACMS y el aporte que la misma otorga a el proceso de aprendizaje. Algunos de los resultados fueron los siguientes:

- La herramienta y las encuestas incrementaron la interactividad

- Las tareas de aprendizaje fueron consideradas de ayuda

- Con respecto a los mensajes, algunos estudiantes consideraron que eran de ayuda y otros consideraron que aportan valor

\subsubsection{Notificaciones móviles para fomentar la práctica reflectiva en Meta-Learning}

Dentro de las líneas de investigación de la utilización de notificaciones en ambientes educativos, existen trabajos realizados acerca de las notificaciones en forma de mensajes móviles dirigidos a los alumnos, con objetivos específicos, relacionados al proceso de aprendizaje. Bernardo Tabuenca, Marco Kalz, Stefaan Ternier, and Marcus Specht hacen referencia al concepto de meta aprendizaje (meta-learning), como "el meta aprendizaje como una conciencia y comprensión del fenómeno del aprendizaje en sí mismo en lugar del conocimiento del sujeto. Por la presente, concebimos las actividades de meta aprendizaje como el aumento del conocimiento y la motivación en el aprendizaje cuando se desencadena por episodios introspectivos de reflexión sobre el propio aprendizaje del usuario" [15]. Es decir, se busca que el alumno, por medio de la reflexión y la autoconciencia del proceso de aprendizaje, pueda alcanzar un nivel de motivación que facilite el aprendizaje de los contenidos obtenidos diariamente, por medio de mensajes que serán enviados a los teléfonos móviles.

Cabe aclarar que se entiende a la reflexión como a "la práctica para tomar conciencia de una base de conocimiento implícita y aprender de la experiencia [6]. Donald Schön acuñó los términos "reflexión en acción" como la práctica reflexiva realizada mientras realizaba una actividad para optimizar la acción inmediatamente siguiente, y "reflexión sobre la acción" como la práctica reflexiva realizada cuando la actividad ha finalizado para revisar, analizar y evaluar la situación y obtener información para mejorar la práctica en el futuro" [15].

El estudio menciona de manera introductoria dos experiencias realizadas por otras investigaciones en las cuales se verifica que :

- Goh et al. [12] concluyó que la utilización de mensajes de texto por 12 semanas a estudiantes, demostrando que los alumnos que recibieron los mismos, performaron mejor que aquellos que no los recibieron. 
- Cavus \& Ibrahim [13] investigaron los efectos de enviar SMS con el objetivo de enseñar nuevas palabras en inglés a 45 alumnos de primer año concluyendo que los mismos disfrutaron y aprendieron nuevas palabras gracias a los mensajes de texto.

A diferencia de los dos casos mencionados, la publicación se enfoca específicamente en el método de reflexión, como se presenta en la Figura 4, por medio de notificaciones y mensajes a dispositivos móviles. Se dividió la investigación en dos grupos:

- Uno con el enfoque de "reflexión en acción" (on action), el cual fue llevado a cabo durante dos días y a 37 alumnos se les envió SMSs con el objetivo de que realicen una reflexión y reporte de cómo habían aprendido.

- Otro con el enfoque de "reflexión durante la acción" (in action) en donde se le propuso a 60 estudiantes universitarios leer un eBook acerca de una temática específica, durante la cual se les pidió reflejar y reportar lo aprendido utilizando notificaciones en los dispositivos móviles.

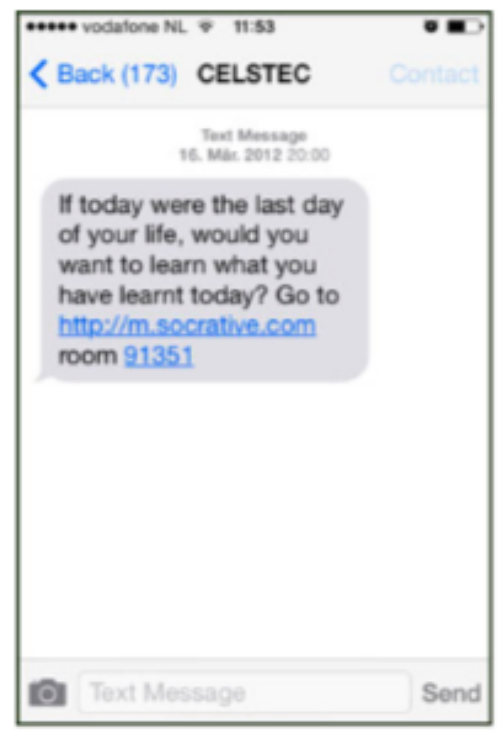

a. Daily SMS received by students.

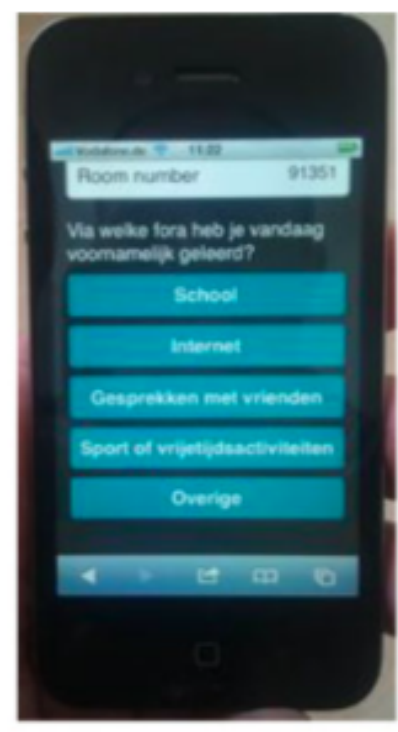

b. Personal response system: What was your main learning channel today?

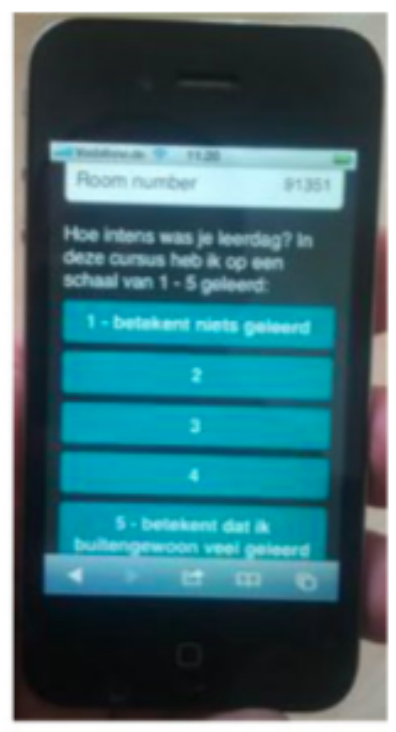

c. Personal response system: How intense was your learning day?

Figura 4: Notificaciones con reflexiones y preguntas [15]

Los ejemplos de las capturas muestran los mensajes enviados a los alumnos a las 8 de la noche, para notificarles de que el sistema estaba listo para recibir las respuestas con sus reflexiones. 


\section{Conclusiones principales:}

Los alumnos aceptaron el uso de SMS recordatorios orientados a la administración del tiempo y no tanto orientado a la consolidación del aprendizaje. Cabe destacar que recibir notificaciones idénticas durante el día no fueron bien aceptadas.

Tal como cita la publicación, acerca del efecto de notificaciones repetidas "esta observación puede concluirse no solo a partir de los resultados de la disminución de la tasa de participación en el primer estudio, sino también en el segundo experimento en el que los participantes informaron que no prestaban atención a las notificaciones posteriores cuando notaron que los dos primeros eran idénticos. Por lo tanto, los efectos de las notificaciones no idénticas posteriores deben explorarse en una investigación más a fondo." [15]

Las notificaciones enviadas a los dispositivos móviles, pueden ser utilizadas por estudiantes de escuelas secundarias para generar reflexiones acerca de lo aprendido en clase y sobre el rol del alumno, como una persona en su rol del que aprende. [15]

Acerca del momento del día en que las notificaciones son enviadas, según el estudio, el horario más efectivo es cerca del fin del día (8 pm), para que los alumnos puedan reflexionar acerca de su día de clases y lo aprendido. Se propone estudiar reacciones relacionadas a enviar notificaciones en momentos no tan predecibles. [15]

Otro de los resultados importantes, fue que el envío de notificaciones de reflexión mientras una actividad de aprendizaje está en curso, no son bien aceptadas por los alumnos.

La mayoría de los participantes respondieron las preguntas enviadas al momento de recibirlas.

Algunas de los testimonios positivos tomados de los alumnos fueron:

"Fue un experimento interesante tomar conciencia de lo que aprendí. Me pareció una experiencia muy útil evaluar la tuya ". [15]

"Creo que es una buena experiencia porque miras hacia atrás a lo que hiciste, descubres cosas que podrías haber hecho o cosas que debes hacer de manera diferente la próxima vez". [15]

"Fue agradable pensar en lo que aprendiste, porque sientes que al menos has aprendido algo que has hecho. Te das cuenta del hecho de que aprendes cosas en la escuela ". [15]

"Críticamente miras lo que has hecho durante el día y detectas áreas en las que puedes mejorar". [15] 
Testimonios negativos acerca de la actividad:

"Me pareció una tontería". [15]

"No muy útil".[15]

Efecto de las notificaciones push en el compromiso de un alumno en una aplicación móvil de aprendizaje

La investigación realizada por un grupo de la Universidad Nacional del Centro, Taiwan, publica en la 2016 IEEE 16th International Conference on Advanced Learning Technologies, estudia particularmente como las notificaciones pueden llegar a influir en el compromiso de un alumno con respecto a una aplicación, que en este caso se focaliza en la enseñanza de Inglés. La aplicación se denominó "English Practice" [16] y podía ser descargada de la tienda de Google. Su menú principal, contiene el acceso a las funcionalidades más relevantes, tal como se muestra en la Figura 5.

Según un informe referenciado, las aplicaciones educacionales están clasificadas como las de menor retención, es decir, son desinstaladas a corto o mediano plazo. Por lo tanto, el equipo de investigación decidió incorporar notificaciones push a la aplicación con el objetivo de analizar su efecto en los estudiantes. De acuerdo a algunos hallazgos, la publicación sostiene que enviar notificaciones es considerada como una solución para lograr un mayor compromiso del alumno, sin descuidar la otra cara de las mismas: pueden ser fuente de interrupción.

En "English Practice", las notificaciones son utilizadas para:

- Notificar a los alumnos acerca de actualizaciones sobre nuevo material de aprendizaje

- Recordarles que repasen unidades de aprendizaje (Figura 6)

- Notificarlos de nuevos mensajes entrantes (Figura 7)

- Notificarlos acerca de nuevos comentarios en ítems de aprendizaje a los cuales el alumno está suscripto

Las preguntas que fueron utilizadas por el estudio fueron [16]:

1. ¿Como las notificaciones afectan en el conteo de sesiones, longitud de las sesiones, tiempo total de consumo y retención?

2. ¿Qué tipo y cuantas notificaciones deben ser enviadas cada día?

3. ¿Las notificaciones molestan a los usuarios e incrementan la tasa de desinstalación de la aplicación? 
Ejemplos de notificaciones y pantalla principal de "English Practice"

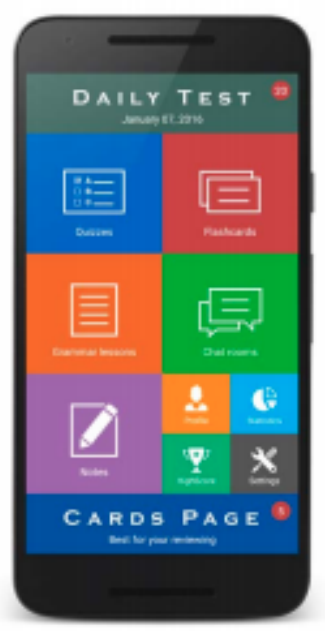

Figura 5 - Menú principal de la app English Practice [16]

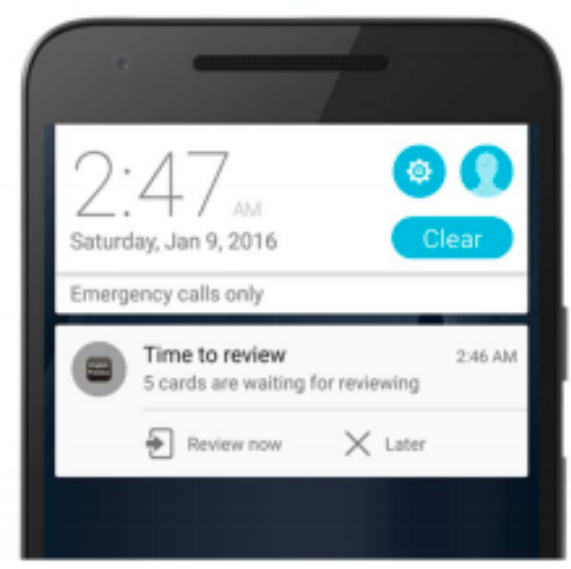

Figura 6 - Notificación en la app English Practice [16]

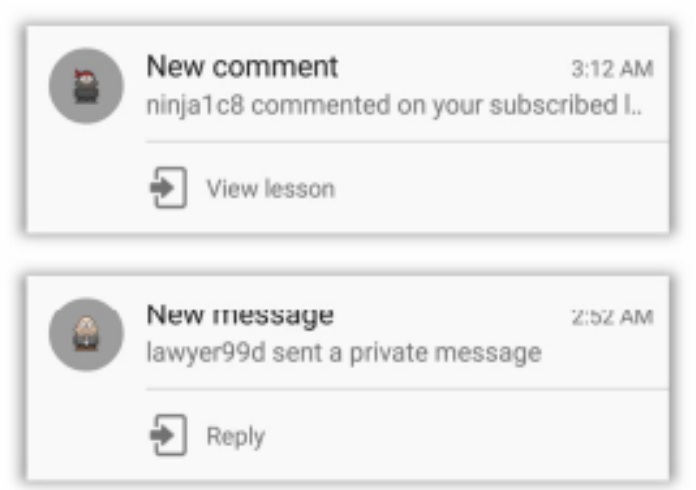

Figure 3. "New comment" and "new message" notification

Figura 7 - Notificación de nuevo comentario y de nuevo mensaje[16] 
Tal como se observa en las capturas de pantalla, las notificaciones tienen un trabajo de diseño teniendo en cuenta la usabilidad del usuario. Cada una contiene un link a una acción, que permite ir directamente a la sección de la aplicación que requiere la atención del usuario. Esto de alguna manera facilita y ahorra tiempo al usuario, el cual no deberá abrir la aplicación y navegar hasta la sección deseada. Esto fue un aspecto destacable en el estudio realizado, para lograr el éxito de las notificaciones.

\section{El poder de las notificaciones push}

Tal como se plantea en la introducción del presente trabajo, las notificaciones tienen un potencial positivo si son utilizadas, tal como cita la publicación "las notificaciones relevantes enviadas a tiempo, tiene el poder de alcanzar a los usuarios y obtener su atención [20, 23, 25]." [16].

Según lqbal and Horvitz, como se cita en la publicación [16] , una notificación es "una señal visual, señal auditiva o alerta háptica, generada por una aplicación o servicio que transmite información a un usuario fuera de su foco de atención actual.", es decir, tiene la capacidad de capturar la atención del usuario, desviándose de su foco actual.

El uso y las consecuencias de las notificaciones pueden ser positivas o negativas, dependiendo de varios factores. La publicación hace referencia a dos estudios realizados por Pielot et al. y Czerwinski et al en donde se analizaron dos escenarios bajo los cuales los usuarios se exponen:

El estudio de Pelot acerca de las notificaciones en dispositivos móviles descubrió que "los participantes tenían que lidiar con 63.5 notificaciones en promedio todos los días, y la presión social en la comunicación personal fue una de las principales razones. Informaron que recibir más mensajes y actualizaciones de redes sociales también hizo que los participantes se sintieran más conectados con los demás. Sin embargo, si las notificaciones push no proporcionan ningún valor al consumidor, pueden ignorarse, o por su naturaleza intrusiva, verse como spam"

El estudio de Czerwinski por otro lado, mostró que "los usuarios sienten que es muy difícil volver a su aplicación cuando son interrumpidos por notificaciones o llamadas entrantes. El estudio indicó que si las aplicaciones siguen enviando notificaciones que no se perciben como útiles, los usuarios se molestan y consideran eliminar esas aplicaciones. De hecho, hoy en día a menudo se abusa de las notificaciones push. Por lo general, los usuarios son bombardeados con múltiples notificaciones push de diferentes aplicaciones, lo que a menudo resulta en que apaguen las notificaciones push completamente" [16]. 


\section{Resultados del estudio}

Algunos de los resultados del estudio realizado indicaron que [16] :

- Los participantes volvieron a utilizar la aplicación con más frecuencia como resultado del envío de notificaciones.

- Las notificaciones colaboraron como motivo para lanzar la aplicación y continuar utilizandola.

- Las actividades sugeridas por las notificaciones derivaron en un incremento en la cantidad de usos de la aplicación y del tiempo de utilización de la aplicación

- Notificaciones de mensajes $(50,7 \%)$ y notificaciones de comentarios $(39,1 \%)$ tienen la tasa de clics más alta. En segundo lugar se encuentran las notificaciones de tests / evaluaciones pendientes a realizar con el $17.1 \%$. Las notificaciones de nuevo contenido en la aplicación tuvo la tasa más baja de clics con un $9.7 \%$.

- Las notificaciones incrementaron la cantidad de sesiones, tiempo del usuario en la aplicación y retención del usuario.

- Se destaca la importancia del diseño de las notificaciones. Notificaciones que no estén diseñadas adecuadamente, pueden incrementar la tasa de desinstalación de la aplicación.

- No todas las notificaciones son apreciadas / de utilidad para el usuario. Por lo tanto, las notificaciones no adecuadas pueden generar un efecto negativo.

\subsubsection{Computación móvil anticipatoria}

Poder anticiparse al posible comportamiento de las personas mediante la información recolectada por tecnología existente en los dispositivos móviles, como ser el teléfono celular, es uno de los objetivos de la computación anticipatoria. Formada por varias disciplinas, como por ejemplo Machine learning, Human Computer Interactions, intentan mediante los datos obtenidos, ya sea históricos o en tiempo real, proyectar el "futuro" de las acciones del usuario. La publicación "Anticipatory Mobile Computing: A Survey of the State of the Art and Research Challenges" cita que "solo las aplicaciones que se basan en el pasado, presente y el futuro anticipado para tomar decisiones juiciosas y procesables pueden ser consideradas como aplicaciones anticipatorias. También cita como definición, la elaborada por [Rosen 1985] "Un 
sistema que contiene un modelo predictivo de sí mismo y / o su entorno, que le permite cambiar de estado en un instante de acuerdo con las predicciones del modelo correspondientes a un instante posterior" [17]

Es decir, dada la cada vez más amplia variedad de fuentes de datos del usuario que provee el teléfono celular, sumado a la capacidad cognitiva de las aplicaciones mediante la utilización de Inteligencia Artificial, se pretende "predecir" eventos futuros de distinta índole, aspecto especialmente interesante para el ámbito de la atención y la gestión de la misma.

Las fases clave de la computación anticipatoria son descritas como se describen en la figura 8 a continuación:

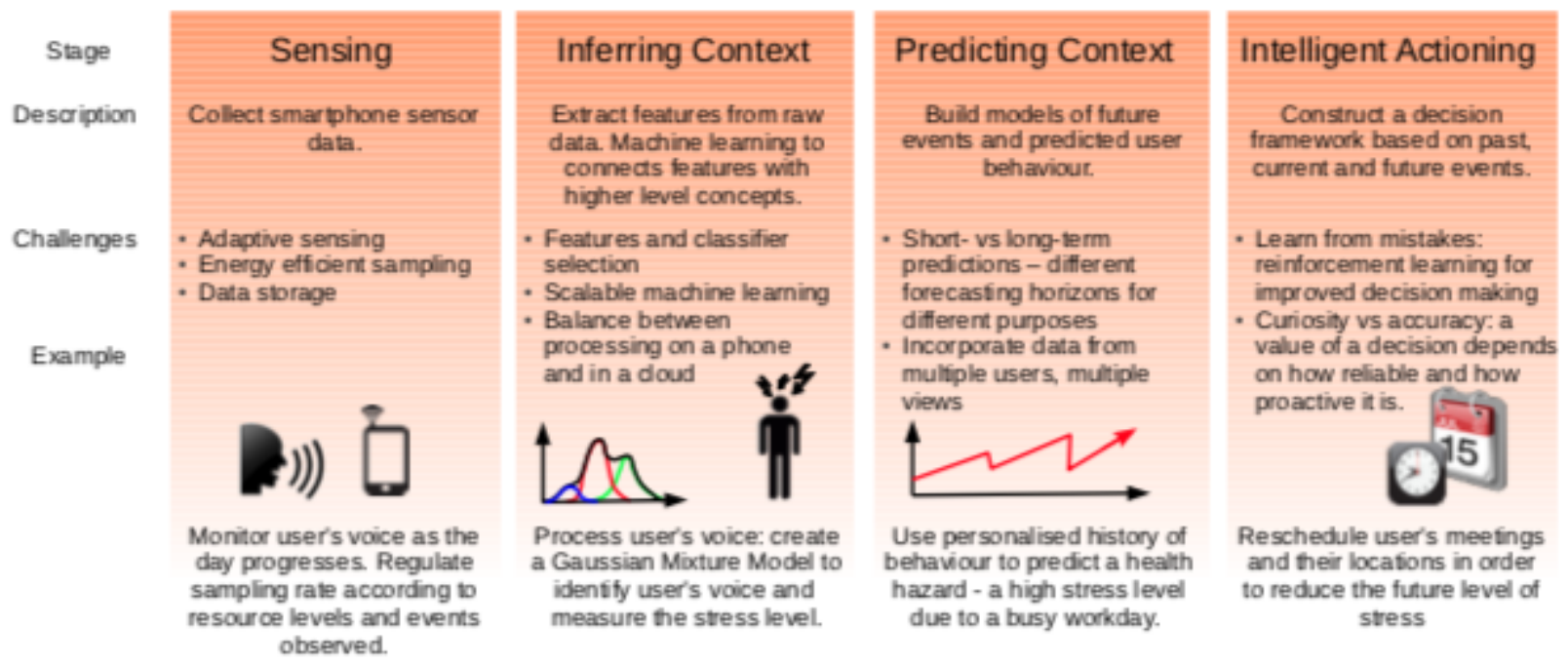

Figura 8: Fases clave de la computación anticipatoria [17]

Sensado: en donde toda la data es colectada del teléfono móvil del usuario

Contexto de inferencia: se extraen los datos clave para ser utilizada por los modelos de Machine Learning.

Predicción del contexto: en base a los modelos del futuro elaborados, se intenta predecir el comportamiento del usuario.

Accionar inteligente: en esta última etapa se construye un marco de decisión basada en eventos del pasado, actuales y futuros.

El comportamiento anticipatorio es una conducta natural, la cual está incorporada tanto en animales como seres humanos que básicamente permite la supervivencia. El paper [17] menciona la definición de Butz, Sigaud and Gerard: "un proceso o comportamiento que no solo 
depende del pasado y el presente, sino también de predicciones, expectativas o creencias sobre el futuro" [Butz et al. 2003]. Basado en este concepto se realiza el planteo de si los dispositivos de computación serán capaces de reproducir esta habilidad.

Ahora bien, este comportamiento es distinto en cada persona, es decir, la clave está en la capacidad de personalizar la anticipación, basado en los senseos y modelos adaptados especialmente a cada individuo.

\section{Computación anticipatoria y su relación con la gestión de atención}

En la actualidad, recibimos mensajes de distintas fuentes, en cada uno de los dispositivos móviles como tabletas, relojes inteligentes y teléfonos celulares. Esto se puede convertir en una interrupción de la atención hacia la tarea que estamos llevando a cabo, tal como cita la publicación en análisis "recibimos mensajes instantáneos irrelevantes mientras trabajamos en un proyecto importante, un teléfono puede sonar en un tono vergonzoso "sin batería" en medio de una reunión, y puede aparecer una ventana emergente de actualización de software mientras estamos conectados temporalmente a un hot spot en una cafetería." [17]

Estas interrupciones generan situaciones de incomodidad, tanto por el momento en que llegan las notificaciones, como el contenido de las mismas, las cuales pueden contener información irrelevante. En futuras ocasiones, esto hará que los usuarios terminen decidiendo ignorarlas.

"Las interfaces de usuario atentas gestionan la atención del usuario para que la tecnología funcione en simbiosis con él, en lugar de en contra de la interrumpibilidad del usuario." [17] cita la investigación.

Por otro lado, Andreas Bulling en su publicación Pervasive Attentive User Interfaces "Hace diez años, Thomas Friedman argumentó que la sociedad había abandonado la era de la información y entró La era de la interrupción. En ese momento, él estaba refiriéndose a las interrupciones causadas por humanos, por ejemplo a través de mensajes instantáneos, correos electrónicos o timbres de teléfonos celulares" [18]. Vivimos siendo interrumpidos con frecuencia, siendo nuestra atención discontinua. Andreas hace referencia al concepto de Atención Continua Parcial, la cual define como "En consecuencia, la atención sostenida se reemplaza cada vez más por la atención parcial continua: el acto de prestar atención simultánea a múltiples fuentes de información pero solo a un nivel superficial. En economía, este fenómeno bien conocido ha llevado a la teoría de la "economía de la atención" que reconoce tanto la escasez como la superficialidad del consumidor atención y, en consecuencia, la importancia de gestionarlo" [18].

Por lo tanto, argumenta que unos de los grandes desafíos de las interfaces de Interacción Humano - Computador $(\mathrm{HCl})$ es lograr convertir la atención continua parcial en atención sostenida (continua). Uno de los conceptos que viene a colaborar con la resolución de esta problemática son las Pervasive Attentive User Interfaces. Andreas sostiene que "Las futuras interfaces de usuario atentas y penetrantes podrían gestionar la atención del usuario: tal vez 
como una "cuenta de atención" que, como una cuenta bancaria, mantiene un saldo de atención disponible. Dibujando desde esta cuenta, las pantallas podrían entonces adaptar dinámicamente la cantidad y el tipo de información presentada a los usuarios basados en su capacidad atencional actual, optimizando así simultáneamente para

rendimiento de la información y con sutileza. Además, en lugar de interrumpir el usuario siempre que haya nueva información está disponible, interfaces futuras podría cambiar la importancia de la información con el nivel de interrumpibilidad actual de los usuarios y el tiempo de entrega de la información apropiadamente, por ejemplo por un período de baja carga cognitiva, atención gratuita capacidad, o incluso aburrimiento" [18].

Contact awareness, o conciencia de contacto es una de las características clave que tienen en cuenta las Pervassive Attentive user Interfaces. Esto se realiza tomando en cuenta los datos obtenidos por el teléfono celular del usuario, como ser ubicación GPS. [Ho and Intille 2005] realizaron una investigación utilizando acelerómetros en el cuerpo de las personas, y lograron identificar que los movimientos en los cuales se cambia de actividad, son los menos nocivos para ocasionar una interrupción. 


\section{CAPÍTULO 3: DESCRIPCIÓN DEL PROBLEMA}

El presente capítulo describe la problemática actual que distintos actores del ambiente escolar atraviesan debido a las interrupciones de la atención generadas por los teléfonos celulares en el proceso de aprendizaje. Estas interrupciones a su vez, se pueden dar en distintos momentos del día, ya que los procesos relacionados al aprendizaje no son exclusivos de la institución educativa, sino que también pueden transcurrir en momentos previos y posterior al arribo los alumnos/as al establecimiento. Un ejemplo claro es la hora de hacer las tareas asignadas por el docente, ya que se pueden producir antes y después de la jornada escolar.

\subsection{Marco de trabajo empleado}

El marco de trabajo que se emplea en esta tesis se fundamenta en una orientación de la Ingeniería de Software Centrada en las Personas (HCSE, en inglés), que permite incluir aspectos básicos de sistemas interactivos como la Experiencia del Usuario en el ciclo central de trabajo. Esta orientación, luego de una década de investigación se catalizó en la integración de la Ingeniería de Software con la forma de pensar y organizar el trabajo por parte de los diseñadores y su adopción como estrategia de innovación con metodologías como Pensamiento de Diseño (Design Thinking)[30], Sprints de Diseño[33], etc.

\subsubsection{Ingeniería de software centrada en las personas}

La ingeniería del software es usualmente conocida como una disciplina que aplica métodos y técnicas de la ingeniería para el desarrollo de software. Durante todo el ciclo de vida de una solución de software, se involucra a distintos actores que son imprescindibles para lograr el objetivo que se persigue. Si bien la tecnología tiene un papel preponderante, las que finalmente van a ser las protagonistas de la solución, son las personas. No tener en cuenta a las personas, con el rol protagónico que poseen y priorizar los aspectos tecnológicos, puede traer consecuencias no deseadas, las cuales son potencialmente costosas de resolver, poniendo en riesgo incluso el cumplimiento de las expectativas deseadas. Teniendo en cuenta estos factores entre otros, surge lo que se denomina Ingeniería del Software Centrada en el Humano o Human Centered Software Engineering. En libro An Introduction to Human-Centered Software Engineering [27], Seffahm Gulliksen y Desmerais introducen el concepto haciendo referencia a la definición de Ingeniería del Software publicada por Pressman, 2005a como una "disciplina bien establecida que comprende los procesos asociados al desarrollo del software, los métodos utilizados para analizar, diseñar y testear software de computadoras, la gestión de técnicas 
asociadas con el control y monitoreo de proyectos de software y las herramientas utilizadas para soportar procesos, métodos y técnicas". Los autores detectan que existe un gap entre la Ingeniería del Software y la Ingeniería de Software Centrada en el Humano, sosteniendo que "agregando que la Ingeniería del Software debería ser centrada en el humano, queremos enfatizar que hay una necesidad de un cambio de foco en el desarrollo de sistemas que ponen objetivos, necesidades y deseos del usuario en el primer sitio. Por humanos no solo se entiende al usuario final del sistema, sino también a los usuarios secundarios del sistema". Es decir, existe un ecosistema con el que interactúa el software, que va más allá del usuario final del mismo. Por ejemplo, en el presente trabajo, si bien el usuario final es el alumno/a, también su entorno se verá influenciado, como ser el maestro/a que van a experimentar los resultados de la aplicación, así como los padres que son responsables de los niños/as y también interactuaran con la aplicación así como los profesionales que formarán parte del diseño y desarrollo de la solución.

Cada integrante del ecosistema necesitará herramientas, en el camino a recorrer para lograr que la aplicación sea desarrollada satisfactoriamente, desde la elicitación de requerimientos y entendimiento de la necesidad hasta el desarrollo, testeo y mantenimiento del software. Es decir, se puede interpretar que la Ingeniería del Software de alguna manera puede tener una tendencia a priorizar la implementación tecnológica sobre las necesidades concretas del ecosistema de personas del que será parte. Con el fin de acortar las distancias entre la Ingeniería del Software y la Ingeniería del Software Centrada en el Humano, teniendo en cuenta las necesidades de los distintos participantes antes mencionados, los autores proponen abarcar la problemática poniendo en consideración tres puntos principales:

- Requerimientos del lado del usuario: el usuario suele ser subestimado en su rol clave en el proceso de desarrollo de software. El origen de una solución debería ser la o las necesidades de las personas que lo van a utilizar. Tambíen es importante conocer su experiencia y sus interacciones con los sistemas para lograr cumplir sus objetivos. Ahora bien, este aspecto trae aparejado un desafío, que es el de poder expresar realmente lo que necesitan y sus interacciones. Las personas, son personas y por lo tanto a la hora de expresarse, es posible que omitan información debido a que se trata de conocimiento tácito (Polanyi, 1996) o que simplemente les cuesta comunicar sus ideas y problemas. Por lo tanto se plantea la necesidad de aplicar métodos y técnicas de observación y análisis que permitan comprender los requerimientos de las personas. También es importante resaltar la importancia de involucrar a los usuarios desde el momento cero y en las distintas etapas del desarrollo de software para colaborar al entendimiento de cómo la solución propuesta puede mejorar su vida diaria.

- Requerimiento del lado del desarrollador: los desarrolladores también tienen necesidades que cubrir a la hora de desarrollar los requerimientos definidos. Diseñar soluciones teniendo en cuenta las limitaciones tecnológicas y traducirlas a implementaciones de alto nivel de usabilidad requiere de herramientas adecuadas. Los programadores quieren hacer un buen trabajo, teniendo en cuenta las restricciones de 
tiempo, presupuesto y tecnológicas impuestas por determinadas tecnologías. Estas tareas consumen tiempo para lograr aplicaciones lo más óptimas y performantes. Por este motivo, se suelen concentrar en ellas y por lo tanto es natural que le puedan dedicar poco tiempo a la cooperación con los usuarios.

- Requerimientos del lado de los profesionales de la usabilidad: los profesionales que se dedican a la usabilidad de la solución, denominados UX (user experience) actualmente, son los encargados del diseño de las interacciones del usuario con la aplicación. Su tarea tiene entre sus principales objetivos, lograr que la aplicación sea amigable y simple en su uso, para lograr que el usuario pueda ejecutar sus tareas sin inconvenientes y de la mejor manera posible en la solución propuesta. En muchos casos, existe un riesgo de que su trabajo quede subrogado.

\subsubsection{Design thinking}

La evolución más fuerte del movimiento hacia una Ingeniería de Software Centrada en las Personas lo constituye el conjunto de metodologías conocidas como Design Thinking, propuestas fundamentalmente a partir del trabajo conjunto entre la empresa IDEO, la Escuela de Diseño de la Universidad de Stanford y el Hasso Plattner Institute [28]. TIm Brown, Executive Chair de IDEO, define a Design Thinking como "un enfoque de la innovación centrado en el ser humano que se basa en el conjunto de herramientas del diseñador para integrar las necesidades de las personas, las posibilidades de la tecnología y los requisitos para el éxito empresarial" [29]

Su metodología centrada en el ser humano integra la experiencia del diseño, las ciencias sociales, la ingeniería y los negocios. Combina el enfoque del usuario final con la colaboración multidisciplinaria y la mejora iterativa para producir productos, sistemas y servicios innovadores. El pensamiento de diseño crea un entorno interactivo dinámico que promueve el aprendizaje a través de prototipos conceptuales rápidos.

Si bien Design Thinking tiene una serie de fases bien definidas, como se grafica en el lado izquierdo de la Figura 9, el lado derecho de la misma refleja mejor la realidad. La secuencialidad y la identificación de los puntos de inflección requiere de práctica y aprendizaje continuo. 

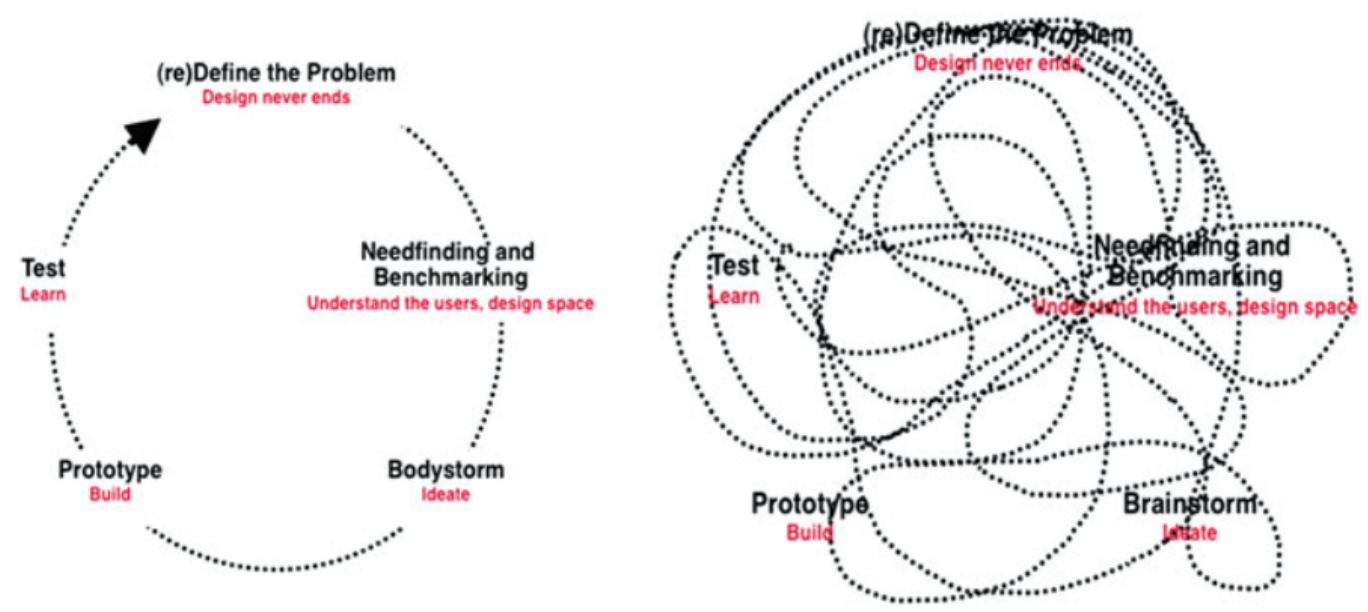

Figura 9: Proceso de design thinking idealizado y en la realidad [31]

Design thinking se apoya en tres premisas o reglas básicas:

- Ambigüedad. Quien piensa como diseñador mantiene la ambigüedad, se permite pensar "fuera de la caja" para facilitar nuevos descubrimientos

- Rediseño. Todo diseño es rediseño. Todo el tiempo estamos resolviendo necesidades que han estado con la humanidad por siglos, evolucionando a nuevas y mejores soluciones.

- $\quad$ Tangibilidad: hacer las ideas tangibles siempre facilita la comunicación

Basado en estas premisas, se ha propuesto una organización del trabajo en etapas iterativas e incrementales: Empatizar, Definir, Idear, Prototipar y Testear [30] (Figura 10). Todo en un constante ciclo de mejora y refinamiento de la solución.

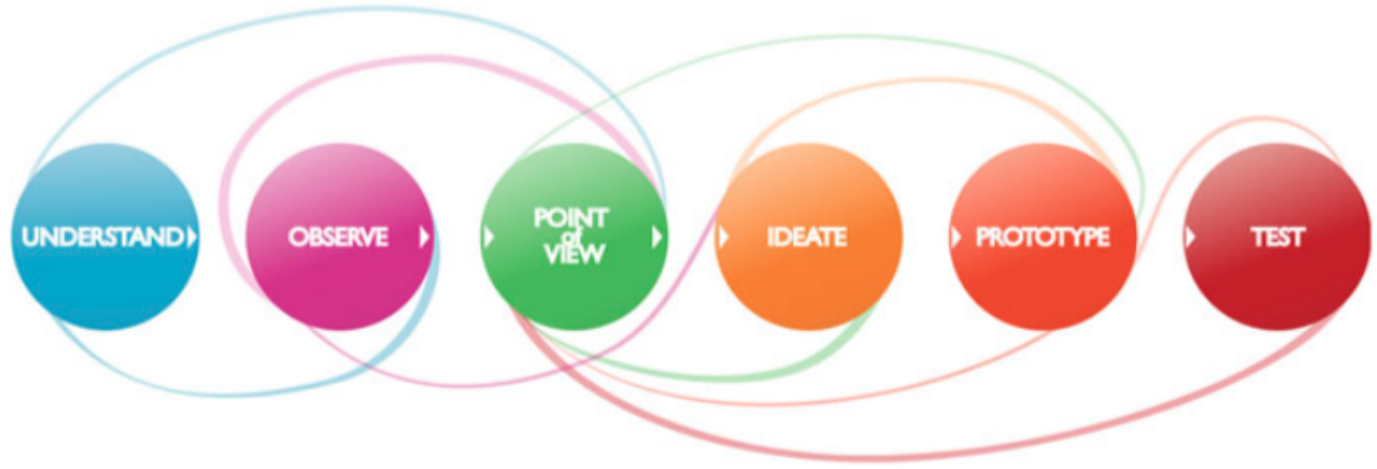

Figura 10 - Ciclo de DT a utilizar [30]

En este marco de HCSE y DT, utilizaremos la metodología propuesta Hasso Platner[31] y adaptada por Gabrysiak que incluye un proceso Design Thinking altamente iterativo orientado a la prototipación basada en escenarios[32]. 
El proceso incluye las siguientes etapas:

- Entender y observar: etapa durante la cual se realiza el entendimiento del problema a resolver por medio de la investigación y la observación. El principal objetivo es obtener información del contexto de la temática en cuestión.

- Punto de vista: durante esta etapa se obtiene una visión en detalle de la necesidad a cubrir, desarrollando conocimiento y proponiendo ideas que resulten en un impacto positivo en la vida del usuario. Se validan requerimientos e insights con los usuarios.

- Ideación: etapa durante la cual, basado en todo el conocimiento obtenido en las instancias anteriores, se propone una solución inicial. Adicionalmente se elaboran prototipos para interactuar con el usuario con el objetivo de validar el entendimiento del problema a resolver, en un dominio específico.

- Prototipado: en la etapa de prototipado, se elabora un prototipo de la posible solución propuesta. Usualmente es interactivo y permite al usuario visualizar y experimentar el enfoque propuesto.

- Pruebas y aprendizajes: luego de realizar el prototipo, se procede a utilizarlos con usuarios. Como resultado se obtiene feedback, que permitirá validar el rumbo a seguir por el producto, con el fin de cumplir los objetivos propuestos. En caso de ser necesario, se puede ajustar tanto el problema, como la solución propuesta. Con el aprendizaje obtenido, se vuelve a iterar hasta obtener la solución mínima valuable.

\section{Reglas del Design Thinking}

En el libro Design Thinking de Christoph Meinel, Larry Leifer y Hasso Plattner basados en una serie de experiencias con actividades de design thinking, lograron hallazgos dentro de los cuales denominan las cuatro reglas del design thinking [28]:

Regla 1 - El rol humano: Toda la actividad de diseño es, en última instancia, de naturaleza social

Existen estudios que demuestran que la innovación exitosa utilizando actividades de design thinking, nos volverán siempre al punto de vista centrado en el humano. Es decir, resolver problemas técnicos con el objetivo de solucionar los problemas a los humanos. La premisa es reconocer el factor humano.

Regla 2 - La regla de la ambigüedad: Ios Design Thinkers tienen que preservar la ambigüedad 
Esta regla hace referencia a la importancia de tener un ambiente en donde se permita descubrir para innovar en ambientes donde las restricciones son muchas y el miedo a fallar está siempre latente. Es clave llevar nuestros conocimientos al límite, con la libertad de poder ver las cosas de una manera diferente.

Regla 3 - La regla del re-diseño: Todo diseño es rediseño

El diseño y la innovación fueron solucionando problemas desde el inicio de los tiempos. A medida que el tiempo pasa, nuevas soluciones son necesarias para nuevos problemas. Entender cómo se lograron cubrir esas necesidades, nos permitirá aprender del pasado y mejorar la estimación de las condiciones tecnológicas y sociales que podremos encontrar en los próximos años.

Regla 4 - La regla de la tangibilidad: haciendo las ideas tangibles siempre facilita la comunicación

Hacer visible lo invisible nos acerca al entendimiento de las ideas, que de otra manera se dificulta hasta que exista alguna versión de la solución que, puede ser o no coincidente con lo que realmente se esperaba. Para colaborar con el alineamiento de expectativas y necesidades, se promueve el uso de prototipos, considerados medios de comunicación que permitirán generar visibilidad de ancho de banda, granularidad, constantes de tiempo y dependencias de contexto.

\subsection{Empatizar y definir}

Empatizar es la primera etapa con la que inicia Design Thinking, cuyo principal objetivo es entender a las personas y los problemas que enfrentan en su día a día. Para esta fase se puso en marcha un proceso de caracterización de actores por medio de la técnica de Personas y de definición de los posibles puntos problemáticos a través del cartografiado de actividades conocido como Journey Map[20]

\subsubsection{Representación de los actores por medio de Personas}

Personas es una herramienta de modelado de usuarios, que permite describir patrones de comportamiento, objetivos, habilidades, actitudes y ambiente de los mismos. Tal como lo describe su creador Alan Cooper [19] , ".. no son personas reales, pero las representan a lo largo del proceso de diseño. Son arquetipos hipotéticos de usuarios reales. Aunque son imaginarios, se definen con gran rigor y precisión. En realidad, no "inventamos" tanto nuestro personaje como para descubrirlo como un subproducto del proceso de investigación." 
Es decir, Personas es una herramienta que se utilizará para crear entidades basadas en la investigación realizada de los distintos participantes del flujo de aprendizaje, no busca representar a alguien en particular, sino a un conjunto de patrones de comportamiento que nos ayudarán a identificar puntos de dolor y oportunidades de mejora en el camino de búsqueda de posibles soluciones.

Algunas de las características de las personas son:

Nombre: puede ser ficticio, ya que como se mencionó anteriormente, puede no representar una persona particular, sino un conjunto de características o patrones de comportamiento de una o más personas.

Datos demográficos: puede incluir Edad (o rango de edad), Profesión, Provincia, Ciudad entre otros.

Objetivos: el o los objetivos que desea cumplir la Persona, con respecto al flujo de actividades bajo análisis. En este caso, dicho flujo se representará por medio de un Journey Map.

Biografía: breve descripción de los rasgos de personalidad y rutinas de la persona dentro del contexto del flujo en análisis.

Motivaciones: listado de vehículos movilizadores de la Persona, que pueden estar directamente, indirectamente o no relacionadas con los objetivos perseguidos por la misma, definidos en la sección Objetivos.

Frustraciones: listado de situaciones emocionales que obstaculizan directa o indirectamente con el cumplimiento de los objetivos perseguidos por la Persona.

Tecnología: sistemas operativos de las tecnologías utilizadas por los alumnos/as. En este caso son Android, iOS y Windows.

\section{Confección de la Persona alumno/a}

Para poder confeccionar el modelo de persona del alumno, se realizaron una serie de entrevistas a Maestras/os y Padres, que permitieron obtener las características principales y comunes de los alumnos y alumnas. Se realizaron visitas a escuelas de Capital Federal, así como también entrevistas remotas ubicadas en distintos lugares del país como ser Posadas, Misiones y La Plata con el fin de obtener distintos puntos de vista que pudieran enriquecer el modelado de la Persona. Con el objetivo de lograr empatizar con los entrevistados, alineados con la metodología de Design Thinking, se aplicó el formato de entrevista libre, en donde se realizaron algunas preguntas guías, donde el protagonista se expresa libremente y es el centro de atención. 
Con respecto a los Maestros/as, pertenecen a escuelas públicas, donde las realidades sociales son variadas. Por ejemplo la Maestra de Posadas, da clases en una escuela en donde la mayoría de los alumnos son de bajos recursos, en un entorno en el que algunos alumnos tienen celulares y otros no. Mientras que la maestra de Capital Federal, tienen aulas con mayoría de niños con acceso a un celular. Con respecto a los padres, también vienen de distintas realidades sociales, algunas con mayores necesidades básicas cubiertas que otros. Para garantizar la anonimidad de los maestros/as y padres / madres, se identifica a los mismos como Maestra 1, Padre 1, etc. Estas entrevistas no solo se utilizaron para la confección de la Persona, sino también para elaborar el Journey Map del alumno/a como de la maestra/o, los cuales se presentan en la sección siguiente.

Entrevistas realizadas:

Maestra 1

- Modalidad: presencial

- Lugar: visita a la escuela

- Tipo de escuela: escuela primaria pública de la Ciudad de Buenos Aires

Maestra 2:

- Modalidad: virtual.

- Lugar: entrevista tomada desde su casa, utilizando Zoom y Whatsapp.

- Tipo de escuela: escuela primaria pública de Candelaria, Misiones.

Maestra 3:

- Modalidad: virtual.

- Lugar: entrevista tomada desde su casa, utilizando Zoom y Whatsapp.

- Tipo de escuela: escuela primaria pública de la Provincia de Buenos Aires.

Padre 1:

- Modalidad: virtual.

- Lugar: entrevista tomada desde su casa, utilizando Zoom y Whatsapp.

- Tipo de escuela: escuela primaria pública de la Provincia de Buenos Aires.

Para ver el detalle de las entrevistas y contexto de las mismas por favor referirse a la sección de Entrevistas correspondiente a los Apéndices.

En la figura 11, se describe a la Persona que representa al alumno/a, resaltando sus principales características, a tener en cuenta a la hora de analizar la situación actual y los potenciales usuarios de la solución a proponer. 


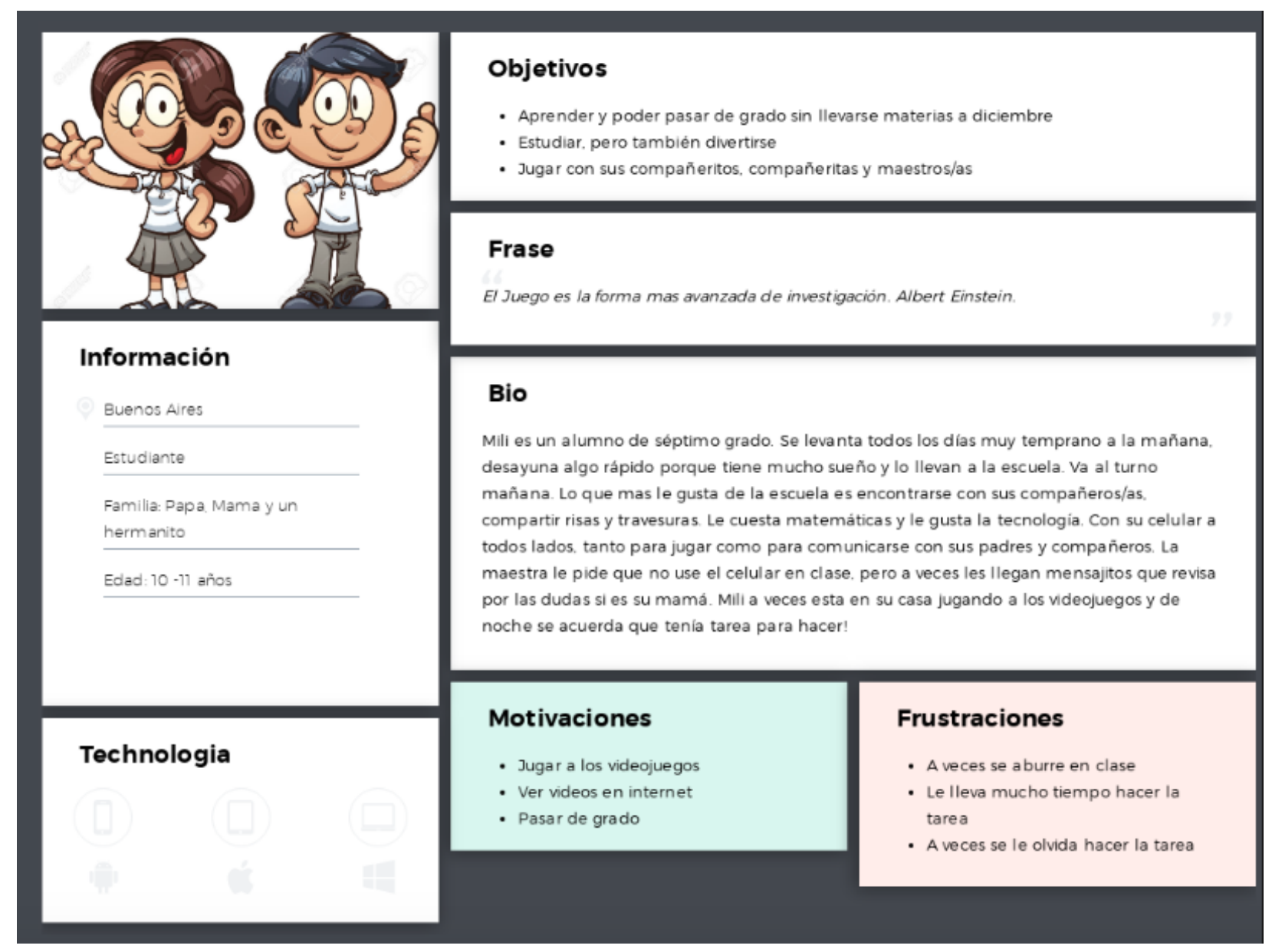

Figura 11: Alumno/a Persona

Descripción del flujo de comportamientos de un niño/a previo, durante y posterior un día escolar

Para poder identificar los problemas y oportunidades del día a día de los alumnos/as en su relación con el proceso de aprendizaje, es interesante realizar un análisis de los distintos momentos en lo que esto sucede. Las actividades relacionadas con aprender no solo suceden en la escuela, sino también en los distintos núcleos en donde el niño/a se desenvuelve, como por ejemplo la familia y los compañeritos/as de escuela. Es por eso que se intentan describir las distintas instancias de la vida escolar, como ser: antes de la escuela, durante la escuela y posterior a la escuela.

\subsubsection{Journey Map}

Existen distintas herramientas para poder relatar y graficar el día de un alumno/a. El presente trabajo utilizará el Journey Map. El Journey Map tal como lo define S.Gibbons de Nielsen Group, "es una visualización del proceso que una persona recorre para poder lograr un 
objetivo. En su forma más básica, el Journey Map comienza compilando una serie de acciones del usuario en una línea de tiempo. A continuación, la línea de tiempo se completa con los pensamientos y emociones de los usuarios para crear una narración. Esta narración es condensada y pulida, lo que finalmente lleva a una visualización" [20]

Tal como se menciona en el párrafo anterior, esta herramienta no solo permite identificar procesos, sino también emociones que la persona va experimentando en el camino. Cabe destacar que en muchos de los Journey Maps se describe la interacción del usuario con un servicio o aplicación. En este caso, con el fin de utilizar y aprovechar las ventajas de la herramienta, la interacción será entre los alumnos/as con la escuela y el proceso de aprendizaje (el cual sería el equivalente al servicio).

\subsubsection{Componentes del Journey Map:}

Objetivos del estudiante: objetivos buscados por el alumno/a relacionados con la jornada escolar, que incluyen las tres fases descritas. Es decir, también se consideran los momentos de ocio y descanso.

Expectativas del estudiante: expectativas del alumno/a con respecto a la escuela y proceso de aprendizaje durante las fases descritas. Adicionalmente, se contemplan los momentos de ocio y descanso.

Procesos y canales: simboliza los medios utilizados por los alumnos/as para lograr los objetivos de aprendizaje. Pueden ser herramientas como sitios web de la institución educativa, buscadores de internet, documentación escrita y/o digital.

Experiencia emocional: simboliza las emociones que el alumno/a va transitando durante las distintas fases y subfases del proceso de aprendizaje. Son representadas por medio de una línea en el tiempo simboliza el sube y baja emocional, usualmente alineados con los sentimientos de placer y las frustraciones.

Puntos de dolor: tal como se definió en el proyecto de tesis, un punto de dolor es un momento o momentos en los cuales se producen situaciones que dificultan el logro del objetivo de la tarea del usuario, en ese caso el alumno.

Oportunidades de mejoras: son posibles acciones o ideas que pueden colaborar con la mejora del proceso de aprendizaje, tanto de los niños/as como la interacción con los maestros/as. Cada una dentro del contexto de las fases y subfases definidas. 


\subsubsection{Fases del Journey Map}

Antes de la escuela: incluye los momentos previos a ir a la escuela. Esto puede incluir un día domingo por ejemplo, previo a un lunes de clases. A su vez esta fase se encuentra dividido en subfases:

- Revisar tareas

- Buscar Material

- Realizar tareas

- Rendir prueba

Durante la escuela: incluye el período en el cual el niño/a se traslada a la escuela y el transcurso de su día escolar. Las subfases de este período son:

- Ir a la escuela

- Atender a clases

- Entregar la tarea

Posterior a la escuela: incluye la vuelta al hogar, momentos de distracción / descanso y preparación. Las subfases de este período son:

- Volver al hogar

- Descansar

- Estudiar para la prueba

Fase: antes de la escuela

La Figura 12, describe las características principales del alumno en su momento previo al inicio de la jornada escolar y sus distintos momentos. 


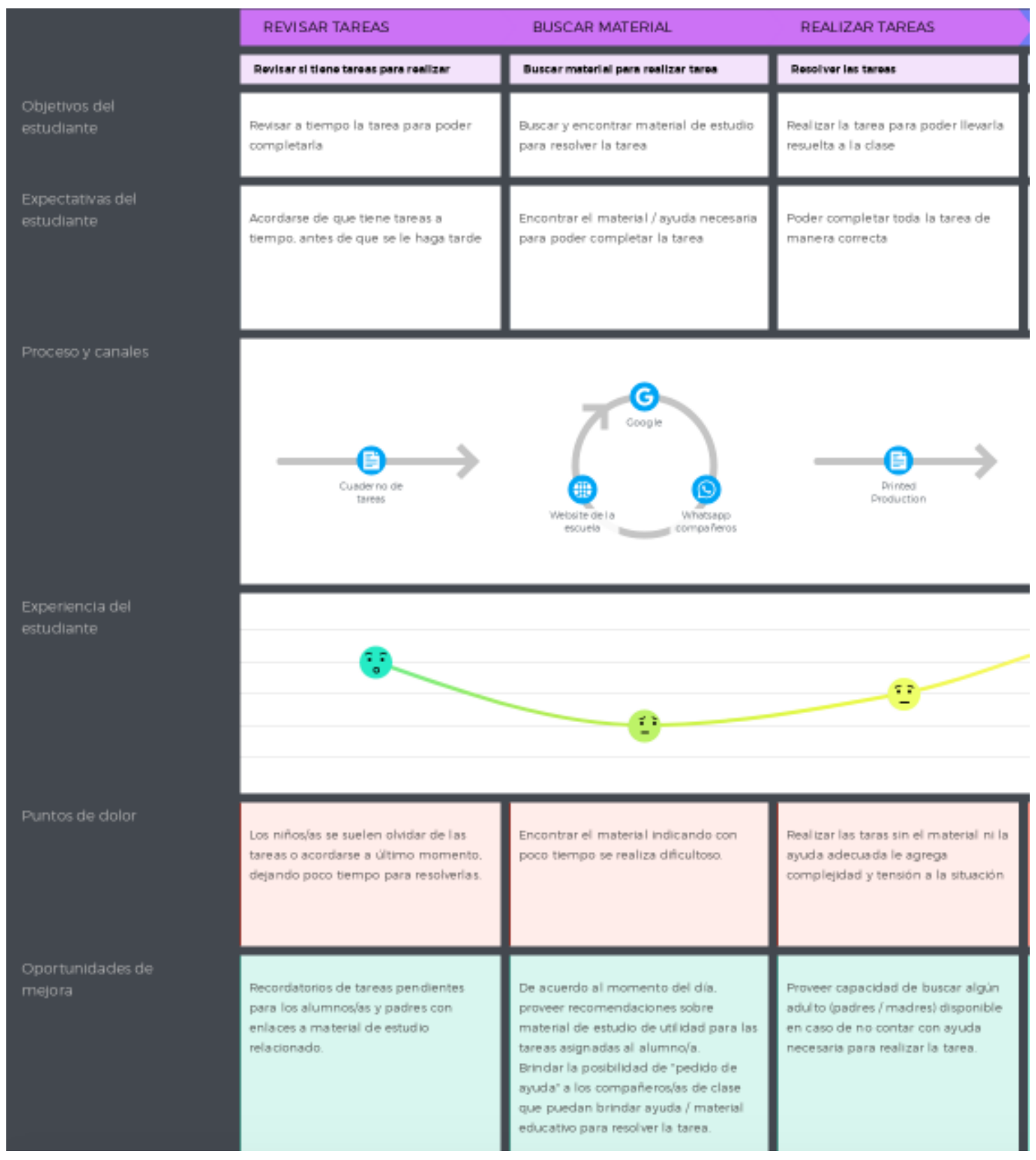

Figura 12: Journey Map - Descripción de los momentos previos a la escuela 


\section{Fase: durante la escuela}

La jornada escolar, como se muestra en la Figura 13 inicia a partir de la ida a la escuela, cuando el niño/a va en camino, siendo transportada por su tutor o tutora. Una vez en la escuela, pasan por momentos de entregas de tareas, así como también de rendir pruebas.

\begin{tabular}{|c|c|c|c|}
\hline IR A LAESCUELA & ATENDER LAS CLASES & ENTREGAR LA TAREA & RENDIR PRUEBA \\
\hline Ir do is cacses a is escuain & Atender las clases dictadias por la maestralo & Entregar la tweas ras lizads an casa & Resolver dudins \\
\hline Llegar a la escuela a horario & $\begin{array}{l}\text { Aprender los temas enseñados en clase } \\
\text { Aesolver dudas que puedan plantearse }\end{array}$ & $\begin{array}{l}\text { Validar el aprendizaje de los conceptos } \\
\text { ensentados en la diase }\end{array}$ & $\begin{array}{l}\text { Fendir las pruebss para poder } \\
\text { pasar de grado }\end{array}$ \\
\hline Llegar a la escuela a horario & $\begin{array}{l}\text { Aprender los conceptos dictados por el } \\
\text { docente y obtener material de consulta } \\
\text { adicional } \\
\text { Onertirse en clase aprendiendo con sus } \\
\text { compañeros/as }\end{array}$ & $\begin{array}{l}\text { Que la tarea realizada en el hogar y io } \\
\text { dlase este corrects } \\
\text { si hay correcciones que realtzar. tener } \\
\text { el material de consulta disponible }\end{array}$ & $\begin{array}{l}\text { Aprobar las pruebas aplicando } \\
\text { el conocimiento apeendido } \\
\text { durante las clases. sin llevarse } \\
\text { materias a diciembre. }\end{array}$ \\
\hline
\end{tabular}
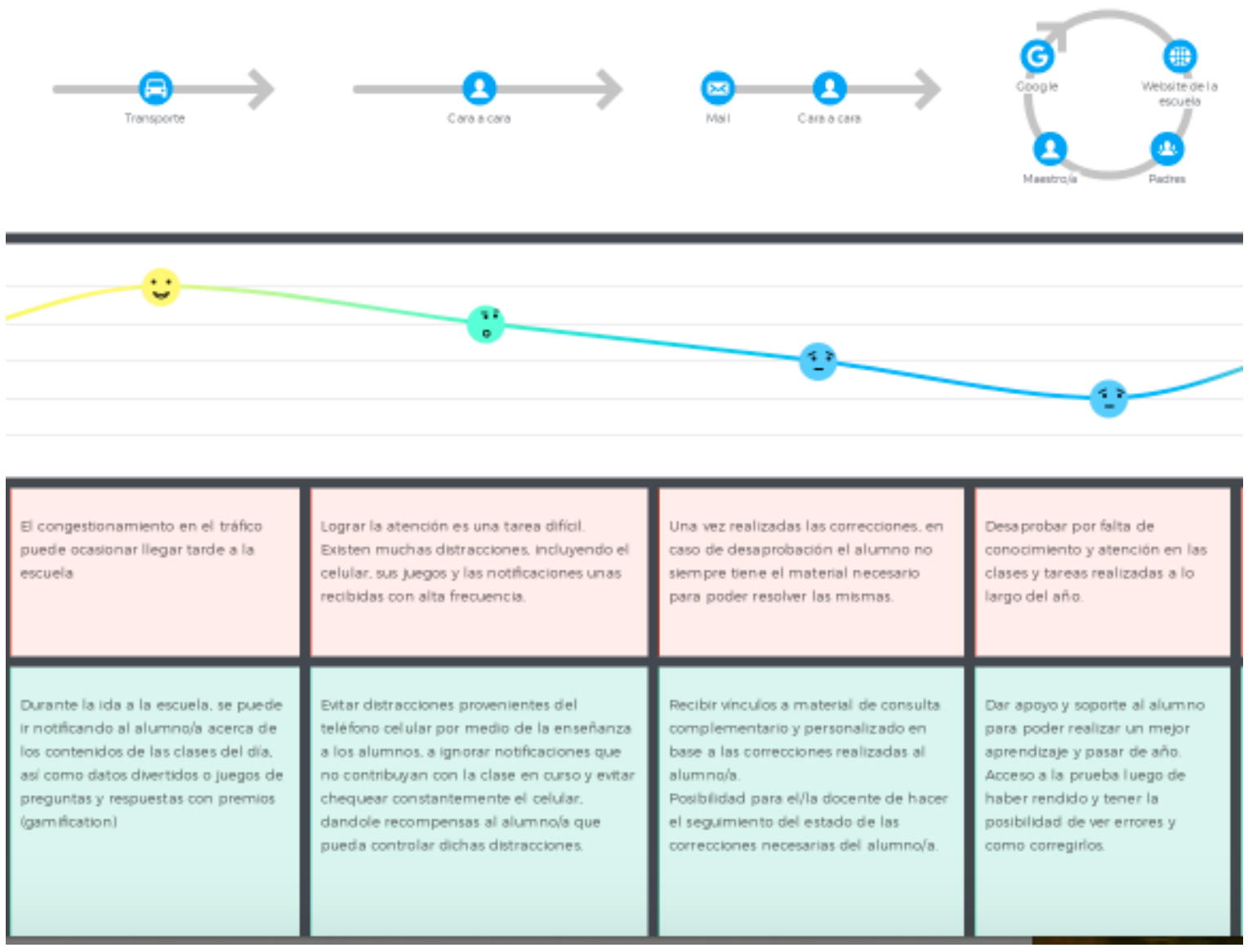

Figura 13: Journey Map - Durante la jornada escolar 


\section{Fase: posterior a la escuela}

Una vez finalizada la jornada escolar, se emprende el viaje de retorno al hogar. Una vez en sus casas, se da a lugar al descanso y tiempo de esparcimiento de los niños/as. También, dependiendo del período del año, pueden tener momentos de estudio para las pruebas. La figura 14 resume dicha sección del Journey Map.

\begin{tabular}{|c|c|c|}
\hline VOLVER AL HOGAR & DESCANSAR & ESTUDIAR PARA LA PRUEBA \\
\hline Volver a cass & Devenneser & Estudiar \\
\hline $\begin{array}{l}\text { Volver al hogar luego de un dia de } \\
\text { elases }\end{array}$ & Descansar luego de un dia escolar & $\begin{array}{l}\text { Estudiar para apeobst las pruebas de las } \\
\text { escuela }\end{array}$ \\
\hline $\begin{array}{l}\text { Luego de una joenada escolar. } \\
\text { volver a casa para descansar y } \\
\text { hacer actwidades extra escolares }\end{array}$ & $\begin{array}{l}\text { Hacer actwidades que permitan } \\
\text { descansar del dis escolar Idormir } \\
\text { uns siesta. Jugar wideojuegoa. } \\
\text { deportes. etcl }\end{array}$ & $\begin{array}{l}\text { Estudiar los contenidos dictados en } \\
\text { dase. para poder aprobar las pruabas y } \\
\text { posteriormente pasar de año. }\end{array}$ \\
\hline
\end{tabular}

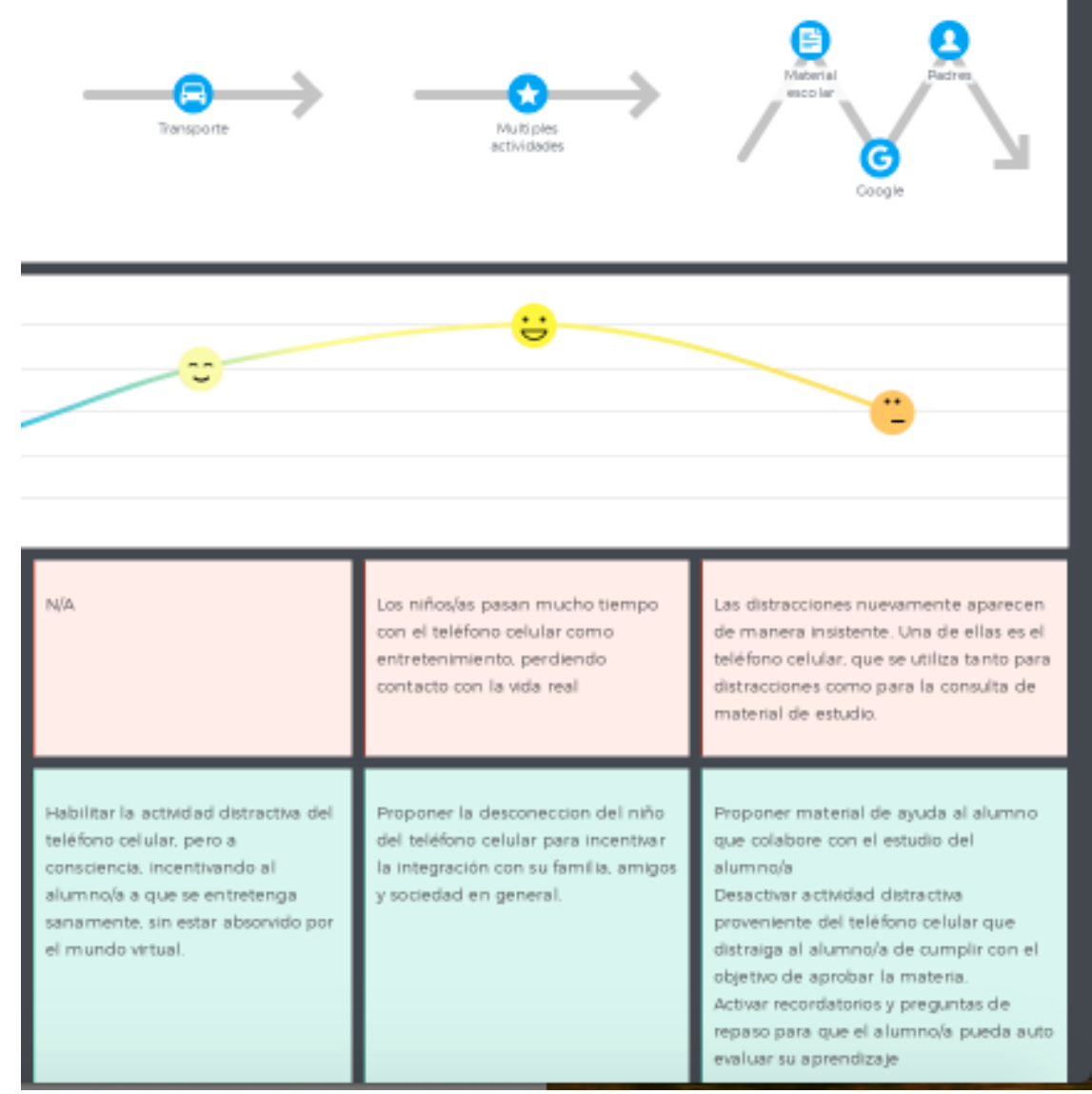

Figura 14: Journey Map - Posterior a la jornada escolar 


\section{Principales hallazgos en el Journey Map del alumno/a}

Como resultado de la etapa de empatizar correspondiente a la metodología Design Thinking, se busca obtener la definición del problema a resolver. Por medio de la observación como herramienta principal, y el ponerse "en los zapatos" de las personas que forman parte del ecosistema, cubriendo sus interacciones principales, se realiza una inmersión en las distintas situaciones y etapas del día del alumno/a. Este proceso cuyos hallazgos fueron documentados en el Journey Map, refleja en los puntos de dolor, los principales problemas identificados, los cuales confirman la hipótesis de la fuente de distracción que generan los teléfonos celulares en los alumnos/as. Pero no son solamente influencias negativas, sino también medios para buscar información tanto en clase, como a la hora de hacer la tarea en casa, incluyendo principalmente derivados de internet, desde distintos dispositivos móviles, como por ejemplo tablets, laptops y teléfonos celulares.Los sitios y buscadores web utilizados son Google, Youtube entre otros. Así mismo, los puntos de dolor no solo se circunscriben a la hipótesis inicial; también se registraron hallazgos que generan problemas de distinta índole a las personas involucradas, dada la visión holística con la que se abordan, como por ejemplo el olvido de la tarea y los apuros que esta situación ocasiona.

De la mano de los puntos de dolor, también derivan oportunidades de mejora, también documentadas en el Journey Map, las cuales brindarán las bases sobre las cuales se trabajará la solución propuesta, priorizando las iniciativas que colaboren con la solución central de la distracción causada por el celular en clase.

A continuación se describen los puntos de dolor y oportunidades de mejora identificadas en cada instancia:

\section{Antes de la escuela}

Puntos de dolor:

- Olvido de realizar las tareas. Se acuerdan a último momento con poco tiempo para resolverlas.

- Encontrar el material necesario para resolver la tarea con poco tiempo resulta dificultoso.

- Realizar las tareas sin el material ni la ayuda necesaria, agrega tensión a la situación.

Oportunidades de mejora:

- Recordatorios de tareas pendientes a tiempo.

- De acuerdo al momento del día y a la tarea a ser completada, proveer enlaces y sugerencias de material relacionado

- Proveer medios para pedir ayuda a maestros/as, padres, madres y compañeritos/as

- Motivar el encuentro y la resolución de tareas en persona y en grupo 


\section{Durante la escuela}

Puntos de dolor:

- Llegadas tarde al colegio por demoras en el tránsito

- Dificultades para lograr captar la atención de los alumnos/as durante las clases dada la gran cantidad de fuentes de distracción existentes. El teléfono celular es una de ellas, con sus notificaciones, redes sociales y juegos disponibles.

Oportunidades de mejora:

- Utilizar el tiempo camino a la escuela, realizando repaso de los contenidos aprendidos o a aprender por medio de preguntas y respuestas en un entorno de gamification.

- Educar al alumno/a en cómo gestionar las distracciones provenientes del teléfono celular, promoviendo su uso responsable. Es decir, el uso del celular como elemento de colaboración en el proceso de aprendizaje, premiando en estos casos y sancionando (restar puntos) en casos donde el uso sea indebido.

\section{Posterior a la escuela:}

- Los niños/as pasan mucho tiempo con el celular, jugando, viendo videos lo cual si no se les controla el tiempo puede ser perjudicial

- Estas distracciones pueden incluso llegar a prolongarse e influir a la hora de recordar que tenían que hacer la tarea y estudiar para las pruebas.

Oportunidades de mejora:

- Habilitar el uso del celular para los momentos de distracción, pero motivando el contacto con su ambiente real y no virtual.

- Incentivar el juego y encuentro con sus compañeritos/as de clase.

- Proponer material y actividades de repaso de los temas aprendidos en clase, incentivando el aprendizaje y fijación de conocimientos. 


\section{CAPÍTULO 4: SOLUCIÓN PROPUESTA}

En este capítulo avanzamos en las etapas de Ideación y Prototipado y describimos la solución propuesta para colaborar con la solución de los puntos de dolor detectados en el proceso de aprendizaje y la atención, analizado en el Journey Map del alumno/a. Si bien el alcance principal del presente trabajo estará puesto en los alumnos/as, se podrán derivar propuestas que abarquen diferentes participantes del ecosistema escolar.

Principales puntos de dolor a ser abarcados por la solución propuesta:

- Olvido de realizar las tareas. Se acuerdan a último momento con poco tiempo para resolverlas.

- Encontrar el material necesario para resolver la tarea con poco tiempo resulta dificultoso.

- Realizar las tareas sin el material ni la ayuda necesaria, agrega tensión a la situación.

- Llegadas tarde al colegio por demoras en el tránsito

- Dificultades para lograr captar la atención de los alumnos/as durante las clases dada la gran cantidad de fuentes de distracción existentes. El teléfono celular es una de ellas, con sus notificaciones, redes sociales y juegos disponibles.

- Los niños/as pasan mucho tiempo con el celular, jugando, viendo videos lo cual si no se les controla el tiempo puede ser perjudicial

- Estas distracciones pueden incluso llegar a prolongarse e influir a la hora de recordar que tenían que hacer la tarea y estudiar para las pruebas.

\subsection{Aprender jugando}

En la era digital, de las pantallas táctiles, los teléfonos celulares son de altas prestaciones y el acceso a Internet de alta velocidad, los videojuegos van adquiriendo cada vez más atractivos, tanto por sus diseños gráficos como por sus historias y opciones de jugar en red. Desde batallas épicas como League of Legends, pasando por grupos de asalto y guerra por supervivencia como el Fornite, o por aventuras en un mundo de fantasía animé oriental como Pokémon, los videojuegos y todo su ecosistema, como por ejemplo las notificaciones que generan, logran capturar la atención de los niños/as a toda hora, sin importar el día de la semana, generando una fuente de distracción potencialmente negativa, teniendo en cuenta el proceso de aprendizaje en las escuelas. 
Ahora, ¿es posible aprovechar ese potencial de concentración y dinámica de aprendizaje (si, los niños/as aprenden solos a jugarlos, no leen el manual de usuario antes de empezar a jugar) para aprender en la escuela? Para ello es necesario empezar por definir el concepto que refiere a aplicar los conceptos y reglas de los videojuegos en distintos tipos de actividades denominado Gamification. De acuerdo a la publicación de investigadores de la Universidad de Columbia, NY Gamification in Education: What, How, Why Bother? (Gamification en la Educación, Qué, Cómo, Porque debería importar?), define Gamification como "La gamificación, definida como el uso de la mecánica del juego, la dinámica y los marcos para promover los comportamientos deseados ( MacMillan, 2011). " [21]

La investigación menciona que las personas dedican horas a desarrollar sus capacidades de resolución de problemas, resiliencia, persistencia y creatividad.

Definido el concepto de gamification, surgen distintas incógnitas acerca de la aplicación del mismo al ambiente educativo. Es decir, por ejemplo, actualmente las escuelas implementan un sistema de recompensas y castigos o penalizaciones. Un aprobado, se puede interpretar como una recompensa por haber aprendido los conceptos requeridos, así como un reprobado en caso contrario. También si un alumno/a adquiere un promedio de notas altos, puede calificar para ser abanderado o escolta de la bandera nacional. ¿Esto significa que las escuelas están aplicando gamification? No necesariamente. Es por eso que que tal como mencionan los profesores investigadores de Columbia "Comprender el papel de la gamificación en la educación, por lo tanto, significa comprender en qué circunstancias los elementos del juego pueden impulsar el comportamiento de aprendizaje.La mayoría de los estudiantes no describirían las actividades en el aula en la escuela como experiencias lúdicas. Claramente, la existencia de elementos de juego no se traduce directamente en compromiso." [21]

Si bien los videojuegos desde los inicios fueron vistos como fuentes de distracción, también tienen el potencial de colaborar con el desarrollo de habilidades clave en el desarrollo de los niños/as. Según la publicación previamente mencionada [21], las tres áreas en las cuales gamification puede intervenir son:

Cognitiva: por medio del aprendizaje de las reglas del juego, que pueden ser incluso complejas, por medio de la exploración y descubrimiento. [21]

Emocional: los niños/as pasan por una gran variedad de emociones como por ejemplo la curiosidad, pasando por la frustración, optimismo y orgullo.[21]

Social: permiten probar nuevas identidades y roles, requiriendo la toma de decisiones.[21]

Gamification tiene el potencial de poder aplicarse a distintos ámbitos, más allá de las escuelas. Generan un atractivo casi natural de los niños y niñas de la era digital. Muchos aprenden solos, sin mucha explicación previa ni entrenamiento. Es realmente llamativo como toman las pantallas y se lanzan a explorar, ganando cada vez más habilidades y mejorando a medida que 
pasa el tiempo, todo por sus propios medios. Estas características motivacionales han permitido introducirse en medios donde incluso, se utilizan para colaborar con el tratamiento de discapacidades en el aprendizaje. A continuación se describen algunos casos de aplicación de gamification para distintas situaciones, en las cuales el principal objetivo es lograr captar la atención del participante y pueda obtener los beneficios de las actividades propuestas, ligadas al proceso cognitivo.

\subsubsection{Entrenando planificación y memoria de trabajo a niños/as de tercer grado}

Publicación de la revista Mind, Brain and Education, que desarrolla el trabajo realizado por un grupo argentino de investigadores de la Universidad de Buenos Aires y Torcuato Di Tella. Consiste en un videojuego denominado Matemarote mediante el cual se promueve el entrenamiento de las capacidades cognitivas de niños y niñas de 8 años aplicando conocimientos de neurociencia educacional. Consiste en dos juegos que entrenan la memoria de trabajo y habilidades de planificación. Los resultados citados por la publicación son los siguientes: "La memoria de trabajo y la planificación son habilidades cognitivas fundamentales que respaldan el razonamiento fluido. Mostramos que 2 juegos que entrenan la memoria de trabajo y las habilidades de planificación en niños en edad escolar promueven la transferencia a 2 tareas diferentes: una prueba de atención y una prueba de razonamiento fluido. También mostramos una mejora a largo plazo de las capacidades de planificación y memoria en niños de 8 años después de jugar juegos de computadora adaptativos específicamente diseñados para incorporar estas funciones cognitivas. La capacidad de memoria de trabajo se extendió de 5 a 7 elementos al usar nuestros juegos. Además, la progresión constante en la tarea indica que esta capacidad se puede entrenar rápidamente. Las habilidades de planificación persistieron en una forma de juego no markoviana, donde un movimiento está muy influenciado por movimientos previos, evitando copias de seguridad." [22] La mejora específica se dió en notas obtenidas en las materias matemáticas y lengua. Los científicos también identificaron una mejora en la reacción de los niños/as entre 100 y 150 milisegundos con respecto al grupo de control.«Parece poco -subraya Goldin-, pero es lo que puede mejorar un chico en dos o tres años de vida».

Avioncito: juego utilizado para el entrenamiento del control inhibitorio y razonamiento fluido.

Pancho es un niño que le gustan los avioncitos de papel y los tira en dos direcciones. Dependiendo de la dirección en que lo tira, el participante debe presionar una tecla predefinida. Ahora bien, los avioncitos son de dos colores distintos. Por lo tanto, a la dirección se le suma otra variable: el color. El color y la dirección definen las teclas que el jugador debe presionar para ganar puntos y avanzar en el juego. Todo esto se realiza en una cantidad de tiempo acotada. A continuación, en las Figuras 15, 16, 17 y 18 se puede observar un ejemplo de secuencia de la dinámica antes mencionada. 


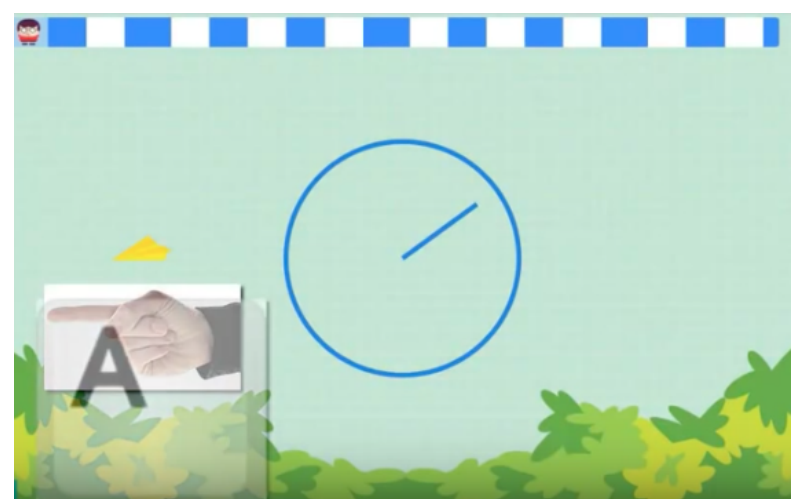

Figura 15: Si el avioncito es amarillo y va en dirección izquierda, se debe presionar la tecla A. [25]

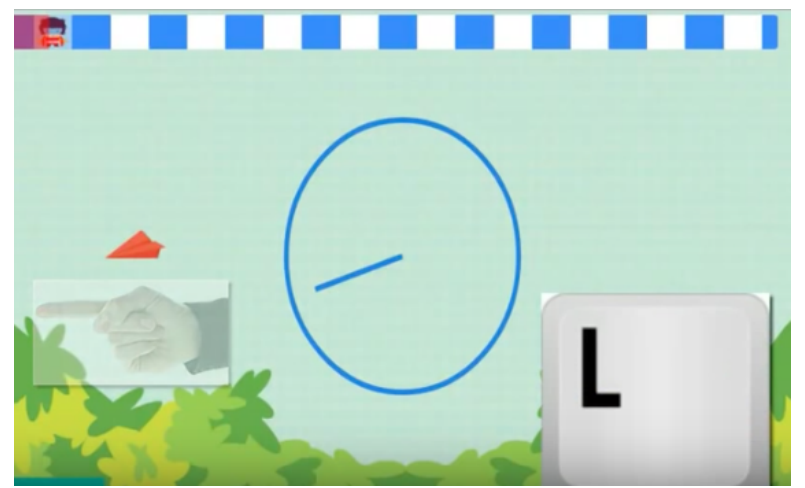

Figura 17: $\mathrm{Si}$ el avioncito es rojo y va en dirección izquierda, se debe presionar la tecla L. [25]

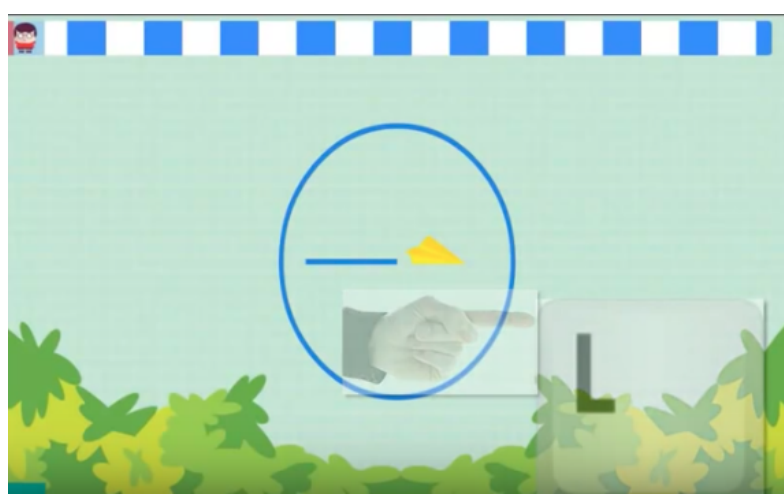

Figura 16: Si el avioncito es amarillo y va en dirección derecha, se debe presionar la tecla L.[25]

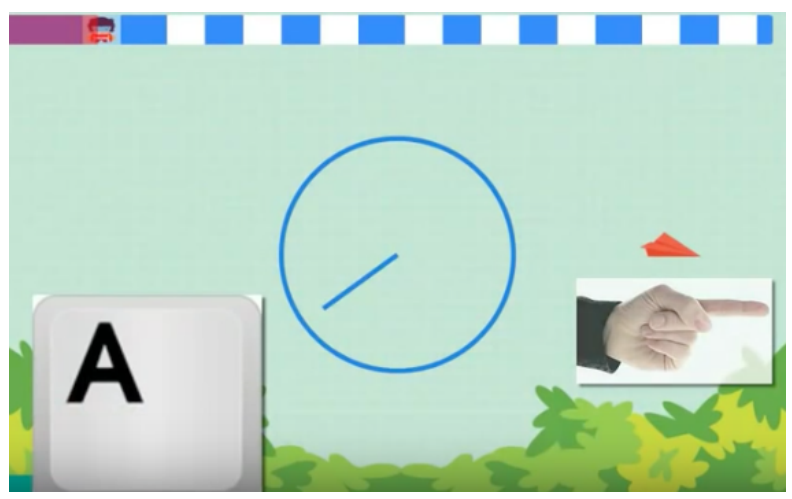

Figura 18: $\mathrm{Si}$ el avioncito es rojo y va en dirección derecha, se debe presionar la tecla A. [25] 


\section{The number race (la carrera de números): videojuego para la remediación de la}

discalculia

La publicación de la revista Behavioral and Brain Functions (Funciones de comportamiento y del cerebro), llevada a cabo por prestigiosos neurocientíficos, entre ellos el prestigioso Stanislas Dehaene, ganador de múltiples premios por su aporte al campo de la neurociencia, describe el trabajo realizado en la elaboración de un videojuego para el tratamiento de una discapacidad en el aprendizaje denominada discalculia, en niños y niñas de entre 5 y 8 años de edad. Se basa en "hipótesis de que la discalculia se debe a un "déficit central" en sentido numérico o en el vínculo entre el sentido numérico y las representaciones simbólicas de números" [23]

Su funcionamiento se describe en la publicación como "The Number Race" capacita a los niños en una entretenida tarea de comparación numérica, presentando problemas adaptados al nivel de rendimiento del niño individual. Reportamos especificaciones matemáticas completas del algoritmo utilizado, que se basa en un modelo interno del conocimiento del niño en un "espacio de aprendizaje" multidimensional que consta de tres dimensiones de dificultad: distancia numérica, fecha límite de respuesta y complejidad conceptual (desde el procesamiento de numerosidad no simbólico hasta operaciones simbólicas cada vez más complejas)."[23] En las figuras 19, 20 y 21 se resume el juego en una secuencia de pantallas con nivel de dificultad progresivo. Con los puntos obtenidos puede avanzar lugares en el tablero.

a.

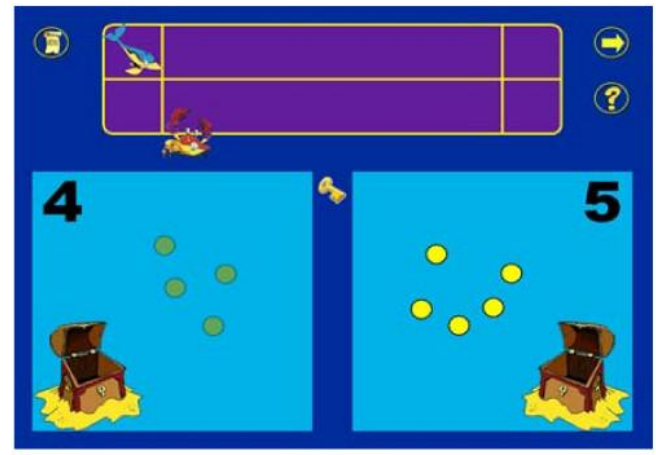

Figura 19: a. Muestra de pantalla de comparación. El niño interpreta el personaje del delfín, y tiene que elegir el mayor de dos números, antes de que su competidor (el cangrejo) llegue a la llave y robe la mayor cantidad. personajes gana (en este caso, el competidor). [23]

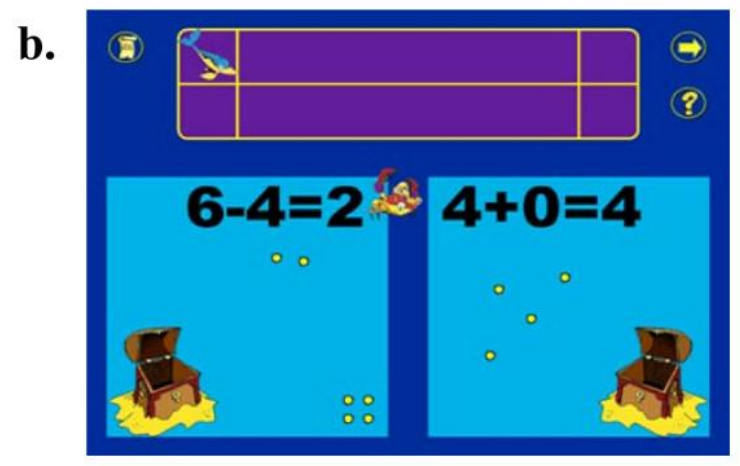

Figura 20: b. Otra pantalla de comparación de muestra, tomada en un nivel de dificultad más alto en la dimensión de "complejidad", donde se requieren sumas y restas para hacer una comparación correcta. La pantalla muestra cómo las operaciones se concretan mediante operaciones correspondientes en conjuntos de objetos, después de que uno de los personajes gana (en este caso, el competidor). [23] 


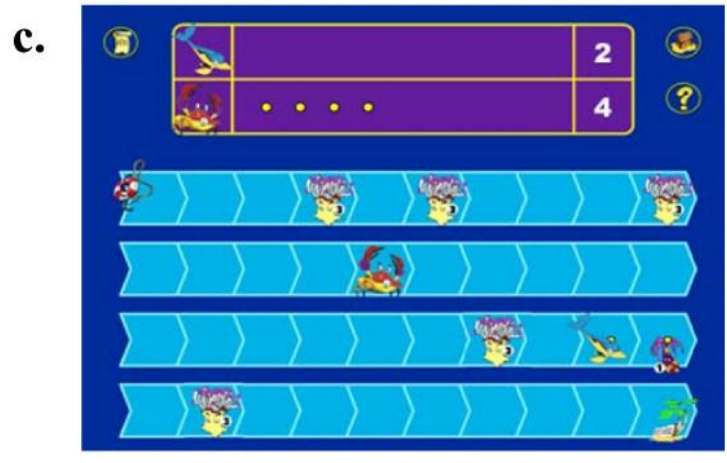

Figura 21: C. Pantalla de tablero de muestra. Después de cada comparación, el niño usa fichas ganadas para mover un número correspondiente de casillas en el tablero de juego, donde debe evitar caer en peligros (aquí representado por anemo-nes). Una vez que llega al final del tablero, gana un pez "recompensa" para agregar a su colección. Ganar suficientes recompensas desbloquea el acceso al siguiente personaje. [23]

Los resultados arrojados luego de la experimentación se describen a continuación:

"El algoritmo fue validado en una pequeña muestra de niños de 7 a 9 años que tenían dificultades de aprendizaje matemático. Se adaptó con éxito al rendimiento de los niños (incluso a sus dificultades individuales) y mantuvo el éxito medio de los niños cerca de la tasa deseada. El aprendizaje de los niños podría verse como un aumento en el volumen de conocimiento y como un eventual éxito en áreas de fracaso inicial." [23]

"Estos resultados, junto con los resultados de las pruebas previas y posteriores (ver el documento adjunto [1]), sugieren que el software puede ser útil para remediar la discalculia, al menos para niños de 7 a 8 años y menores. Además, existe la posibilidad de utilizar el software para investigar diferentes causas y subtipos de discalculia." [23]

\section{Aprendizaje basado en juegos para niños/as con dislexia}

El artículo publicado en la revista science direct, titulado "Aprendizaje basado en juegos digitales para niños con dislexia: una perspectiva constructivista social sobre el compromiso y el aprendizaje durante el juego grupal" [24] presentan un videojuego denominado Words matter (las palabras importan) diseñado para niños/as con dislexia. 
Tal como cita la publicación, "La dislexia es una dificultad de aprendizaje que, según se argumenta, impacta entre el $4-8 \%$ de los niños en el Reino Unido afecta principalmente las habilidades involucradas en la lectura precisa y fluida de palabras y ortografía (Rose, 2009). A medida que los niños con dislexia se dan cuenta de que las dificultades los distinguen de sus compañeros, su disposición a participar en la alfabetización a menudo disminuye (Zisimopoulos y Galanaki, 2009)".[24]

Tal como las demás experiencias previamente citadas, en este caso se realizó una intervención utilizando el aprendizaje basado en juegos digitales (Digital Game Based Learning), para lidiar específicamente con el aspecto motivacional que trae aparejada la problemática cognitiva.

También se tomó en cuenta un estudio reciente realizado por Holmes (2011), en donde demuestra que el entrenamiento y práctica con técnicas DGBL "aumentó el compromiso de los niños con actividades de alfabetización, fomento el refuerzo de habilidades y mejoró su percepción del progreso en la lectura" [24]. Se destaca adicionalmente, la importancia de la participación de adultos como guía en las tareas propuestas por el juego.

Los principales targets del juego Words Matter son: la decodificación, deletreo y fluidez de palabras.

- Habilidades: siete habilidades que se centran en la identificación de consonantes, vocales, mezclas y patrones de letras, sílabas, sufijos,prefijos y letras confusas. Cada una de las habilidades está clasificada en niveles de dificultad, lo que le permitirá ir avanzando de niveles. En las Figura 22 y 23 se observa un ejemplo de juego de sílabas.

- Géneros: uno de los principales desafíos del juego es lograr el compromiso de los jugadores, dado un amplio espectro de dificultades que el niño/a posee. Para esto se realizó el juego de mundo abierto, compuesto de 11 mini juegos, que permiten el entrenamiento y práctica en distintos subniveles, sobre los cuales se logra progresar, siguiendo las recomendaciones de jugar "poco y frecuente".

- Narrativa: el juego se da en una vida del más allá, basada en la tradición centroamericana el Día de los muertos. A los diseñadores del juego les resultó atractiva su estética y la oportunidad de resaltar un rol de fantasía. "La narrativa del juego principal comienza con el jugador que descubre que el mundo de los muertos necesita la ayuda de los vivos para su mundo para seguir existiendo." [24] En este contexto, se busca la motivación del participante en convertirse en héroe.

- Actividades y mecánica: si bien la mecánica del juego se basa en acciones tomadas por los jugadores para avanzar en su progreso, cuenta con particularidades que lo diferencian de los juegos conocidos. Como menciona la publicación, "mientras que todos los minijuegos cuentan con una mecánica pedagógica centrada en objetivos preocupados por las siete habilidades de alfabetización, algunos también cuentan con objetivos centrados en el juego en conjunto con los objetivos pedagógicos" [24] 
- Progreso y logros: el juego permite a los niños/as jugar de dos maneras distintas:

- Explorar el mundo abierto y seleccionar el mini juego que es sugerido por personajes del lugar.

- Encontrar un personaje del juego accediendo al "Libro fantasma".

Cada personaje del juego se adquiere como amigo, así como también su serie de habilidades de alfabetización asociadas. El participante irá desbloqueando nuevos personajes a medida que va progresando en el juego.

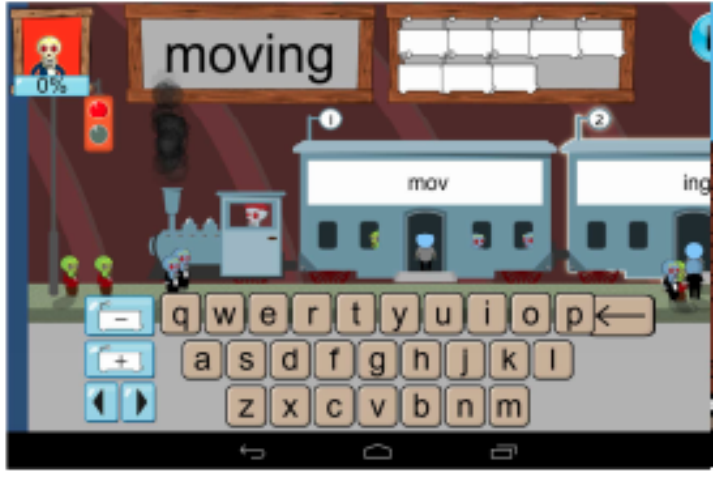

Figura 22: Despachador de trenes: para hacer avanzar al tren, el niño/a deberá tipear las sílabas de la palabra mostrada en pantalla [24]

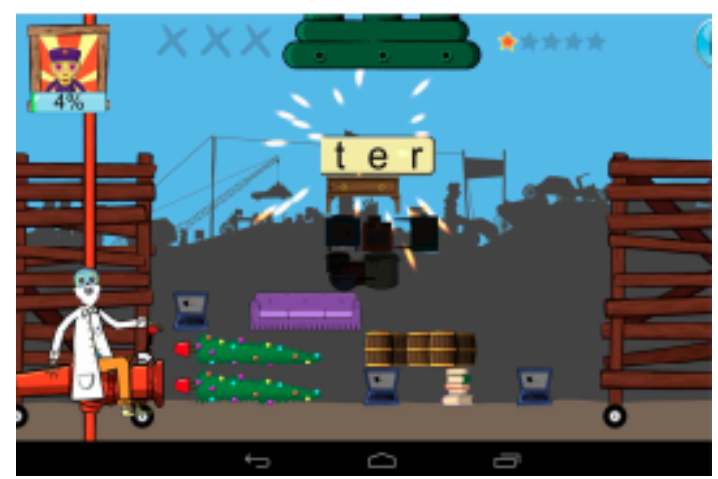

Figura 23: Patio de basura: requiere que el niño identifique

división correcta de una palabra. El niño debe entonces

apilar la basura creada en filas. El juego continúa mientras la basura no se acumule. [24]

\section{Conclusiones:}

Algunas de las conclusiones que se obtuvieron de la experimentación con los juegos para la dislexia, extraídas de la investigación publicada son:

"Hemos tomado un enfoque más matizado para argumentar que el tipo de aprendizaje privilegiado en los juegos de práctica y entrenamiento puede beneficiar especialmente el desarrollo de las habilidades para ciertos tipos de alumnos, como los niños con dislexia".[24]

"El mismo discurso que fomenta el compromiso social con los compañeros puede cumplir la función intraindividual de mejorar la autoestima del niño, donde el juego se convierte en un foro para ensayar los fracasos y éxitos del estado del juego."[24] 
"Aunque los niños parecen gravitar naturalmente hacia modos sociales de juego, una forma adicional de estimular el compromiso social es a través de la introducción de nuevos eventos de juegos que los jugadores pueden compartir entre ellos."[24]

"El juego en parejas sirve como el ejemplo más fuerte de cómo los niños se benefician de esta práctica: los niños con dificultades reciben un flujo constante de andamios de juego mientras que sus compañeros se empoderan asumiendo el papel de tutoría entre compañeros."[24]

"Los niños a veces se enfrentan a desgloses irreparables (separando en sílabas) que les obligan a salir del juego. En esos casos, siempre recurrirán a un tutor para ayudarlos a superar el ejercicio. Los desgloses intratables surgieron de la naturaleza de la tarea de aprendizaje por la cual los niños necesitaban comprender las reglas lingüísticas y cómo aplicarlas dentro de la actividad del juego, a veces a través de una serie de pasos complejos."[24]

"Similar a las formas en que los niños compartieron sus experiencias y su performance con los juegos en voz alta, también expresan en voz alta el contenido (palabras) en el que estaban trabajando, las reglas lingüísticas que estaban aplicando, sus expectativas de rendimiento, y los resultados que observaron."[24]

\subsubsection{Gamification en la educación y la economía de la atención}

En los ejemplos antes mencionados se describen distintas situaciones y objetivos para los que se utiliza gamification. Mejorar las capacidades cognitivas relacionadas a la toma de decisiones, memoria, dislexia, cálculos matemáticos. Ahora bien: ¿Cómo las técnicas de gamification podrían colaborar con la problemática de pérdida de atención en clases, ese bien tan preciado y necesario para lograr un correcto aprendizaje? ¿ Cómo enseñar a los niños a poder evitar las distracciones generadas por ejemplo por las notificaciones recibidas en los dispositivos móviles?. Tal como se hizo referencia en la sección del estado de la cuestión, algunas entidades optan por prohibir el uso de celulares en las aulas, mientras que otras prefieren racionalizar su uso durante las horas de clases.

El presente trabajo intenta proponer posibles respuestas a dichos planteos y puntos de dolor identificados en el capítulo de Descripción del problema del presente trabajo, alguno de los cuales son:

- Enseñar jugando a los niños y niñas de las escuelas a mantenerse alejados de las pantallas durante las horas de escuela y premiarlos si lo logran

- Entrenar a los niños y niñas para protegerse de las distracciones y efectos negativos que pueden generar el uso excesivo de los smartphones en la vida diaria

- Motivar los encuentros en persona con compañeritos y compañeritas de la escuela 
- Colaborar para incentivar la curiosidad e investigación de temas relacionados a la currícula escolar

\subsubsection{Componentes esenciales en el diseño de juegos}

Si bien los objetivos del juego pueden estar claros y definidos, a la hora de lograr un real compromiso de los niños/as y continuidad en su uso, es recomendable seguir ciertos lineamientos en su diseño. Tener juegos sin los lineamientos básicos de un juego real, corre el riesgo de la pérdida de interés y posterior desuso. Desde su complejidad, pasando por las distintas actividades, deben tener una dinámica atractiva que mantenga a quienes lo vayan a jugar, comprometidos y con ganas de avanzar y progresar. Elizabeth Lawley, profesora de juegos interactivos y medios del Instituto Tecnológico de Rochester opina que "gamification puede ayudar a enriquecer experiencias educacionales de una manera en la que los estudiantes van a reconocer y responder"[26]. En la misma publicación Análisis de gamification en la educación, menciona que Elizabeht "advierte sobre reducir la complejidad de juegos bien diseñados a sus elementos superficiales (por ejemplo los badges y puntos de experiencia) se queda corto en lograr el atractivo para los estudiantes"[26]. También opina que "limitar la implementación de las dinámicas del juego a solo su características superficiales, puede dañar el interés y atractivo actual del juego" [26]

Continuando con los lineamientos, la publicación [26] antes mencionada, basada en una serie de literatura disponible acerca de las dinámicas y conceptos de diseño de juegos, lista los siguientes componentes que un juego debería tener lo siguientes elementos:

- Libertad para fallar

- Rápida retroalimentación

- Progresión

- Relato de una historia (storytelling)

Libertad para fallar: elemento que le brinda al jugador la posibilidad de experimentar, fallar y volver a intentarlo. Lo motiva a tomar riesgos y seguir adelante con el juego, priorizando el proceso de aprendizaje sobre el resultado final.

Rápida retroalimentación: apela a la informar al jugador como va con respecto al juego, incluyendo estado de avance, nivel en que se encuentra, si perdió o ganó puntos y algún tipo de resumen.

Progresión: refiere a el avance de los participantes del juego a través de los distintos niveles o misiones. Avanzar de un nivel a otro, requiere haber podido cumplir con los requisitos necesarios definidos por el juego. El nivel de progresión también puede hacer referencia a las 
habilidades adquiridas por el jugador, que forman parte del proceso de aprendizaje. En el caso de la presente propuesta, podría ser "a mayor cantidad de distracciones aprende a evitar en un tiempo determinado, mayor progreso irá teniendo el jugador".

Relato de una historia (storytelling): tal como cita la publicación [26] "como señala Kapp, la mayoría de los juegos emplean algún tipo de historia. SimCity cuenta la historia de construir una ciudad desde cero, Monopoly cuenta la historia de hacerse rico a través de la propiedad a riesgo de perderlo todo. También señala que "las personas aprenden los hechos mejor cuando los hechos están incrustados en una historia en lugar de en una lista con viñetas", y proporciona un buen ejemplo de cómo incluso una simple integración de la narración puede ser utilizada con buenos resultados"

\subsection{Concentrate: un juego para ayudar a la concentración}

Concentrate es la propuesta del presente trabajo y consiste en un juego interactivo para teléfonos móviles, cuyo principal objetivo es lograr que los alumnos aprendan a no prestar atención a las distracciones generadas por el móvil. Siguiendo la filosofía de colaborar a la educación del uso de teléfonos móviles en lugar de la prohibición, se intenta aportar con el diseño de aplicaciones que tengan en cuenta la economía de la atención, teniendo en cuenta el contexto y momentos del día en el que se encuentra el alumno/a.

\section{Concentrate}

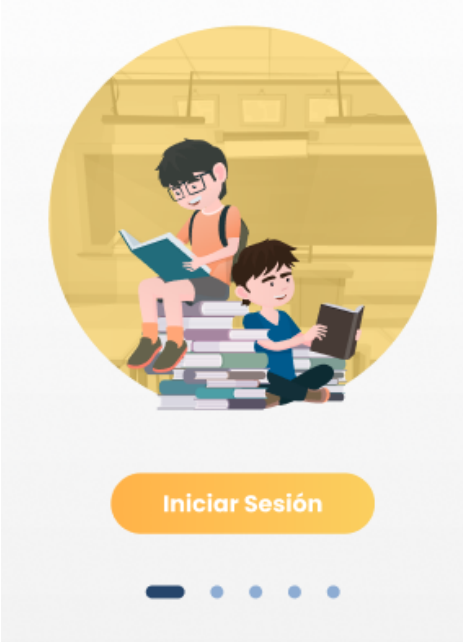

Figura 24: Concentrate: inicio de sesión 


\subsubsection{Historia del juego (Storytelling)}

Concentrate es la historia de un profesor Qwad, que luego de pasar años haciendo experimentos e investigando el medio ambiente, sus resultados arrojaron resultados preocupantes: si no nos dedicamos a cuidar el medio ambiente, nuestro planeta tierra estará en peligro. Mientras los seres humanos estamos distraídos invirtiendo tiempo en las redes sociales, juegos electrónicos, amigos virtuales y produciendo insumos de materiales contaminantes, el clima se pone cada vez más severo, la naturaleza y sus animalitos están empezando a sufrir sus efectos. Para empezar a salvar al planeta, el profesor necesita de voluntarios de todo el mundo, para poder realizar misiones y convertirse en héroes. Pero como todo héroe tiene una gran responsabilidad, es necesario un gran entrenamiento e ir cumpliendo con misiones que lo irán preparando para el objetivo final: proteger animales salvajes y su hábitat, nuestro planeta.

¡Que tamaño desafío! Pero, si apenas conocemos a esos animales por algún video en internet o documentales, ¿cómo podremos llegar a protegerlos?. Bueno, por algo hay que empezar...

En esta gran aventura nuestra primera misión consistirá en cuidar a algún animalito que podamos tener en nuestras casas, como por ejemplo ¡Brodie! Quien se muestra en la Figura 25 , un perrito de gran personalidad, guardián de los reinos de pelotas de tenis, que cuando no hay nadie en casa, se queda a cargo del cuidado de las casas donde viven niños.

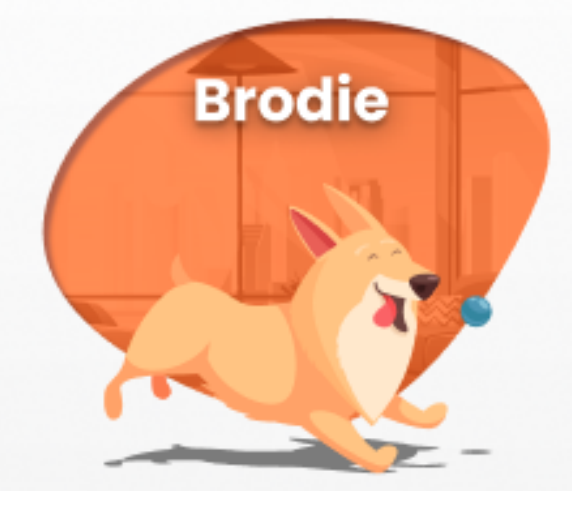

Figura 25: Personaje disponible para su selección en la aplicación

A medida que el participante vaya adquiriendo mayores habilidades de poder concentrarse y cuidar a su animalito, irá adquiriendo mayores responsabilidades. La cantidad de animalitos irá incrementando, hasta poder llegar a proteger grandes leyendas de la selva, como ser un León africano, una simpática suricata o una jirafa, entre otros.

Si bien esta es una idea inicial de la historia, irá progresando y evolucionando en su argumento con continuas iteraciones de prueba con los niños e incluso una vez que el juego salga en sus primeras versiones. 


\subsubsection{Reglas básicas del juego}

El principal objetivo del juego es que el niña/o vaya pasando distintos niveles y mayores niveles de dificultad a medida que avanza el juego. Esto lo irá logrando, entre otras cosas, aprendiendo a ignorar distracciones provenientes de su teléfono celular. A nivel general, las reglas del juego son las siguientes:

1) Al inicio del juego, el niño/a podrá elegir su participante entre varias opciones. Estas serán mascotas y sólo podrá tener una.

2) El animalito seleccionado estará al cuidado del participante y tendrá esta responsabilidad durante los horarios de clase.

3) Los horarios de clase serán definidos por el maestro/a, quién tendrá su propio usuario del juego.

4) Una vez iniciada la clase, cada participante deberá prestar atención a la clase. El / la participante tendrá tres oportunidades (strikes) para sumar puntos y pasar a la siguiente misión.

5) Cada vez que desbloquee o lea alguna notificación haciendo tap en la pantalla, le restará una oportunidad (1 strike). Al final de la misión, si no tiene ningún strike, se lleva todos los puntos.

- Si tiene 1 strike se lleva el $50 \%$ de los puntos

- Si tiene 2 strikes se lleva el $25 \%$ de los puntos

- Si tiene 3 strikes, deberá contestar un cuestionario relacionado a la materia sobre la cual tuvo clases.

- Si el porcentaje de respuestas correctas es >= 60 de las preguntas del cuestionario, recuperará el $50 \%$ de los puntos.

- Si el porcentaje de respuestas correctas es $>=40$ y $<60$ de las preguntas del cuestionario, recuperará el $25 \%$ de los puntos.

- Si el porcentaje de respuestas correctas es < 40, no recuperará ningún punto.

6) Los cuestionarios de la clase serán confeccionados por el maestro/a y serán del tipo verdadero o falso.

7) Con los puntos acumulados, el jugador/a podrá:

- adquirir accesorios para su animalito

- desbloquear mini juegos, accesibles en horarios fuera de clase 


\subsubsection{Journey Map del Alumno/a}

El Journey Map del alumno/a iniciará con los preparativos para configurar la aplicación. Eso es necesario una única vez. Se deberá registrar utilizando algunos de los métodos de autenticación más populares como ser Google o Facebook. De no tener ninguno de estos dos, tendrá la opción de crear sus propias credenciales (usuario y contraseña). Luego recibirá una introducción al juego y podrá seleccionar su personaje. Una vez seleccionado, ya estará listo para iniciar su misión. Ahora la pregunta es ¿cuándo inicia la misión? Dado que uno de sus principales objetivos será evitar las distracciones generadas por el celular en clase, el inicio de la misión coincidirá con el inicio de clases. La aplicación sabrá tanto el horario de inicio y fin ya que estos serán configurados por el Maestro/a, esto permitirá que Concentrate se active en en modo misión en los teléfonos celulares de los alumnos/as, con el objetivo principal de evitar que se distraigan con notificaciones. En caso de ceder a la tentación de leer las notificaciones 0 desbloquear el celular, se penalizará al alumno/a con 1 strike, poniendo en riesgo los puntos de la misión asignada. Al finalizar la clase y por lo tanto la misión, los resultados serán mostrados al alumno/a, con los puntos obtenidos y resumen de la actividad. En caso de tener 3 strikes, tendrá la oportunidad de responder un cuestionario de la asignatura e intentar recuperarlos. Como paso final del Journey Map, con el objetivo de premiar el haber evitado distracciones, dependiendo de la cantidad de puntos acumulados, se le habilitará al alumno/a el canje de los mismos por accesorios para sus animalitos, mini juegos y la oportunidad de pasar a la siguiente misión. En la Figura 26, se muestra el Journey Map del alumno/a y las funcionalidades propuestas en cada instancia para el Alumno/a y el Maestro/a

$\boldsymbol{V}$

\section{CONCENTRATE JOURNEY ALUMNA/O}

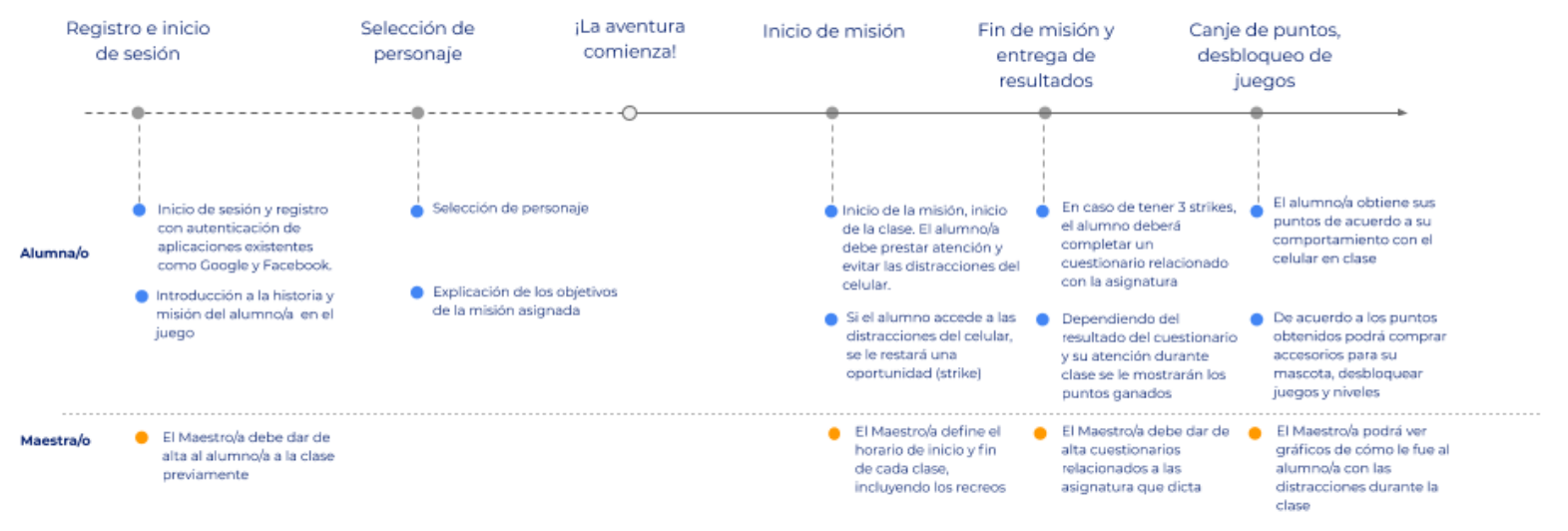

Figura 26: Concentrate: Journey Map del alumno/a 


\subsubsection{Concentrate: flujo del alumno}

Inicio de sesión y bienvenida: el flujo del alumno inicia con el registro, en donde se tiene que registrar para poder empezar a utilizar la app. Esto lo podrán hacer solos o con la guía de su maestro/a. A continuación se puede observar la secuencia de pantallas del prototipo diseñado.

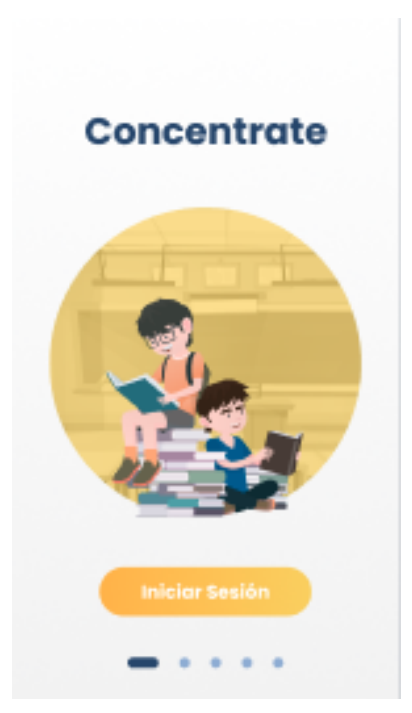

Figura 27: Bienvenida al juego para luego dar paso al inicio de sesión

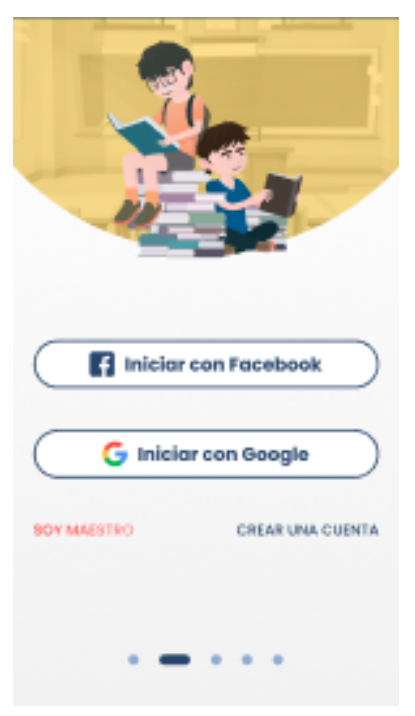

Figura 28: Selección de método de autenticación. La versión para maestro/a tendrá un texto identificatorio.

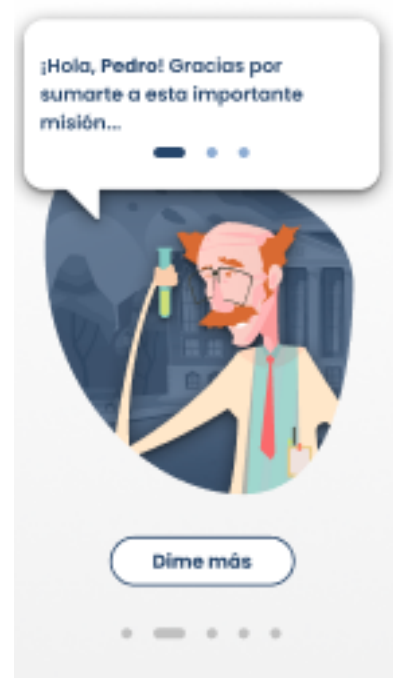

Figura 29: El profesor Qwad le da la bienvenida al alumno/a, dándole una introducción de la historia. 
Selección de personaje: la intención de permitir la selección de personajes entre distintos animalitos, es que los niños/as puedan empatizar y elegir con quien mejor se sientan a través de su mascota de preferencia. A medida que vayan avanzando de niveles podrán cuidar a más de un animalito, aumentando sus responsabilidades. En las figuras 30,31 y 32 se observa la secuencia de bienvenida e introducción a la historia detrás del juego.

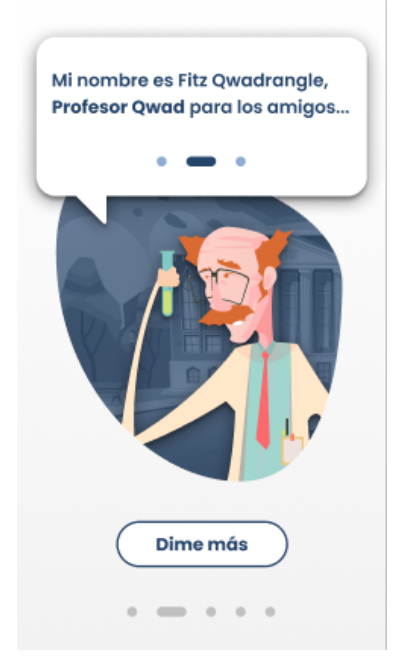

Figura 30: El profesor se presenta y da lugar a la selección de personajes

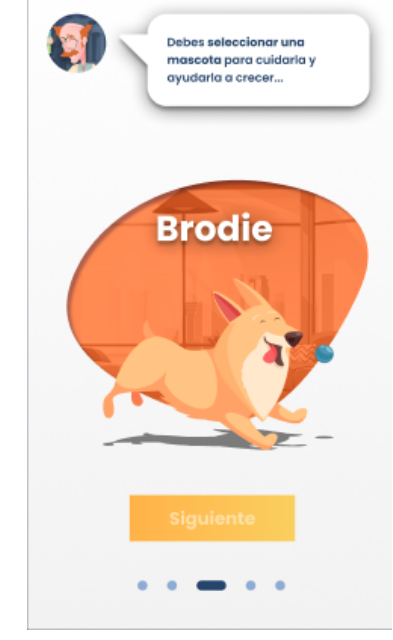

Figura 31: El alumno/a puede seleccionar entre varios animalitos, en esta caso se muestra a Brodie.

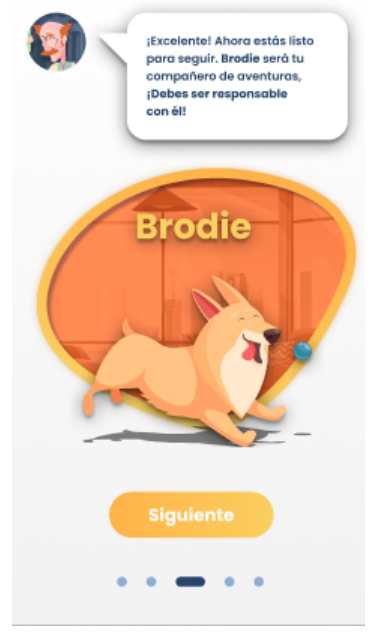

Figura 32: Una vez seleccionado el personaje, el mismo se resalta y todo está listo para iniciar la misión. 
Misión en curso: una vez seleccionado el personaje, se le asigna una misión al alumno/a en donde tendrá que cuidar a su animalito. ¿Cuál es la manera de cuidarlo?. No prestando atención al celular y sus notificaciones. En las Figuras 33, 34, 35, 36 y 37 se ve una secuencia de pantallas que muestran las consecuencias que genera una distracción hacia el celular.

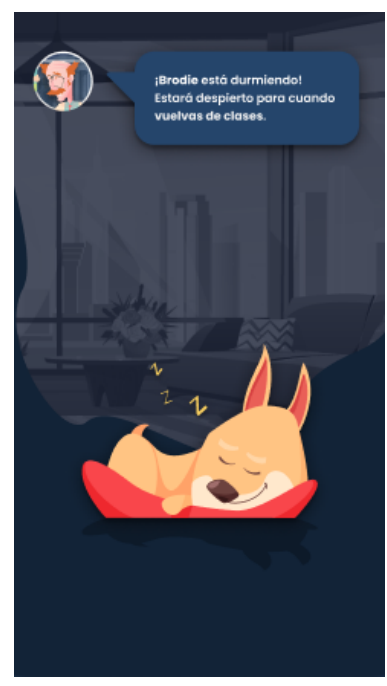

Figura 33: Iniciada la primera misión de cuidar a Brodie, mientras no se utiliza el celular.

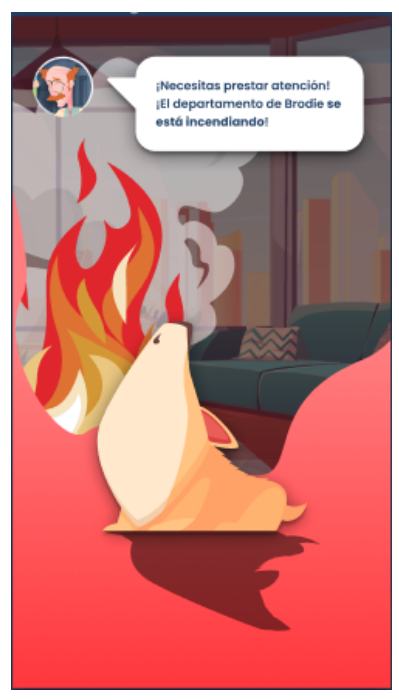

Figura 36: A la tercera distracción (2 strikes) Brodie queda bajo una amenaza. Su ambiente se vuelve muy peligroso.
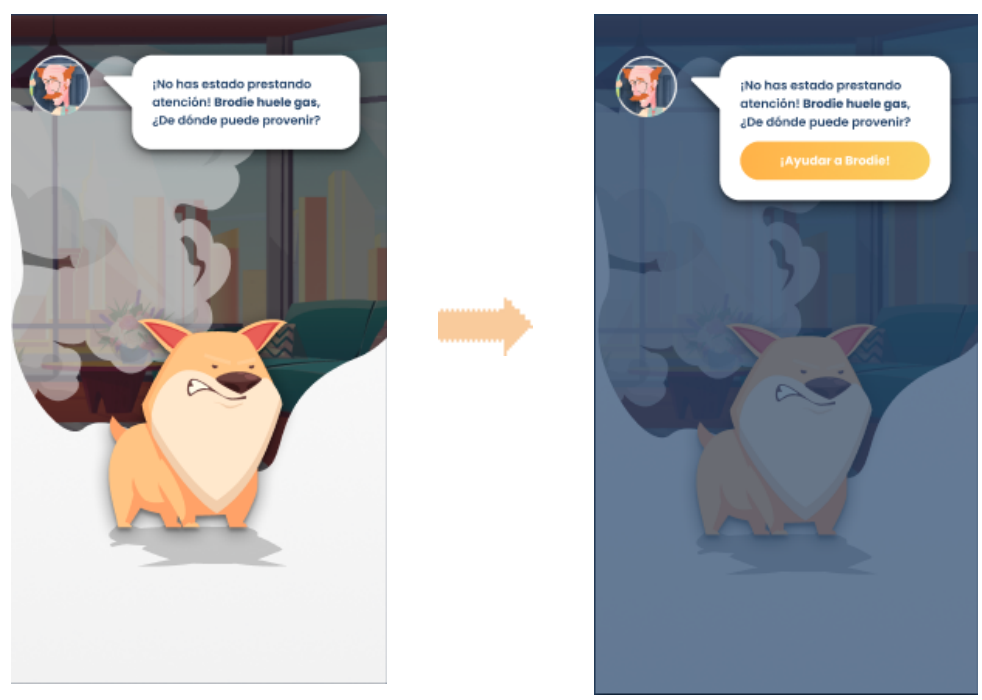

Figura 34: El alumno/a accede a una notificación recibida en el celular. Brodie se incomoda ante detectar algo amenazante en su ambiente.
Figura 35: El profesor Qwad alerta de la situación al alumno/a y es penalizado con 1 strike. Haciendo tap en ayudar a Broddie el celular se bloquea.

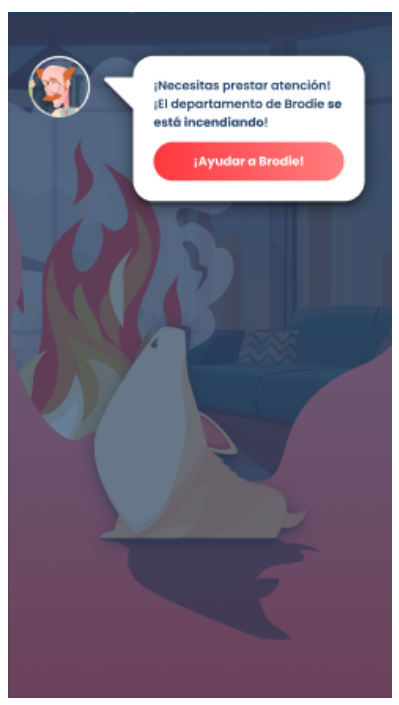

Figura 37: El profesor Qwad alerta de la situación al alumno/a y es penalizado con 1 strike. Haciendo tap en ayudar a Broddie el celular se bloquea. 
Fin de misión y oportunidad de recuperar puntos: la finalización de la misión, estará usualmente sincronizada por el fin de la clase en curso. En caso de que el alumno haya sido penalizado con 3 strikes, tendrá la oportunidad de recuperar puntos respondiendo una serie de preguntas de opción múltiple relacionadas a la materia. A mayor cantidad de preguntas respondidas, más puntos podrá recuperar.La maestra/o tendrá su propia interfaz para cargar las preguntas y respuestas. Las figuras 38,39 y 40 muestran la secuencia de pantallas diseñadas para este escenario.

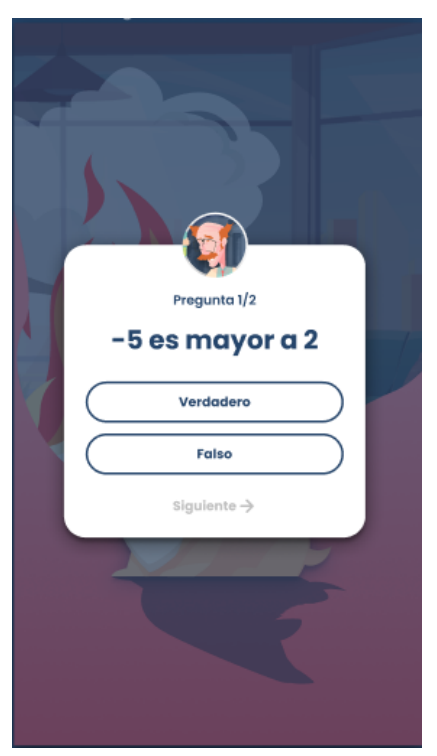

Figura 38: Para recuperar puntos, se le presentarán una serie de preguntas de verdadero o falso. Estas preguntas fueron dadas de alta por el maestro/a.

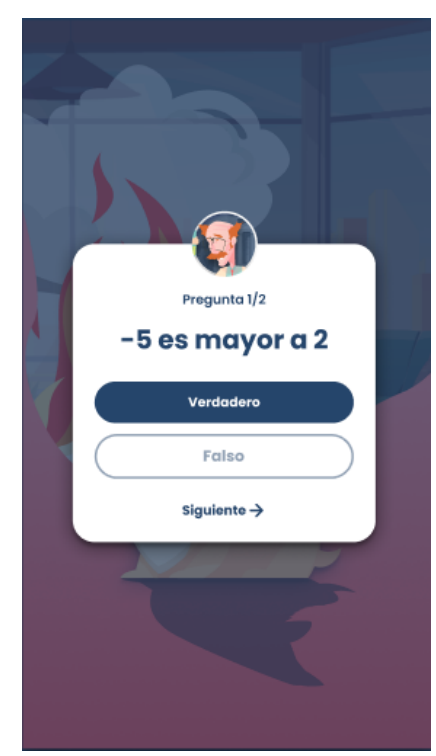

Figura 39: El alumno/a puede seleccionar verdadero o falso.

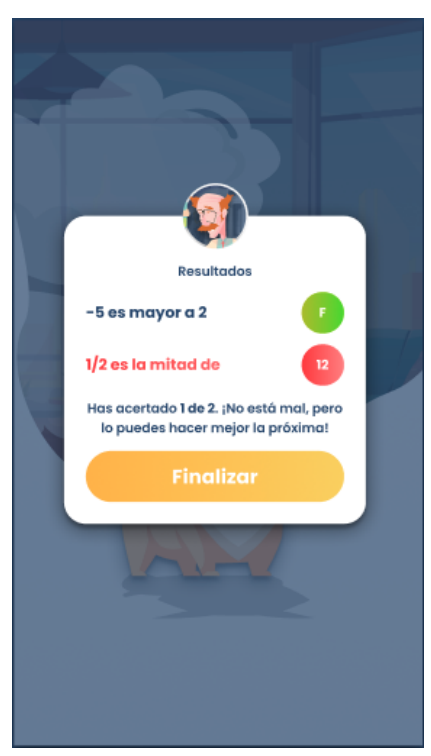

Figura 40: Al finalizar el cuestionario, se le entregan los resultados al alumno/a. Dependiendo de la cantidad de preguntas correctas serán los puntos que recuperará. 
Canje de puntos por accesorios: una de las formas de premiar al alumno/a por cuidar a su animalito y no distraerse con el celular, es por medio de puntos ganados. Estos puntos pueden ser canjeados por accesorios para nuestro animalito. En las figuras 41, 42 y 43 se puede ver el antes y el después de Brodie con su nuevo accesorio.

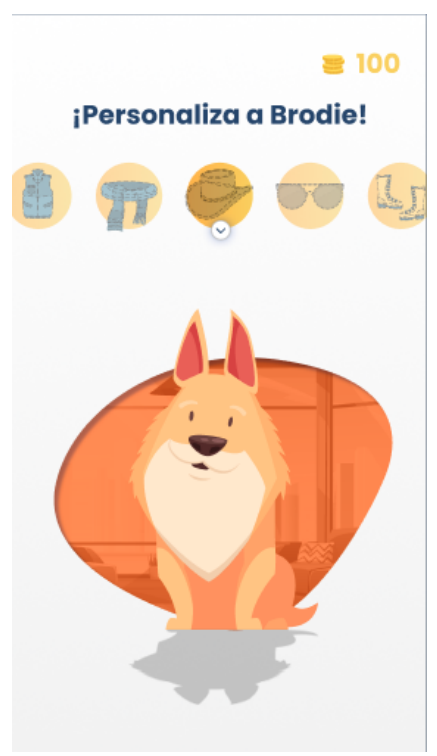

Figura 41: selección de tipo de accesorio.

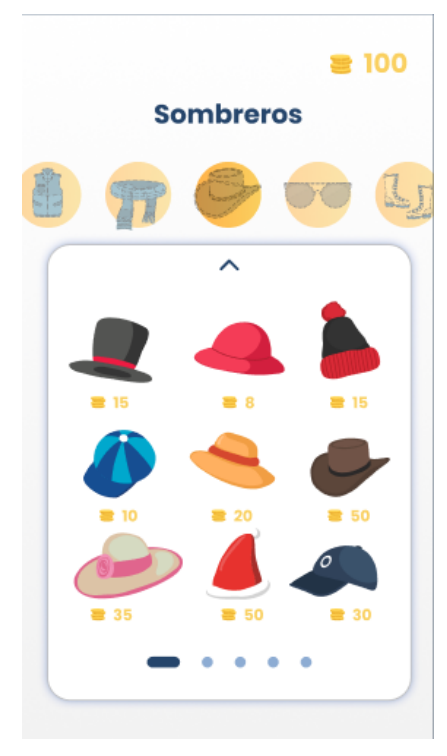

Figura 42: selección de sombrero.

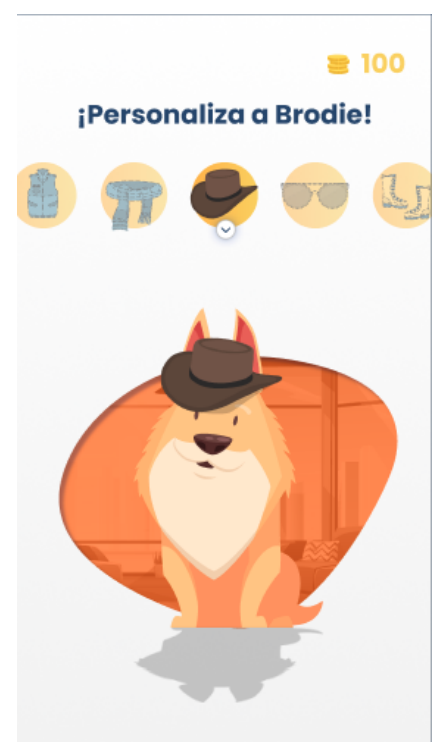

Figura 43: vista previa de cómo le queda el sombrero seleccionado a Brodie. 
Canje de puntos por desbloqueo de mini juegos: otra de las formas de premiar al alumno/a es dándole la posibilidad de desbloquear mini juegos, por medio del canje de puntos. Estos pueden requerir más puntos y esfuerzo para lograr obtenerlos.La figura 44 muestra un ejemplo ilustrativo de los mini juegos disponibles para ir desactivando.

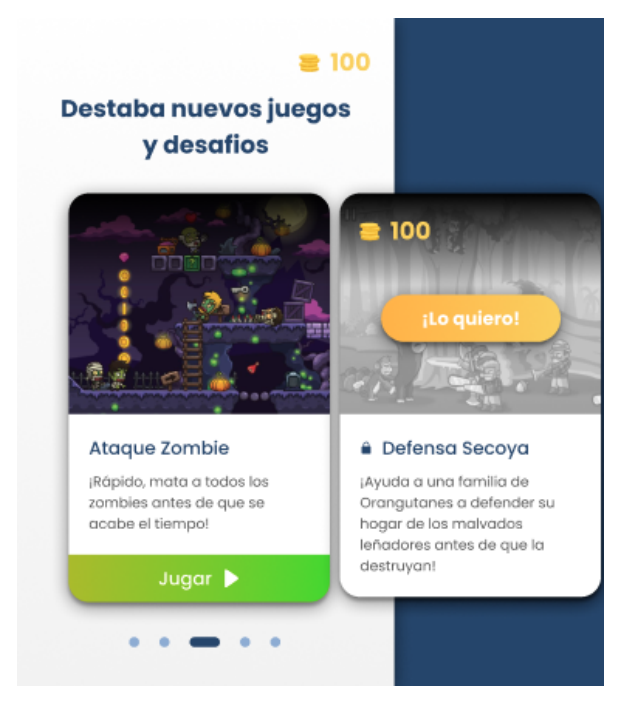

Figura 44: Dependiendo de los puntos ganados, podrá desbloquear mini juegos o comprar accesorios para su animalito.

\subsubsection{Journey Map del Maestro/a}

El maestro/a deberá autenticarse en la aplicación, al igual que los alumnos/as con los métodos ya existentes como ser Google o Facebook. Una vez iniciada la sesión deberá de dar de alta las clases que dicta. En caso de dar clases en más de una escuela, deberá dar de alta ambas ingresando datos básicos como nombre de la escuela y turno (mañana o tarde). Posteriormente, deberá proceder a dar de alta las asignaturas que tiene a cargo. Este paso será clave para Concentrate, ya que se especificará entre otros datos, el horario de inicio y fin de cada asignatura, permitiendo saber a la app en qué momentos deberá activar las misiones a los alumnos/as, con el objetivo de colaborar en evitar distracciones que el celular pueda ocasionar. Durante la duración de la clase, el alumno/a estará cumpliendo la misión de cuidar a su animalito elegido, y para ello debe ignorar su teléfono celular. A continuación el maestro/a tendrá la oportunidad de crear preguntas y respuestas del tipo verdadero o falso. Estas preguntas, relacionadas con la currícula de la asignatura, serán entregadas a los alumnos/as en el caso de que su nivel de distracción con el celular, haya sido igual o mayor a 3 (3 strikes), brindando la chance de recuperar puntos en el juego. Luego del inicio de las clases y misiones, el maestro/a tendrá la oportunidad de visualizar en un gráfico, cuales son las clases que son más propensas a distracciones, viendo la cantidad de veces que sus alumnos/as accedieron al celular. Esto le permitirá tomar distintas acciones para incentivar el compromiso y atención en 
dichas asignaturas. Dependiendo de la instancia del Journey Map, estarán disponibles distintas funcionalidades en Concentrate, tanto para el alumno/a como la maestra/o, las cuales se encuentran resumidas en la figura 45.

\section{CONCENTRATE JOURNEY MAESTRA/O}

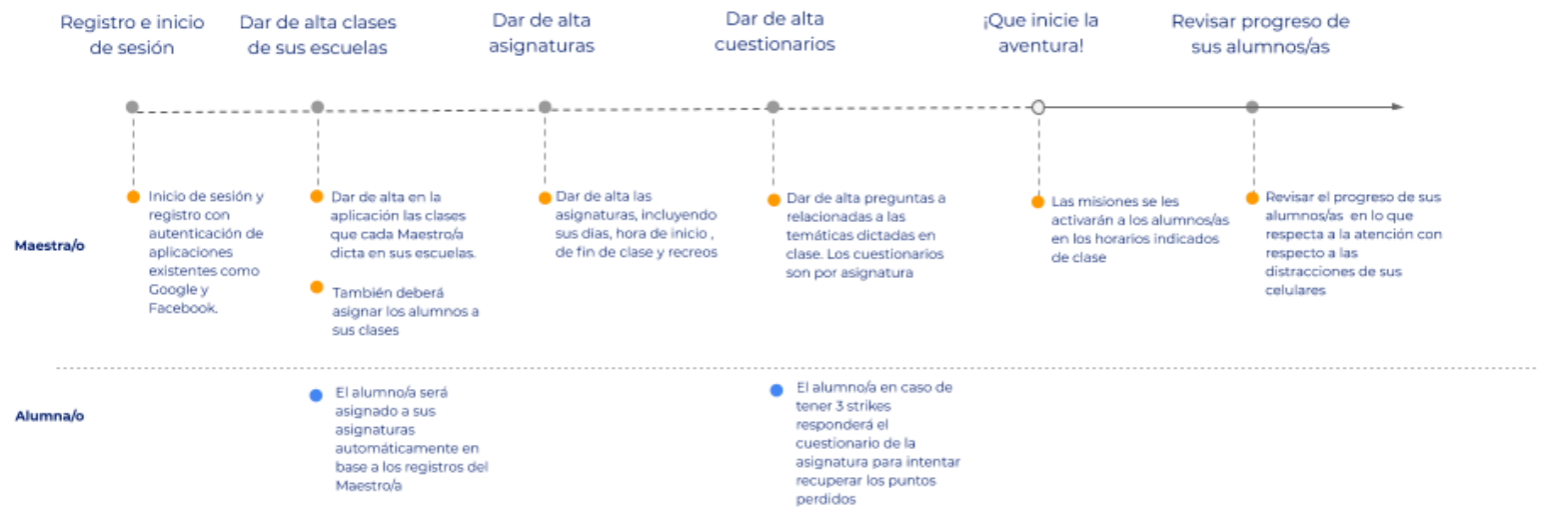

Figura 45: Concentrate: Journey Map de la maestra/o

Nota técnica: con respecto a cómo asignar alumnos a las clases, es posible que se realice de manera masiva con las planillas escolares, por medio de algún proceso automático y así evitar dar de alta los alumnos manualmente.

\subsubsection{Concentrate: flujo del Maestro/a}

Inicio de sesión y bienvenida: al igual que el alumno/a, el maestro/a tendrá su propio flujo de registro en la aplicación (figura 46), incluyendo la selección de modo de autenticación (figura 47). Una vez registrado/a, la pantalla principal (home) le mostrará las clases que tiene asignadas, entre las cuales podrá navegar y a su vez podrá ver novedades del día como se observa en la figura 48. 


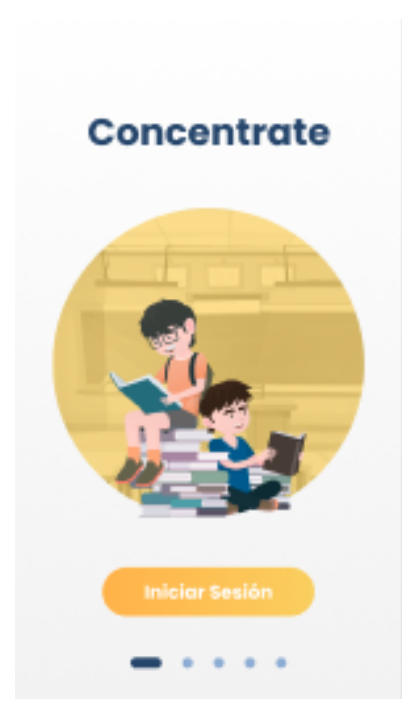

Figura 46: Bienvenida al juego para luego dar paso al inicio de sesión

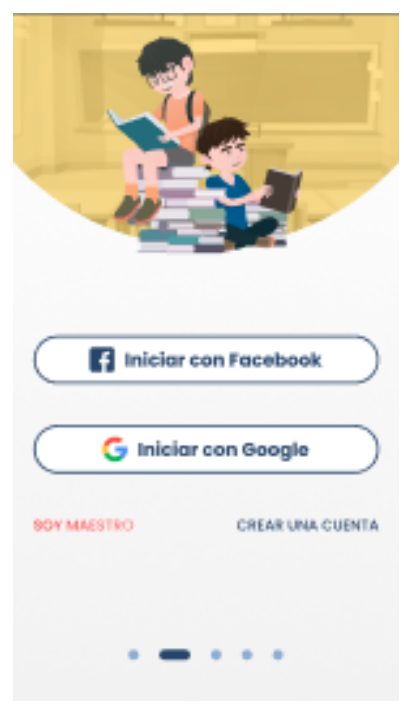

Figura 47: Selección de método de autenticación. La versión para maestro/a, tal como se muestra en la pantalla, incluye la leyenda de SOY MAESTRO.

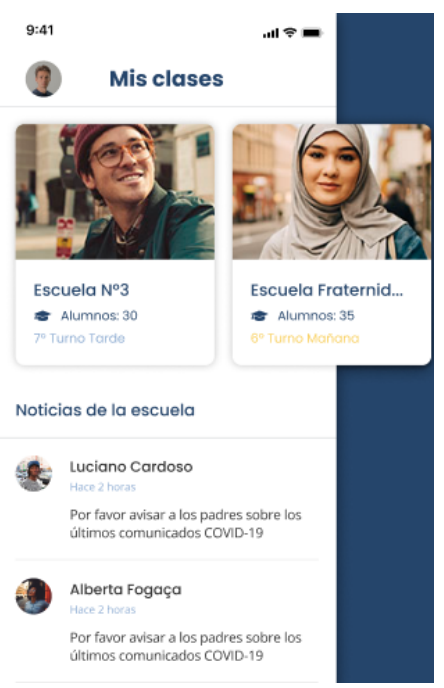

Figura 48: Luego de autenticarse satisfactoriamente, el maestro/a podrá ver sus clases. También podrá ver noticias de las escuelas publicadas por otros maestros/as.

Edición de una clase: el maestro/a podrá administrar sus clases, dando de alta las materias, con su hora de inicio y hora de fin, incluyendo los recreos, como se describe en la pantalla de las figuras 49 y 50 . Esto será clave para Concentrate, ya que será en dichos rangos horarios en los que se activarán las misiones de los alumnos/as. Por otro lado, si el alumno/a se distrae durante una misión, se le dará la oportunidad de recuperar puntos al final de la clase. Para esto, el maestro/a dará de alta preguntas y respuestas relacionada a cada clase tal como se observa en la pantalla de la figura 51. 


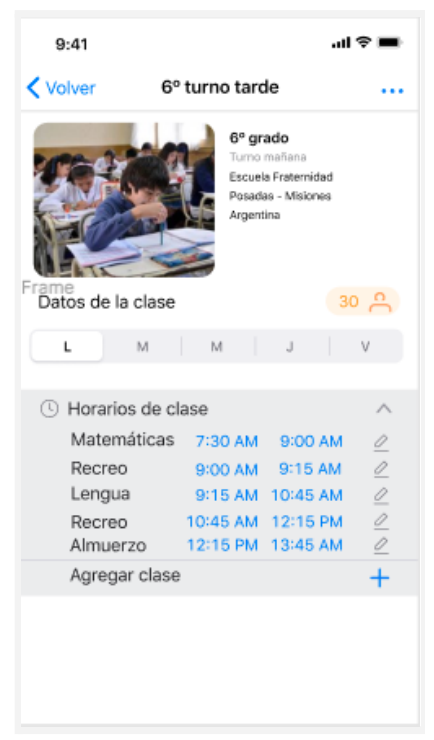

Figura 49: Al entrar al detalle de una clase haciendo tap en ella, se puede ver información específica. Incluye datos de la escuela, cantidad de alumnos y un calendario con las clases con su correspondiente horario de inicio y fin. También se muestran los horarios de recreo. La opción "Agregar clase" permite crear nuevas. El ícono del lápiz permite la edición de dicha clase.

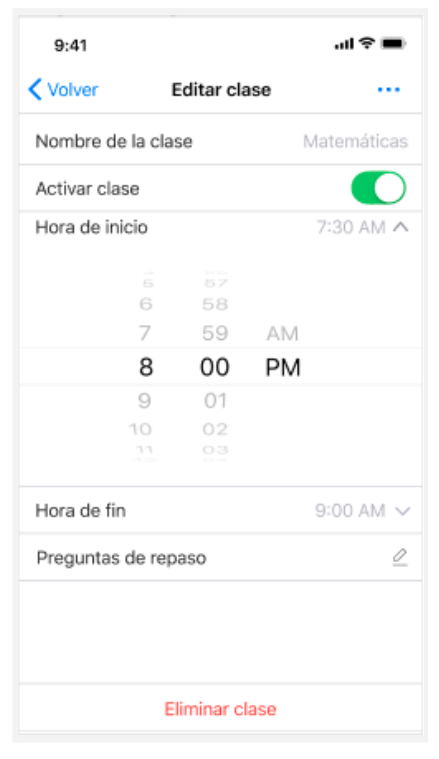

Figura 50: En la edición de la clase, se puede activar / desactivar la clase si por algún motivo no se dictará, editar el horario de inicio, horario de fin. También se puede eliminar la clase. Haciendo tap en el lápiz de preguntas de repaso, se brinda la opción de edición de las mismas.

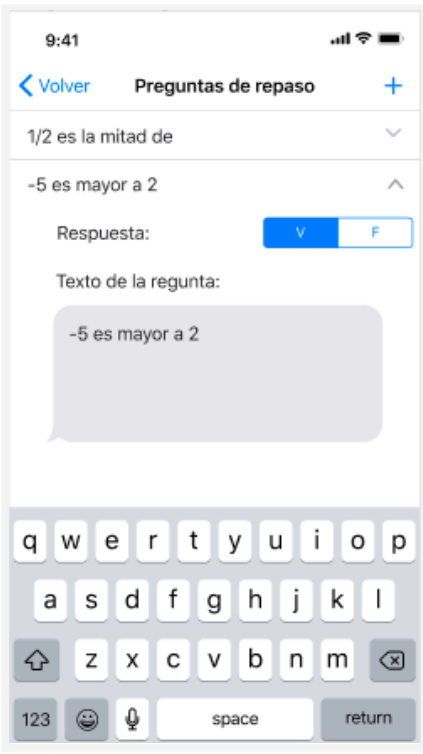

Figura 51: En la edición de las preguntas es posible listar las existentes, editar su texto, su respuesta (verdadero o falso), eliminarlas y agregar nuevas.

Listado de alumnos y detalle: dentro de las funcionalidades, con el objetivo de poder analizar niveles de distracción por clase y por alumno, el maestro/a dispondrá de gráficos de barra como el mostrado en la figura 54 (distracciones por alumno). Esto le brindará información que podrá ser utilizada para implementar acciones correctivas que permitan mejorar los niveles de atención.A esta funcionalidad se podrá acceder desde la pantalla de la clase (figura 52) y luego seleccionando al alumno/a en la lista (figura 53). 


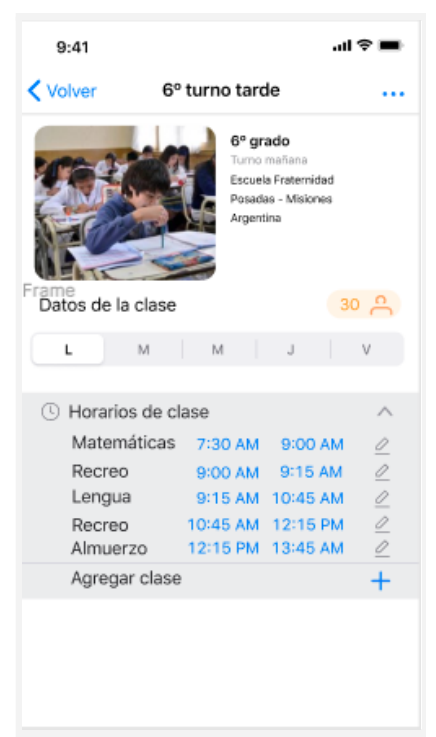

Figura 52: Desde la pantalla de la escuela, es posible acceder a la lista de alumnos haciendo tap en el contador que se muestra resaltado en color naranja(30 en el ejemplo)

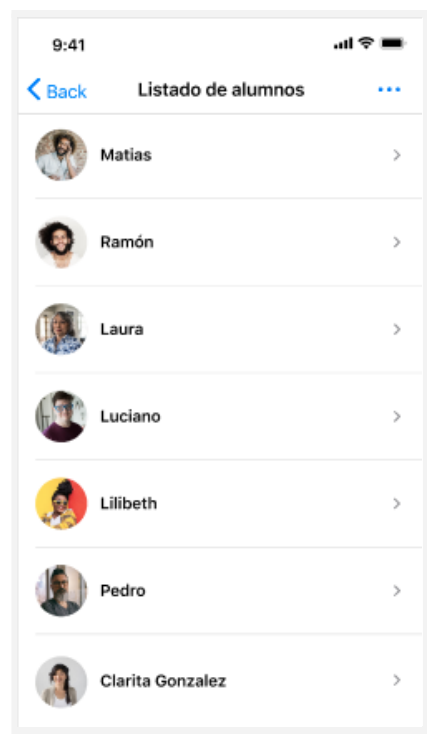

Figura 53: El listado de alumnos/as permite visualizarlos y entrar a ver el detalle.

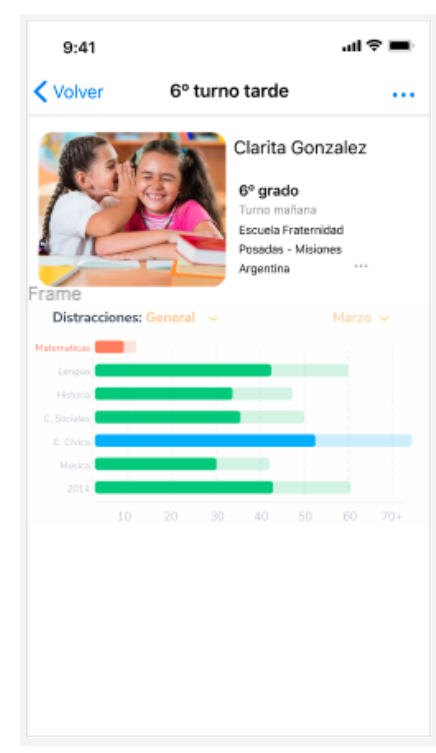

Figura 54: Luego de hacer tap en el renglón del alumno/a, los detalles de las veces que accedió al celular por asignatura se visualizan en forma de gráfico de barras. Este reporte se puede ver por día, mes y año.

\subsubsection{Funcionalidades futuras}

Dentro de las opciones de juego y para versiones futuras o iteraciones evolutivas de la aplicación, se pueden combinar una serie de actividades que contemplen los momentos complementarios a las horas netas de clase en la escuela. Pensando en una solución más abarcativa e integradora, que contemple propuestas promotoras de trabajo colaborativo y exploratorio, proporcionando herramientas que aporten a la solución de otros puntos de dolor encontrados en el Journey Map del alumno/a, se proponen distintas modalidades del juego, que se activarán dependiendo del momento del día en el que se encuentre el alumno/a, ya sea por medio de la detección el horario y lugar en el que se encuentra físicamente o utilizando métodos más avanzados con modelos de Inteligencia Artificial que vayan aprendiendo los comportamientos del alumno/a.

\subsubsection{Modos en que puede entrar el juego dependiendo del contexto del alumno/a:}

Modo de aventura en clase: la aventura inicia con el inicio de clases y finaliza con el fin de las clases. Cada animalito intentará huir de los cazadores y agentes contaminantes que los 
amenazan (las notificaciones). El mapa en donde se desarrolla la aventura será temático dependiendo de la provincia en la que se encuentra el alumno, con el objetivo de proporcionar por ejemplo información geográfica, flora, fauna y cultura local.

Modo exploración: permitirá al niño explorar la ciudad en búsqueda de sitios de interés para su clase en curso. En caso de encontrarlos, le mostrará información acorde y sumará puntos. Se le hará un quiz y en el caso de hacerlo correctamente, sumará puntos adicionales.

Modo tarea con sus compañeritos: a la hora de hacer la tarea, los niños sumarán puntos si se juntan en persona a hacer la tarea. Se les hará preguntas para que investiguen, y las podrán responder en su celular por medio del juego.

\subsection{Testear, validar, continuar testeando}

Como parte de la metodología Design Thinking, el concepto de testeo o pruebas, es de suma importancia para continuar con el proceso de empatía con los usuarios y entender cómo el diseño de la solución propuesta, logra cumplir con los objetivos y necesidades de los mismos. Esta fase del proceso nos permite validar nuestro entendimiento del enfoque de la solución propuesta, así como descubrir nuevos problemas que el usuario podrá enfrentar. Utilizando distintas técnicas, que incluyen la interacción de los usuarios con una potencial solución, observación y obtención de feedback, con el objetivo de validar y refinar el planteo propuesto.

La herramienta por excelencia utilizada durante esta etapa, el cual contribuye a materializar y tangibilizar la solución propuesta, se denomina prototipo. Tal como lo define Meinel [31] "los prototipos en Design Thinking generalmente son maquetas que apoyan la elaboración y evaluación de conceptos de productos con el objetivo de descubrir qué formas son correctas o incorrectas. Esto quiere decir que pueden ser muy experimentales y constar de cualquier material que permita obtener información sobre las ideas detrás del concepto (y no tanto sobre sus especificaciones técnicas)." Es decir, permite confirmar y sumar nuevos hallazgos y realizar ajustes a la solución, previo al inicio del desarrollo del software que implementará la idea.

Con el objetivo de maximizar los resultados de la sesión de prueba o testeo, IDEO, en su publicación Field Guide Human-Centered Design, recomienda seguir los lineamientos o pasos listados a continuación [34]:

Paso 1: presentar el prototipo a las personas para las que fue diseñado. Esto se puede llevar a cabo mediante distintas técnicas [34] como ser entrevistas globales, interceptar personas en el mercado para entrevistar, hacer otra entrevista con los expertos (presentando el prototipo) o realizar una sesión de co-creación diseñada para obtener feedback. 
Paso 2: obtener feedback sincero es lo más importante. Si bien las personas podrán elogiar el prototipo, es importante dejar en claro que el feedback honesto es necesario para generar aprendizaje, incluso si se trata de feedback negativo.

Paso 3: compartir el prototipo de manera de obtener la diversidad de usuarios y personas necesarias. Se sugiere la técnica de Extremes and Mainstreams [30].

Paso 4: registrar el feedback y aprovechar la oportunidad para realizar preguntas adicionales, con el objetivo de refinar y mejorar nuestras ideas de solución.

Como se puede observar, los métodos requieren de mucha interacción con los usuarios, utilizando distintas herramientas para obtener feedback de la solución propuesta. En el caso de Concentrate, es clave el contexto para el que se propuso la solución: la escuela. Es decir, fue diseñada para cumplir el objetivo de colaborar a evitar las distracciones generadas por las notificaciones recibidas en el teléfono celular en clase. La prueba con el prototipo debe llevarse a cabo bajo condiciones de clase activas, en donde el maestro/a interactúa con sus alumnos, mientras sus alumnos/as con celular, reciban notificaciones en distintos momentos, generadas de manera que lleguen durante la clase. Por otro lado, los observadores, tratando de pasar lo más desapercibido posible, deberán ver las reacciones de los alumnos y registrar por ejemplo la instalación y configuración de la aplicación, la recepción de la explicación de la aplicación por parte de la maestra/o, inicio de la clase, los momentos en los que dejan de prestar atención a la clase, entre otros.

\subsection{El método de inspección como herramienta alternativa de testeo}

Dado el contexto actual de la pandemia COVID19 y la suspensión de clases presenciales, dichas pruebas no se podrán llevar a cabo, ya que su principal riqueza se obtiene en base a la observación de la interacción entre el usuario y el prototipo en condiciones reales, actividad que se ve imposibilitada en su implementación, incluso teniendo en cuenta herramientas de teleconferencia, dado que los alumnos/as no están asistiendo a la escuela. Por lo tanto, con el fin de poder llevar a cabo la etapa de Testeo o pruebas de Design Thinking, es necesario realizar una revisión de la usabilidad del prototipo de Concentrate, y así obtener feedback que permita revisar la usabilidad del mismo, entendiendo usabilidad como la "medida en la que "un producto puede ser utilizado por usuarios específicos para lograr objetivos específicos con eficacia, eficiencia y satisfacción en un contexto de uso" tal como lo define la ISO FDIS 9241-210: Ergonomics of human system interaction [35]. 
En la década del 70, momento en el cual la industria predominante de hardware y el software se encontraba en franco florecimiento, el control de calidad era de gran importancia. Un error en el hardware marcado en silicio, conllevaba altos costos de retrabajo. Basado en sus experiencias de control de calidad en hardware Michael Fagan, cofundador del centro de calidad de IBM, propuso una metodología de inspección para software, cuyos principales objetivos eran [36]:

- Buscar y corregir todos los defectos del producto

- Encontrar y corregir todos los defectos en el proceso de desarrollo que dan lugar a defectos en el producto (es decir, eliminar las causas de defectos en el producto)

El método de inspección tuvo gran éxito reduciendo la cantidad de defectos encontrados por el usuario y aumentando la productividad del proceso de desarrollo.

Siguiendo la línea de la inspección, en la década del 90 se empezó a utilizar para evaluar la usabilidad de las interfaces de usuario. Jacob Nielsen, en su publicación Usability Inspections Methods [37], describe cuatro formas de evaluar interfaces de usuario:

- Automática: métricas de usabilidad computadas por medio de la ejecución de un programa que contiene las especificaciones de las interfaces de usuario.

- Empírica: usabilidad llevada a cabo por medio del testeo de las interfaces con usuarios reales.

- Formal: utilizando modelos exactos y fórmulas para calcular métricas de usabilidad.

- Informales: basadas en las habilidades generales y experiencia de los evaluadores.

Si bien el método empírico, representado por el las sesiones de testeo de usuarios es el método más utilizado, en esas épocas, no era tarea sencilla juntar usuarios. Nielsen cita esta situación comentando que "a menudo, los usuarios reales pueden resultar difíciles o costoso reclutar en cantidades suficientes para probar todos los aspectos de todas las versiones de un diseño en evolución, lo que lleva al uso de inspección como una forma de "salvar a los usuarios". Esta situación, entre otras, dieron lugar al nacimiento del Método de Inspección de Usabilidad (Usability Inspections Methods). Nielsen [37] se refiere a los Métodos de Inspección como "nombre genérico para un conjunto de métodos que se basan en que los evaluadores inspeccionen la interfaz. Normalmente, la inspección de usabilidad tiene como objetivo encontrar la usabilidad problemas en un diseño, aunque algunos métodos también abordar cuestiones como la gravedad de los problemas de usabilidad y

la usabilidad general de un diseño completo". Es decir se trata de formas alternativas de poder realizar el testeo, que no sean emìricas. Por otro lado, Vizi [38] resume el mismo concepto como una "colección de métodos no empíricos para evaluar interfaces de usuario, denominados colectivamente métodos de inspección de usabilidad. Estos métodos se consideran no empíricos porque en lugar de recopilar datos u observar a los usuarios interactuando con un sistema, se basan en la capacidad de los jueces que intentan predecir los tipos de problemas que los usuarios experimentaran con una interfaz de usuario." Es decir, lo que se intenta es, mediante la inspección de un experto, poder prever cualquier aspecto tanto negativo como positivo, que impacte en la usabilidad de la interfaz de usuario del software, 
antes de que llegue a manos del usuario objetivo. Dependiendo de la técnica utilizada, serán los objetivos específicos que se persiguen con la inspección. Los métodos descriptos por Nielsen[37] son los siguientes:

- Evaluación heurística: consiste en tener expertos de usabilidad que juzgarán las distintas interfaces y sus elementos cumplen con los principios de usabilidad establecidos.

- Recorridos cognitivos: utiliza un procedimiento detallado en donde se simula a un usuario en el proceso de resolución de problemas en cada paso del flujo de las interfaces, evaluando si los objetivos del usuario y contenido de memoria pueden llevar al mismo a la siguiente acción correcta.

- Inspecciones de usabilidad formal: procedimiento que consiste de seis pasos con roles estrictamente definidos para combinar la evaluación heurística y una forma simplificada de los recorridos cognitivos.

- Recorridos pluralistas: son encuentros en donde usuarios, desarrolladores y personas relacionadas a los factores humanos, exponen un escenario y discuten cada elemento del flujo de interfaces

- Inspección de funcionalidad: lista una secuencia de funcionalidades utilizadas para cumplir tareas típicas, se revisan flujos largos, pasos incómodos, pasos que nos serían naturales para los usuarios realizar y pasos que requieren un alto nivel de conocimiento / experiencia para evaluar el grupo de funcionalidades propuestas.

- Inspección de consistencia:tiene diseñadores que representan varios proyectos inspeccionan una interfaz para ver si hace las cosas de la misma manera que sus propios diseños.

- Inspecciones de estándares: inspecciones realizadas para asegurarse de que una determinada interfaz cumple con los estándares requeridos. 


\subsection{Inspección con heurísticas específicas para aplicaciones móviles educativas basadas en gamificación}

Las heurísticas de Nielsen no son específicas de un dominio, se generaron para inspeccionar las interfaces de usuario tradicionales, es decir, aplicaciones web y de escritorio. Por lo tanto, puede que no sea adecuado para aplicaciones móviles con propósitos pedagógicos. Las aplicaciones móviles son diferentes de las aplicaciones web o de escritorio debido al tamaño de pantalla, la capacidad de entrada limitada y los diferentes métodos de entrada (pantallas táctiles y teclados virtuales). Pero, además, el contexto de la aplicación móvil cambia constantemente, como la ubicación, la conectividad y la posición. Por lo tanto, la capacidad de los usuarios para prestar atención varía y esto debe ser atendido por la interfaz. Los usuarios de aplicaciones móviles tienen necesidades profundas diferentes en comparación con un usuario de escritorio. Por lo tanto, es necesario crear una guía para realizar una evaluación heurística para aplicaciones de aprendizaje móvil. A eso hay que sumarle que el diseño de la gamificación implica la introducción de elementos de diseño de juegos en el desarrollo de software del sistema de destino, y es un desafío. Por lo tanto, la heurística del juego puede facilitar el desarrollo del sistema de gamificación y garantizar que se cumplan los objetivos del sistema. [39][41]

Una investigación relevante al respecto, en particular aplicable al aspecto educativo de la gamificación, es la de Omar y Jaafar (2010) [40], quienes desarrollaron el primer conjunto de heurísticas de jugabilidad dirigidas a los juegos educativos (PHEG). Este conjunto de 34 heurísticas se centra en cinco aspectos: interfaz de usuario, jugabilidad, contenido, educacional y multimedia.

Por otra parte, Tondello, Kappen, Mekler, Ganaba y Nacke (2016)[42] compilaron una lista de 28 heurísticas dirigida a evaluar el diseño en sí de la gamificación. Esta lista distingue entre tres tipos de heurísticas según el tipo de motivación al que se dirige el sistema: motivaciones intrínsecas, extrínsecas y dependientes del contexto.

Con la colaboración de un experto en $\mathrm{HCl}$ realizamos la inspección del prototipo de Concentrate con las heurísticas de PHEG y de Tondello.

El proceso consistió en analizar por parte del experto todo el material proporcionado en dos iteraciones. En la primera registró el cumplimiento de las 15 heurísticas tomadas del subconjunto de framework de Omar 2010 [40] (10 en el área Pedagógica y 5 en el área de Jugabilidad). En la segunda, el experto registró el cumplimiento del conjunto de 28 Heurísticas de Tondello 2016.

En todos los casos, registró el cumplimiento en una escala de Likert de 5 posiciones (desde No cumple para nada hasta Cumple Perfectamente), incluyendo comentarios en forma de texto para explicar las evaluaciones cuando el experto lo consideró necesario.

Le pedimos al experto que realizará las inspecciones para el prototipo de Concentrate, con foco en el Rol del Alumno/a. Como documentación de análisis se le proveyó el prototipo completo 
con todas las pantallas del juego, el documento de Historia del Juego y el Journey Map del Alumno.

\section{Inspección basada en PHEG (Omar 2010)[40]}

De las cinco categorías propuestas por Omar 2010 [40] (ver figura 55), consideramos en particular las relacionadas con el área Educacional y la Jugabilidad.

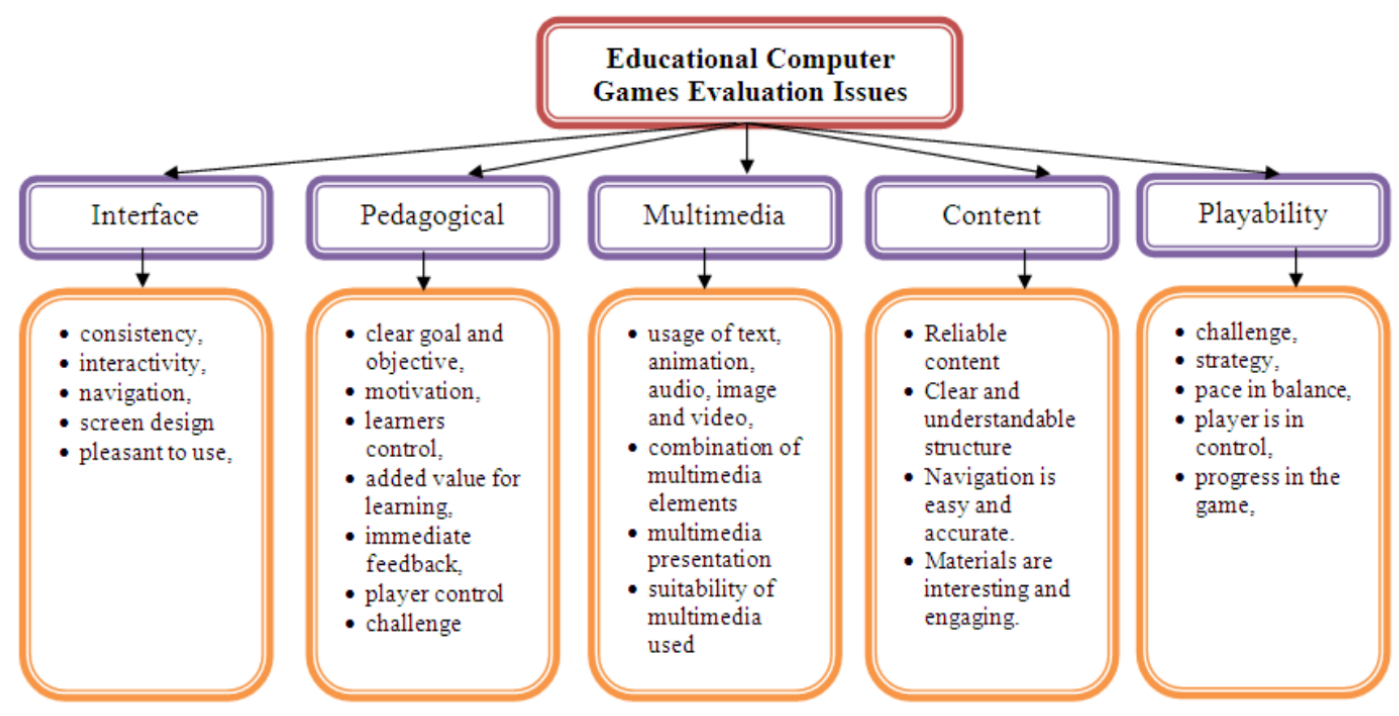

Figura 55: Educational Computer Games Evaluation Issues [40]

En estas áreas, las heurísticas comprenden:

\begin{tabular}{|l|}
\hline Área educacional \\
\hline ED1 Objetivo claro y objetivos de aprendizaje \\
\hline ED2 Las actividades son interesantes y atractivas \\
\hline ED3 El diseño y los contenidos son fiables y probados. \\
\hline ED4 Se puede utilizar como herramientas de aprendizaje autodirigido. \\
\hline ED5 Soporte para habilidades de autoaprendizaje. \\
\hline ED6 Medio para aprender haciendo. \\
\hline ED7 Considera las diferencias individuales. \\
\hline ED8 El desempeño debe basarse en los resultados. \\
\hline ED9 Ofrece la posibilidad de seleccionar el nivel de dificultad en los juegos. \\
\hline ED10 Capacidad para trabajar a su propio ritmo \\
\hline Área jugabilidad \\
\hline J1 El desafío proporcionado está a la altura del estándar del usuario \\
\hline J2 Usuarios capaces de estrategias \\
\hline J3 El ritmo del juego está equilibrado \\
\hline
\end{tabular}


J4 Jugadores capaces de controlar el juego.

J5 Jugadores capaces de conocer el progreso del juego.

En estas áreas, la evaluación obtenida por el prototipo se presenta en los siguientes gráficos de radar con los comentarios para las heurísticas que recibieron menor valoración, en la figura 56.

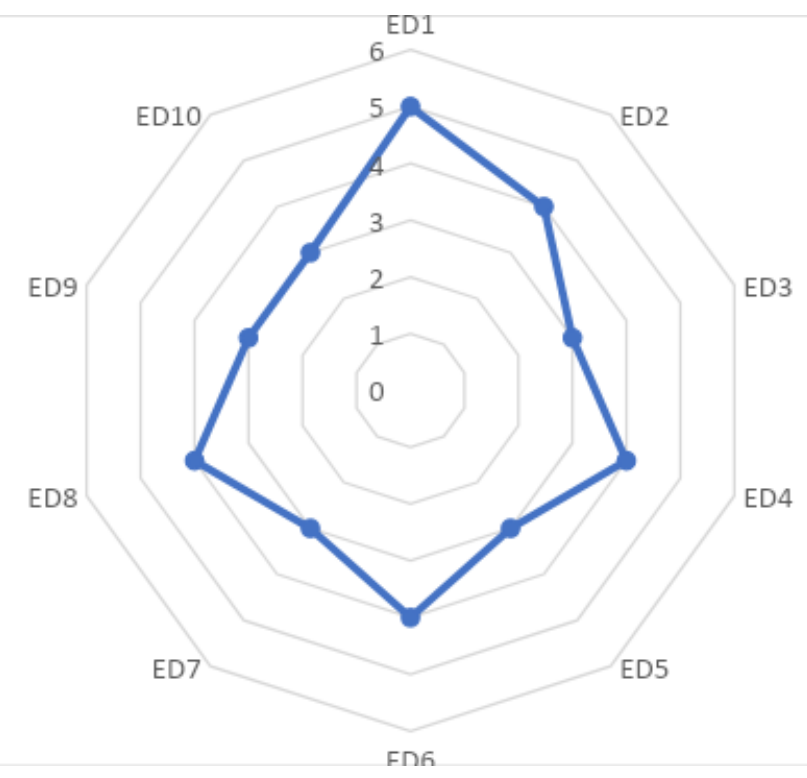

Figura 56: Evaluación de Concentrate, Rol de Alumno, Heurísticas Área Educacional de Omar 2010[40]

En el área Educacional se observan en general valores altos, con un piso de 3 y un máximo de 5 en "ED1 Objetivo claro y objetivos de aprendizaje". Los comentarios del experto en las heurísticas con menor calificación fueron:

ED5. Soporte para habilidades de autoaprendizaje.

Incorporar más funcionalidad para facilitar el reconocimiento de mejoras en la gestión propia de la atención por parte de los alumnos

ED7 Considera las diferencias individuales.

Carece de estrategias de personalización con parámetros fijados por los propios alumnos

ED9 Ofrece la posibilidad de seleccionar el nivel de dificultad en los juegos.

El progreso en niveles de dificultad viene dado por el avance del alumno. Debería incluir modos de experto que permita al alumno ingresar directamente en un nivel avanzado de la escala y eventualmente retornar al inicio 


\section{ED10 Capacidad para trabajar a su propio ritmo}

Refuerza lo indicado en ED9. Requiere nuevas estrategias que permitan al alumno manejar su propio ritmo en la gestión de la atención

La evaluación de Jugabilidad en este esquema recibió una valoración muy alta por parte del experto como indica el gráfico de la figura 57.

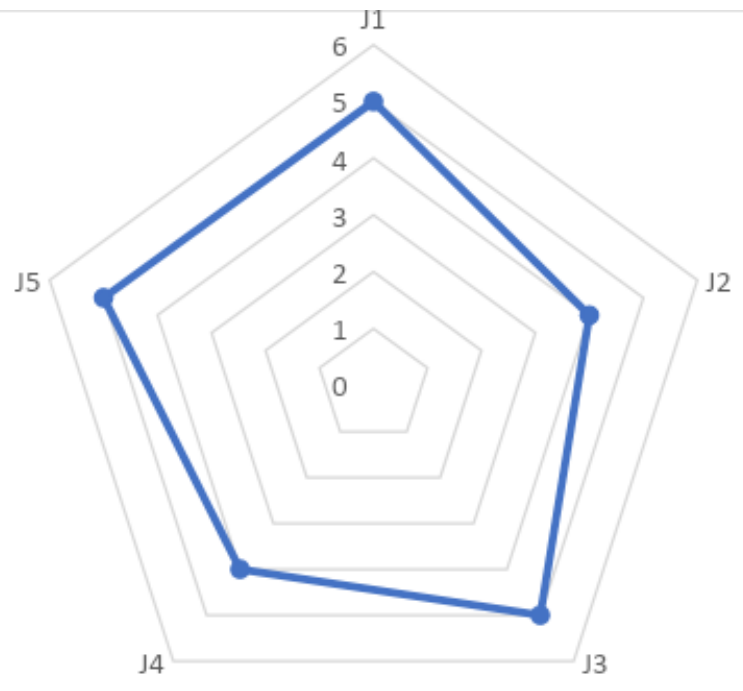

Figura 57: Evaluación con Heurísticas de Jugabilidad del framework de Omar2010[40]

Resulta consistente que la evaluación en esta área disminuye levemente en J2 (Usuarios capaces de estrategias) y J4 (Jugadores capaces de controlar el juego) que coinciden de alguna forma con la valoración y comentarios recibidos en ED9 y ED10.

\section{Inspección basada en Tondello et al (2016)[42]}

Tondello et al [42] presentan un conjunto de pautas para la evaluación heurística del diseño de juegos en sistemas interactivos, que contiene un conjunto de 28 heurísticas de gamificación destinadas a permitir que los expertos evalúen rápidamente un sistema de juego. Las heurísticas están organizadas en tres categorías: motivación intrínseca, motivación extrínseca y contexto. 


\section{Heurísticas de motivación intrínseca}

Propósito y significado: Accesos destinados a ayudar a los usuarios a identificar un objetivo significativo que se logrará a través del sistema y que puede beneficiar a los propios usuarios o a otras personas.

11. Significado: el sistema claramente ayuda a los usuarios a identificar una contribución significativa (para ellos mismos o para otros).

12. Información y Reflexión: El sistema brinda información y oportunidades de reflexión hacia la superación personal.

Desafío y competencia: ofertas destinadas a ayudar a los usuarios a satisfacer su necesidad intrínseca de competencia a través del logro de desafíos u objetivos difíciles.

13. Desafío creciente: el sistema ofrece desafíos que crecen con la habilidad del usuario.

14. Incorporación: el sistema ofrece desafíos iniciales para los recién llegados que les ayudan a aprender cómo funciona.

15. Auto desafío: el sistema ayuda a los usuarios a descubrir o crear nuevos desafíos para ponerse a prueba.

Integridad y maestría: prestaciones destinadas a ayudar a los usuarios a satisfacer su necesidad intrínseca de competencia completando una serie de tareas o recopilando logros virtuales.

16. Metas progresivas: el sistema siempre presenta las próximas metas que los usuarios pueden perseguir y que se pueden alcanzar de inmediato.

17. Logros: el sistema permite a los usuarios realizar un seguimiento de sus logros o avances.

Autonomía y creatividad: ofertas destinadas a ayudar a los usuarios a satisfacer su necesidad intrínseca de autonomía al ofrecer opciones significativas y oportunidades para la autoexpresión.

18. Elección: el sistema ofrece a los usuarios opciones sobre qué hacer o cómo hacer algo, que son interesantes, pero también de alcance limitado según la capacidad de cada usuario.

19. Autoexpresión: el sistema permite a los usuarios expresarse o crear contenido nuevo.

110. Libertad: el sistema permite a los usuarios experimentar con caminos nuevos o diferentes sin miedo ni consecuencias graves.

Relación: Affordances destinadas a ayudar a los usuarios a satisfacer su necesidad intrínseca de relación a través de la interacción social, generalmente con otros usuarios.

111. Interacción social: el sistema permite a los usuarios conectarse e interactuar socialmente.

112. Cooperación social: el sistema ofrece la oportunidad de que los usuarios trabajen juntos para lograr objetivos comunes.

113. Competencia social: el sistema permite a los usuarios compararse con otros o desafiar a otros usuarios.

114. Equidad: el sistema ofrece oportunidades similares de éxito y progreso para todos y significa para que los recién llegados se sientan motivados incluso cuando 
se comparan con los veteranos.

Inmersión: Affordances dirigidas a sumergir al usuario en el sistema para mejorar su experiencia estética, generalmente mediante un tema, narrativa o historia, quepuede ser real o ficticia.

115. Narrativa: el sistema ofrece a los usuarios una narrativa o historia significativa con la que pueden relacionarse.

116. Diversión percibida: el sistema brinda a los usuarios la posibilidad de interactuar y ser parte de la historia (diversión fácil).

El resultado de la inspección en este conjunto de heurísticas se refleja en el gráfico radar de la figura 58 .

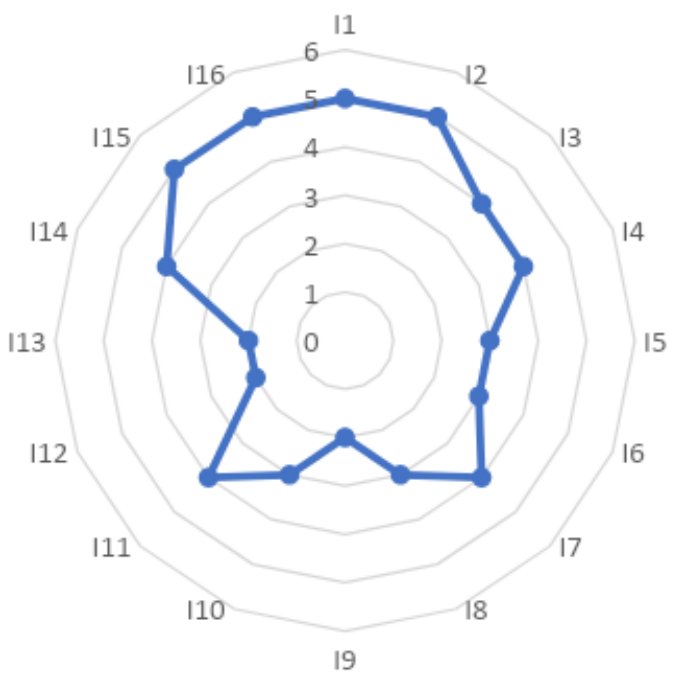

Figura 58: Resultado de inspección en heurísticas de motivación intrínseca, según [42]

El prototipo parece tener un desempeño irregular para este conjunto de heurísticas. Los comentarios del experto son consistentes con los hallazgos de la inspección anterior, en particular en lo relacionado a falta de opciones de recorridos personalizados por parte de los alumnos. También se advierte en estas heurísticas destinadas específicamente al diseño del juego la importancia de incluir mayores opciones de competencia y colaboración entre pares. En particular vale mencionar los siguientes comentarios:

15. Faltan opciones de personalización de estrategias

16. Falta un esquema de metas progresivas

18. Faltan mayores opciones de personalización para los alumnos

19. El sistema no tiene opciones de expresión o comentarios propias de los usuarios 
110. Las estrategias están predefinidas en el juego. Es conveniente agregar opciones de estrategias a cargo de los alumnos.

111. El juego ofrece interacción con maestros y padres, pero falta interacción con compañeros

112. No hay opciones de cooperación con compañeros

113. No hay opciones de competencia con compañeros

\section{Heurísticas de motivación extrínseca}

Propiedad y Recompensas: Affordances dirigidas a motivar a los usuarios a través de recompensas extrínsecas o posesión de bienes reales o virtuales. La propiedad es diferente de la competencia cuando el usuario percibe la adquisición de bienes como la razón para interactuar con el sistema, en lugar de sentirse competente.

E1. Propiedad: el sistema permite a los usuarios poseer bienes virtuales o crear un perfil individual a lo largo del tiempo, que se puede desarrollar mediante el uso continuo del sistema y con el que los usuarios pueden relacionarse.

E2. Recompensas: el sistema ofrece recompensas de incentivos por la interacción y el uso continuo, que son valiosas para los usuarios y proporcionales a la cantidad de esfuerzo invertido.

E3. Economía virtual: el sistema permite a los usuarios intercambiar el resultado de sus esfuerzos con recompensas internas o externas.

Escasez: Asequibles dirigidos a motivar a los usuarios a través de sentimientos de estatus o exclusividad mediante la adquisición de recompensas, bienes o logros difíciles o raros.

E4. Escasez: el sistema ofrece características interesantes o recompensas que son raras o difíciles de obtener.

Evitación de pérdidas: Affordances dirigidas a que los usuarios actúen con urgencia, creando situaciones en las que podrían perder recompensas, bienes o logros adquiridos o potenciales si no actúan de inmediato.

E5. Evitación de pérdidas: el sistema crea urgencia a través de posibles pérdidas a menos que los usuarios actúen de inmediato.

El resultado de la inspección se presenta en el gráfico de la figura 59. En este caso el desempeño es más parejo que las anteriores. El experto señaló la importancia, en particular para la E3 y E5 de agregar más alternativas de recompensas y estrategias de gestión de rapidez que sean acordes con los objetivos de gestión de la atención del juego. Esto plantea claramente un compromiso difícil de resolver entre la necesidad de que el aspecto lúdico de la aplicación requiera acciones de respuesta rápida y la necesidad de promover una atención focalizada en el aprendizaje durante el horario escolar. 


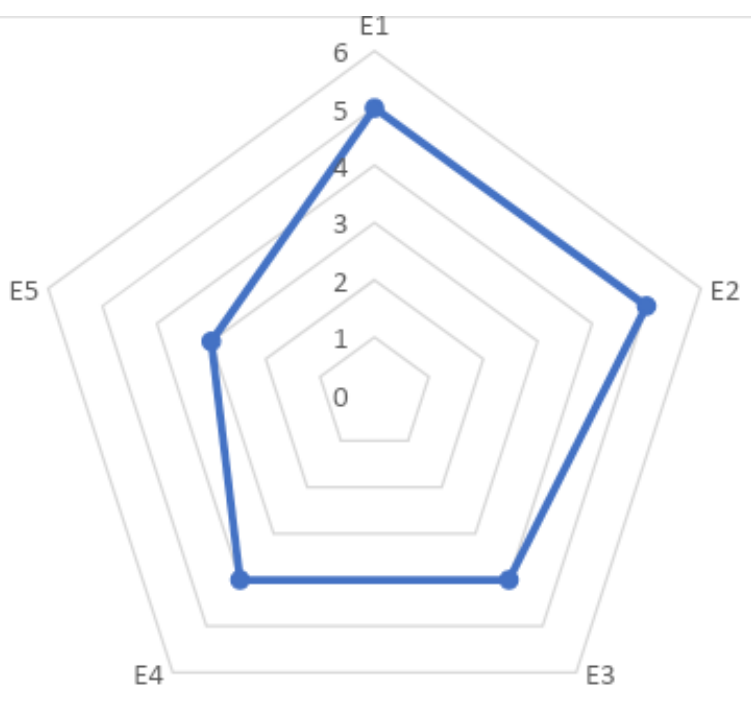

Figura 59: Ilustración 4 Resultado de Inspección con Heurísticas de Motivación Extrínseca [42]

\begin{tabular}{|c|}
\hline \\
\hline $\begin{array}{l}\text { Retroalimentación: Affordances orientadas a informar a los usuarios sobre su } \\
\text { progreso y las próximas acciones o desafíos disponibles. }\end{array}$ \\
\hline $\begin{array}{l}\text { C1. Comentarios claros e inmediatos: los sistemas siempre informan a los usuarios } \\
\text { de inmediato de cualquier cambio o logro de una manera fácil y comprensible. }\end{array}$ \\
\hline $\begin{array}{l}\text { C2. Comentarios procesables: el sistema siempre informa a los usuarios sobre las } \\
\text { próximas acciones y mejoras disponibles. }\end{array}$ \\
\hline $\begin{array}{l}\text { C3. Progreso comprensible: la retroalimentación siempre les dice a los usuarios } \\
\text { dónde se encuentran y cuál es el camino por delante para la progresión. }\end{array}$ \\
\hline $\begin{array}{l}\text { Impredecibilidad: ofertas destinadas a sorprender a los usuarios con tareas, } \\
\text { desafíos, comentarios o recompensas variables. }\end{array}$ \\
\hline $\begin{array}{l}\text { C4. Desafíos variados: el sistema ofrece una variabilidad inesperada en los desafíos } \\
\text { o tareas que se le presentan al usuario. }\end{array}$ \\
\hline $\begin{array}{l}\text { C5. Recompensas variadas: el sistema ofrece una variabilidad inesperada en las } \\
\text { recompensas que se ofrecen al usuario. }\end{array}$ \\
\hline $\begin{array}{l}\text { Cambio y disrupción: ofertas destinadas a involucrar a los usuarios con tendencias } \\
\text { disruptivas [21] permitiéndoles ayudar a mejorar el sistema, de una manera positiva } \\
\text { en lugar de destructiva. }\end{array}$ \\
\hline $\begin{array}{l}\text { C6. Innovación: el sistema permite a los usuarios contribuir con ideas, contenido, } \\
\text { complementos o modificaciones destinadas a mejorar, mejorar o ampliar el sistema } \\
\text { en sí. }\end{array}$ \\
\hline C7. Control de interrupciones: el sistema está protegido contra trampas, piratería u \\
\hline
\end{tabular}

Como se ve en el gráfico de la figura 60, la inspección de este conjunto de heurísticas también ha sido irregular. En particular, el experto indicó que las heurísticas C4 a C6 requieren mayor 
atención en la oferta de desafíos, recompensas y caminos alternativos para los usuarios. Respecto de la C7, el experto consideró que en el estado actual del prototipo no resulta posible evaluar la heurística (Control de hackeos y trampas).

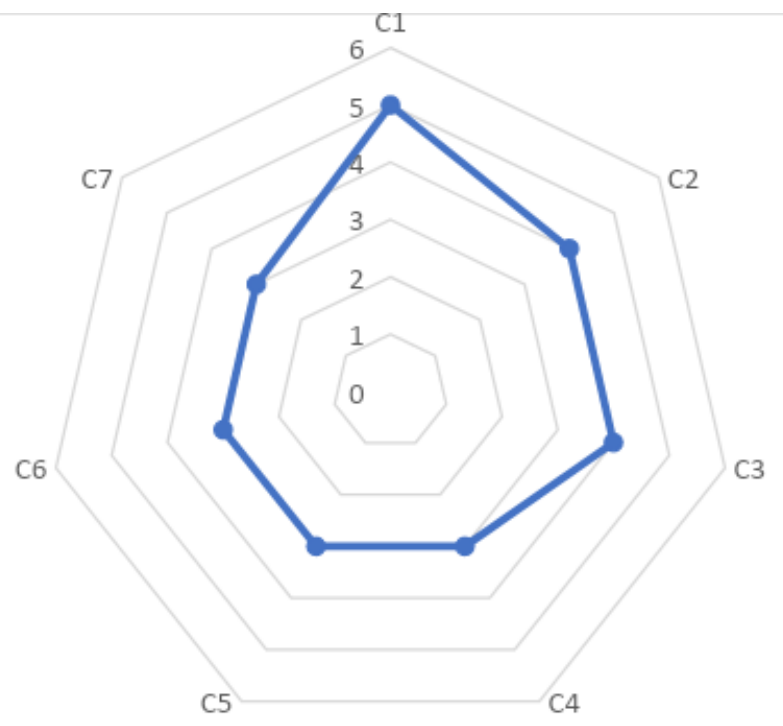

Figura 60: Inspección con Heurísticas dependientes del Contexto, según [42]

\section{Resultados de las Inspecciones}

Como conclusiones de estas inspecciones preliminares con dos conjuntos de heurísticas específicas para aplicaciones móviles de aprendizaje y diseño de gamificación sabemos que será necesaria una batería completa de pruebas de inspección y de pruebas con usuarios para poder recabar los requerimientos de modificaciones para una próxima iteración de prototipado.

Sin embargo, podemos sostener en esta instancia que Concentrate está en una buena senda para cumplir con los objetivos planteados. El prototipo no ha sido evaluado como deficiente para ninguna de las heurísticas utilizadas y las correcciones solicitadas están en línea con los desafíos abordados por la problemática de obtener un buen compromiso entre una dinámica atrayente de juego versus la gestión de una atención focalizada en el tiempo escolar. 


\section{CAPÍTULO 5: CONCLUSIONES}

\subsection{Conclusiones generales}

El presente trabajo se focalizó en la problemática que genera en lo referido a la atención, los teléfonos celulares en las aulas, tomando las notificaciones como uno de los elementos de distracción principales, pero también dándole un enfoque holístico y abarcativo en la búsqueda de propuestas tecnológicas que aporten valor a la experiencia del ecosistema educativo en el camino de las mejoras del proceso de aprendizaje.

Se realizó un relevamiento de las normas educativas tanto a nivel mundial como nacional acerca del uso del teléfono celular en las aulas. Actualmente el uso del celular en las aulas tiene opiniones divididas a nivel mundial y nacional. Por un lado se encuentran las corrientes prohibitivas y por otro las permisivas pero controladas por los docentes. Cabe destacar que no se ponen en tela de juicio ni se evalúan dichas corrientes ya que no están bajo el alcance del trabajo de tesis.

Tomando como eje la corriente permisiva controlada, se evaluaron distintas tecnologías con respaldo científico, en donde se observó que el uso de aplicaciones en dispositivos móviles para niños y niñas con fines educativos pueden tener un impacto positivo en una amplia gama de problemáticas, incluyendo por ejemplo, deficiencias cognitivas. Con pruebas documentadas que evidenciaron progresos significativos en sus pruebas, aplicaciones como Matemarote, Words matter y The number race lograron resultados favorables en la evolución del proceso cognitivo para niños y niñas con dificultades en el aprendizaje, introduciendo una mecánica diferenciadora denominada gamification. Mantener un espíritu lúdico y con reglas propias de los videojuegos fue clave para lograr mantener a los niños/as comprometidos y motivados con los ejercicios asignados, permitiendo obtener progresos sin perder el entusiasmo. Dinámicas específicas relacionados con la prueba y error, proveen valor agregado a la experiencia, permitiendo por ejemplo, aportar al desarrollo de habilidades de tolerancia a la frustración. Por otro lado, como en Words Matter, se evidenció que en algunos casos promovió la socialización de los resultados obtenidos en el juego. Por lo tanto, la combinación de educación + gamification implementada en aplicaciones destinadas al aprendizaje tienen evidencia comprobable con resultados positivos en los niños/as.

Para identificar los problemas que generan las notificaciones y distracciones provenientes del teléfono celular en las aulas, se desarrolló el análisis del día de un alumno/a al que se le permite el uso del celular en la escuela y sus distintos momentos considerando: antes, durante y posterior a la escuela, utilizando una herramienta denominada Journey Map. Incluyendo la interacción con sus padres, madres y docentes, se identificaron los puntos de dolor y 
oportunidades de mejora de la experiencia escolar, teniendo como eje la atención de los alumnos/as, incluyendo situaciones externas a la escuela pero derivadas de la misma, como el momento de hacer la tarea. Los puntos de dolor más recurrente fueron los relacionados a la competencia de la atención que generan las notificaciones provenientes de las aplicaciones instaladas en el celular del alumno/a. Al mismo tiempo se identificaron oportunidades de mejora que aporten a la solución de la problemática de la atención, así como del vínculo general del niño/a con su entorno escolar.

Como solución a la problemática específica de la competencia por la atención en clase, detectada como punto de dolor y basada en las oportunidades de mejoras, se propuso un juego para teléfonos celulares denominado Concentrate, cuyo objetivo principal es colaborar con la educación del niño/a a administrar la atención en momentos de clases. Utilizando una característica diferenciadora, Concentrate opta por el enfoque de la utilización consciente del teléfono celular en las aulas, en lugar de prohibir los mismos.

Utilizando mecánicas de gamification, se planteó un diseño orientado a la economía de la atención, en donde el alumno/a que evita las distracciones del teléfono celular en horarios de clase es premiado y penalizado en caso contrario. Con una historia que pretende ser atrapante, se intenta lograr el compromiso de los niños/as a lo largo de una aventura que irá incrementando su complejidad, así como desbloquear nuevas funcionalidades a medida que se progresa. El maestro/a podrá hacer el seguimiento de las distracciones generadas durante las clases, y gestionar los momentos en los que estará activo el juego, dado que se pueden dar distintas circunstancias en las que se necesite desactivarlo. Si bien el foco principal son los alumnos/as, se brindan herramientas a los padres, madres y docentes para que puedan analizar y actuar acorde a los resultados obtenidos.

Si bien el trabajo del presente trabajo fueron las notificaciones generadas por las aplicaciones del teléfono celular, Concentrate brinda una visión holística, enfocada en la problemática de la distracción en clase, pero dejando abierta las posibilidades de ampliar la dinámica para promover la colaboración dentro y fuera de la clase.

Cabe destacar que dada la investigación realizada, no se encontraron aplicaciones similares en el ámbito comercial ni en el académico, por lo que no se efectuó un análisis comparativo.

Como conclusión, el presente trabajo abarca los objetivos planteados en su totalidad, proponiendo una solución novedosa e innovadora que pretende aportar a la educación de la utilización responsable del teléfono celular en las aulas en la modalidad de aprender jugando. Quedan para posteriores trabajos la validación y su correspondiente evaluación del impacto de Concentrate en las aulas, mediante por ejemplo, la utilización del prototipo presentado. Dado el contexto actual de la pandemia de covid-19, las escuelas se encuentran cerradas, por lo que no se encuentran dadas las condiciones para hacer las pruebas en entornos de clases normales. 


\subsection{Trabajos futuros}

Dentro de las implicancias a futuro, se considera clave realizar pruebas con el prototipo de Concentrate en las aulas, cuando las condiciones epidemiológicas así lo permitan y así obtener feedback de los alumnos, maestros/as, padres y madres. Una de las formas de implementar estas actividades es por medio de lo que se denomina prueba de usabilidad de usuario, para la cual se definen consignas que el usuario deberá llevar a cabo y en base a la observación, se obtienen sensaciones, emociones dificultades y aspectos positivos de la experiencia con la aplicación. Con esta información, es posible realizar ajustes, mejoras al diseño actual y a las funcionalidades propuestas, incluso antes de iniciar la implementación de la aplicación para las plataformas móviles como Android o iOs, consiguiendo de esta manera lograr los objetivos de Concentrate y minimizar el retrabajo necesario para cumplir con las expectativas de los usuarios (alumnos/as, maestros/as y tutores).

También, desde el punto de vista pedagógico es importante realizar estudios cuantitativos y cualitativos de los efectos generados por la aplicación en los alumnos/as, con el objetivo de adaptar los contenidos de la aplicación e incluso evolucionarla a medida que se implementa su uso en las aulas. Esto se puede realizar de manera incremental, haciendo pruebas piloto, analizando los resultados obtenidos, implementar mejoras y continuar las pruebas, permitiendo así ir madurando la aplicación teniendo en cuenta las mejores prácticas y consejos de profesionales expertos en pedagogía.

Por otro lado, se propone continuar con el análisis de las funcionalidades complementarias derivadas del Journey Map, en donde se identificaron los puntos de mejora. Recordatorios para hacer las tareas, actividades colaborativas y complementarias a la escuela combinadas con el entorno de gamification propuesto, amplían la gama de opciones complementarias que Concentrate puede ofrecer para colaborar con la enseñanza de los niños y niñas a la gestión de la atención y uso responsable del teléfono celular. Adicionalmente el estudio de modelos de Inteligencia Artificial que tengan la capacidad de aprender del comportamiento del alumno/a y cuales son sus momentos de mayor distracción, posibilitará la modificación dinámica del juego, ya sea en su dificultad como en sus propuestas didácticas dependiendo del contexto en el que se encuentre.

Otro desprendimiento del trabajo actual es el desarrollo de metodologías de diseño de aplicaciones orientadas al cuidado del recurso finito de la atención en los niños/as. Nuevos desafíos, necesitan de nuevas formas de abordarlos. La tecnología forma parte de nuestras vidas, volviéndose imprescindibles en el mundo actual, pero no siempre su uso ocasiona efectos positivos. Ante abundancia de estímulos, el desafío de administrar la atención será cada vez mayor. Por lo tanto el entrenamiento mental para lograr asignar dicho recurso a las 
cosas que realmente son importantes para el proceso cognitivo, necesita de un enfoque que lo favorezcan. Definir recomendaciones de diseño acordes, será clave para la salud de nuestras mentes. 


\section{Bilbiografía}

[1] Romanello, C. (2019, February). Niños y celulares: sugieren mantenerlos alejados | Sociedad. https://www.losandes.com.ar/ninos-y-celulares-sugieren-mantenerlos-alejados/

[2] Schulkin, J. (2019, March 10). Los centennials argentinos revisan tanto su celular que nada cambió desde la última vez que lo vieron - Infobae. https://www.infobae.com/tecno/2019/03/10/los-centennials-argentinos-revisan-tanto-su-celular-q ue-nada-cambio-desde-la-ultima-vez-que-lo-vieron/

[3] Tryon, W. (2014). Cognitive Neuroscience and Psychotherapy: Network Principles for a Unified Theory. Cognitive Neuroscience and Psychotherapy: Network Principles for a Unified Theory, 1-678.

[4] Gitelman, D. R. (2003). Attention and its disorders. British Medical Bulletin, Vol. 65, pp. 21-34. https://doi.org/10.1093/bmb/65.1.21

[5] Libro Record de Fabricio Ballarini (Pag 122)

[6] LOI $n^{\circ}$ 2018-698 du 3 août 2018 relative à l'encadrement de l'utilisation du téléphone portable dans les établissements d'enseignement scolaire _ Legifrance. (n.d.).

[7] Ban phones in schools, says minister Nick Gibb - BBC News. (n.d.). Retrieved September 22, 2019, from https://www.bbc.com/news/uk-politics-47095053

[8] Church, T., Office, E. E., Church, T., \& Office, E. E. (2018). Relationships Education, Relationships and Sex Education (RSE) and Health Education. (November), 1-6. Retrieved from

https://consult.education.gov.uk/pshe/relationships-education-rse-health-education/supporting_d ocuments/20170718_Draft guidance for consultation.pdf

[9] Kaimara, P., Poulimenou, S. M., Oikonomou, A., Deliyannis, I., \& Plerou, A. (2019). Smartphones at Schools? Yes, Why not? European Journal of Engineering Research and Science, 1-6. https://doi.org/10.24018/ejers.2019.0.cie.1288

[10] Spector, Jonathan. (2016). Smart Learning Environments: Concepts and Issues. 
[11] Meishar-Tal, H., \& Gross, M. (2014). Teaching sustainability via smartphone-enhanced experiential learning in a botanical garden. International Journal of Interactive Mobile Technologies, 8(1), 10-15. https://doi.org/10.3991/ijim.v8i1.3441

[12] Mishra, P., \& Koehler, M. J. (2006). Technological pedagogical content knowledge: A framework for teacher knowledge. Teachers College Record, Vol. 108, pp. 1017-1054. https://doi.org/10.1111/j.1467-9620.2006.00684.x

[13] E.Hartnell-Young \& Nadja Heym (2008). How mobile phones help learning in secondary schools. Learning Sciences Research Institute.University of Nottinghamwww.Isri.nottingham.ac.uk

[14] Braun, I., Kapp, F., Hara, T., Kubica, T., \& Schill, A. (2018). AMCS (Auditorium Mobile Classroom Service) - An ARS with learning questions, push notifications, and extensive means of evaluation. CEUR Workshop Proceedings, 2092. CEUR-WS.

[15] Tabuenca, B., Kalz, M., Ternier, S., \& Specht, M. (2015). Stop and think: Exploring mobile notifications to foster reflective practice on meta-learning. IEEE Transactions on Learning Technologies, 8(1), 124-135. https://doi.org/10.1109/TLT.2014.2383611

[16] Pham, X. L., Nguyen, T. H., Hwang, W. Y., \& Chen, G. D. (2016). Effects of push notifications on learner engagement in a mobile learning app. Proceedings - IEEE 16th International Conference on Advanced Learning Technologies, ICALT 2016, 90-94. https://doi.org/10.1109/ICALT.2016.50

[17] Pejovic, V., \& Musolesi, M. (2015). Anticipatory mobile computing: A survey of the state of the art and research challenges. ACM Computing Surveys, 47(3), 1-30. https://doi.org/10.1145/2693843

[18] Bulling, A. (2016). Pervasive Attentive User Interfaces. Computer, 49(1), 94-98. https://doi.org/10.1109/MC.2016.32

[19] Cooper, A.(1998) The Inmates Are Running the Asylum: Why High-Tech Products Drive Us Crazy and How to Restore the Sanity (ISBN 0-672-31649-8).

[20] Gibbons, S. (2018). Journey Mapping 101. Retrieved November 19, 2019, from Journey Mapping 101 website: https://www.nngroup.com/articles/journey-mapping-101/

[21] Lee, J., \& Hammer, J. (n.d.). (PDF) Gamification in Education: What, How, Why Bother? Retrieved December 15, 2019, from Gamification in Education: What, How, Why Bother? website:https://www.researchgate.net/publication/258697764_Gamification_in_Education_What _How_Why_Bother 
[22] Goldin, A. P., Segretin, M. S., Hermida, M. J., Paz, L., Lipina, S. J., \& Sigman, M. (2013). Training Planning and Working Memory in Third Graders. Mind, Brain, and Education, 7(2), 136-146. https://doi.org/10.1111/mbe.12019

[23] Wilson, A. J., Dehaene, S., Pinel, P., Revkin, S. K., Cohen, L., \& Cohen, D. (2006). Principles underlying the design of "The Number Race",an adaptive computer game for remediation of dyscalculia. Behavioral and Brain Functions, 2(1), 19. https://doi.org/10.1186/1744-9081-2-19

[24] Vasalou, A., Khaled, R., Holmes, W., \& Gooch, D. (2017). Digital games-based learning for children with dyslexia: A social constructivist perspective on engagement and learning during group game-play. Computers and Education, 114, 175-192. https://doi.org/10.1016/j.compedu.2017.06.009

[25] Vasalou, A., Khaled, R., Holmes, W., \& Gooch, D. (2017). Accepted Manuscript Digital games-based learning for children with dyslexia: A social constructivist perspective on engagement and learning during group game-play based learning for children with dyslexia: A social constructivist perspective on engagement and learning during group game. Computers \& Education. https://doi.org/10.1016/j.compedu.2017.06.009

[25] Goldin, A. P., Segretin, M. S., Hermida, M. J., Paz, L., Lipina, S. J., \& Sigman, M. (2012). Avioncito, de Mate Marote. Juego para niños de escuela primaria. - YouTube. Retrieved December 30, 2019, from https://www.youtube.com/watch?v=xD8UMVwmTC4

[26] Stott, A., \& Neustaedter, C. (2013). Analysis of Gamification in Education. Carmster.Com, 1-8. Retrieved from http://carmster.com/clab/uploads/Main/Stott-Gamification.pdf

[27] Seffah, A., Gulliksen, J., \& Desmarais, M. C. (2005). An Introduction to Human-Centered Software Engineering (pp. 3-14). Springer, Dordrecht. https://doi.org/10.1007/1-4020-4113-6_1

[28] Christoph MeinelLarry LeiferHasso Plattner. (2011). Design Thinking | SpringerLink. Springer, Berlin, Heidelberg. Retrieved from https://link.springer.com/book/10.1007\%2F978-3-642-13757-0

[29] Tim Brown. (n.d.). IDEO Design Thinking | IDEO | Design Thinking. Retrieved August 22, 2020, from https://designthinking.ideo.com/

[30] Platner, H. Introduction to Design Thinking (2010). Process guide. Institute of Design at Stanford.DOI:https://dschool-old.stanford.edu/sandbox/groups/designresources/wiki/36873/attac hments/74b3d/ModeGuideBOOTCAMP2010L.pdf

(Consultado 2018)

[31] H. Plattner, C. Meinel, and U. Weinberg. Design Thinking (German). Number ISBN-13:

978-3868800135. mi-Wirtschaftsbuch, 2009 
[32] Gabrysiak G, Giese H, Seibel A. Towards next generation design thinking: scenario based prototyping for designing complex software systems with multiple users

[33] por, E., Bringué Sala, X., Sádaba Chalezquer, C., Zemborain, M., Cantú, C., \& Bunge, P. (n.d.). LA GENERACIÓN INTERACTIVA EN LA ARGENTINA Niños y jóvenes ante las pantallas.

[33] Jake Knapp John Zeratsky Braden Kowitz. (n.d.). The Design Sprint - How It Works The Sprint Book. In Simon \& Schuster. Retrieved September 19, 2020, from https://www.thesprintbook.com/buy

[34]ideo.org. (2015, January 1). Design Kit. https://www.designkit.org/resources/1.

[35] International Organization for Standardization, ISO FDIS 9241-210: Ergonomics of human system interaction - Part 210: Human-centered design for interactive systems (formerly known as 13407). Switzerland,2009.

[36] Manfred Broy, E. D. (2001). Pioneers and Their Contributions to Software Engineering. In Pioneers and Their Contributions to Software Engineering. Springer Berlin Heidelberg. https://doi.org/10.1007/978-3-642-48354-7

[37] Nielsen, J. (n.d.). Usability Inspection Methods. Conference Companion CHI'94 0 USA April 24-28. Boston,Massachusetts, 1994.

https://rauterberg.employee.id.tue.nl/lecturenotes/0H420/Nielsen\%5b1994\%5d.pdf

[38] Virzi, R. A. (1997). Usability Inspection Methods. In Handbook of Human-Computer Interaction (pp. 705-715). Elsevier. https://doi.org/10.1016/b978-044481862-1.50095-9

[39] Kumar, B.A., Goundar, M.S. \& Chand, S.S. A framework for heuristic evaluation of mobile learning applications. Educ Inf Technol 25, 3189-3204 (2020).

[40] Omar, H. M. @, \& Jaafar, A. (2010). Heuristics evaluation in computer games. 2010 International Conference on Information Retrieval \& Knowledge Management.

[41] Rajanen, M., \& Rajanen, D. (2018). Heuristic evaluation in game and gamification development. In GamiFIN (pp. 159-168).

[42] Tondello, G. F., Kappen, D. L., Mekler, E. D., Ganaba, M., \& Nacke, L. E. (2016). Heuristic evaluation for gameful design. In Proceedings of the 2016 Annual Symposium on

Computer-Human Interaction in Play Companion Extended Abstracts (pp. 315-323). 


\section{Apéndices}

\section{Entrevistas}

\section{Maestra 1}

\section{Contexto}

Mae es una maestra de sexto grado de primaria. Tiene 30 alumnos en el turno mañana y asiste a clases de lunes a viernes. Nos cuenta acerca de un día de clases con los niños, desde su llegada a la escuela por la mañana temprano, hasta que retornan a sus hogares.

\section{Registro de entrevista}

Iniciamos como todas las escuelas, izando la bandera, algún anuncio de las maestras o directora y luego todos al aula. Los lunes suelen ser muy "pum para arriba", vienen del finde donde la mayoría se desconecta de la escuela, salen a jugar y pasear con sus familias, amiguitos así que llegan con energías recargadas y muchas ganas de compartir con sus compañeritos /as. Eso es lindo, verlos tan contentos y con ganas. A continuación, empezamos repasando lo que vimos en la última clase de matemáticas para ponerlos en sintonía y arrancar. Y acá es donde uno se da cuenta quien hizo la tarea que se les dió para hoy, quienes saben que no lo hicieron y quienes con toda sinceridad me dicen que se olvidaron. Muchos chicos tienen a sus padres que les están detrás y los acompañan en las tareas, pero una gran mayoría tiene padres que lamentablemente no les alcanzan las horas para poder ayudarlos o estar pendientes.

¿Cómo haces con esta situación? ¿Y con los niños que siempre se olvidan de hacer la tarea?

La realidad es que no puedo estar en cada casa para recordarles que tiene tarea para el lunes. Todo esto depende mucho de distintos factores, de el apoyo de los padres, la educación en cuanto a la responsabilidad que desde acá intentamos colaborar. En el peor de los casos, en donde veo alguna situación de alerta, en la cual no cumplir con las tareas para la casa se haga una constante, me comunico con la psicopedagoga para poder entender el porqué y contactar a los padres o tutor en caso de ser necesario.

Continuando con tu relato de la clase, ¿cómo continúa? ¿cómo es lidiar con la atención de los niños y niñas?

Es todo un tema. ¡Hoy en día los niños /as vienen con una dosis extra de estimulación! Muchos de ellos pasan mucho tiempo ante pantallas, ya sea de sus celulares o tablets mirando videos 
de distintas temáticas y jugando. Es como que los absorbe, se los lleva de este planeta y los rapta en otro mundo. Tienen la capacidad de aprender muy rápido cómo usar la tecnología que les da la opción de mirar y hacer lo que ellos más les gusta al instante, sin esfuerzo. Yo siempre intento hacer las clases lo más interactivas posible, para mantenerlos enganchados, dándoles actividades para que las resuelvan en grupo, pero así y hay temas teóricos que nos toca dar y son los momentos que más cuestan. Pero a pesar de esas situaciones, seguimos adelante, el tema es que al no lograr enfocar su atención por mucho tiempo, necesitan de mucho repaso y tareas para fijar conocimientos.

Sabemos que en CABA los celulares están prohibidos en la escuela. Aquí en las provincias lo dejan a criterio del docente. ¿Cómo te manejas con ese tema?

Mirá, lo que hago es pedirles que guarden su celular al iniciar el día y que solo lo usen en los recreos o para alguna situación de necesidad particular. Ahora, la realidad es que muchos lo usan igual a escondidas. No es tan fácil controlar siempre todo, hay momentos de atención y hay momentos más desestructurados en la clase, en donde lo usan. Son conductas que suelen en parte venir de la casa, en donde el papá, la mamá y sus hermanitos pasan mucho tiempo con el celular.

¿Usarías el celular con fines educativos?

$\mathrm{Si}$, por supuesto. Usualmente en algunos trabajos prácticos, podemos llegar a usar las cámaras de fotos, siguiendo ciertas consignas, que les permitan documentar con fotos. Pero el tema es que se puede desvirtuar rápidamente. Los niños son niños y los celulares son como un fuente muy tentadora de distracciones. Es por eso que siempre terminamos prohibiendo el celular en clase, es muy difícil así. 


\section{Maestra 2}

\section{Contexto}

Lila es una maestra de sexto grado en una escuela donde asisten niños/as provenientes de familias de bajos recursos. Su clase tiene 32 alumnos y el nivel de asistencia no siempre es el óptimo. Algunas familias a veces salen a trabajar y se llevan a sus hijos con ellos, dadas las dificultades económicas. Lograr la atención de los niños y niñas en este contexto es todo un desafío.

\section{Registro de entrevista}

Los niños y niñas van llegando a la escuela por la mañana, algunos llegan en horario y muchos otros un poquito tarde. Algunos lo hacen acompañados por alguno de sus tutores y otros lo hacen con hermanitos y hermanitas. Nos juntamos en el patio para izar la bandera y darles la bienvenida. A veces hay anuncios de la directora y después nos vamos al aula. Es un momento donde todos suelen estar contentos y alborotados de encontrarse con sus compañeritos y compañeritas. Entramos al aula y empezamos con la materia del día, siempre les pregunto que tal les fue con las tareas, si es que les di para hacer en casa. En esos momentos puedo ver en sus caritas los que la hicieron, los que no y los que se olvidaron y les agarra por sorpresa.

¿Cómo haces con esta situación? ¿Y con los niños que siempre se olvidan de hacer la tarea?

Muchos vienen de familias con carencias, sus padres trabajan todo el día, no tienen quien los ayude ni les está preguntando o recordando si hicieron la tarea. Nos toca armarnos de paciencia y tratar de ayudarlos a suplir ese rol de apoyo que no tienen en sus casas. Como no puedo ir uno por uno, la forma que encuentro de hacerlo para todos, es haciendo un repaso de las tareas para que al menos completemos algunas entre todos.

Continuando con el relato de tu día de clases, una vez que inicias, ¿Cómo es la tarea de lograr captar la atención de los niños y niñas?

Hay días y días. Los lunes suelen ser los más difíciles porque llegan de un finde, con muchas ganas de hablar entre ellos, contarse sus cosas y seguir jugando. Muchas veces logro que presten atención y otras veces se me complica. Cuando empiezo a enseñar un tema, trato de hacerlo lo más interactivo posible, con ejemplos de la vida diaria y haciéndoles preguntas para ver si entendieron. Pero bueno, son niños y hay días que me dan dolores de cabeza jaja.

¿Y el celular? ¿Qué papel juega en este tipo de situaciones en el aula? 
Los niños de esta escuela son de bajos recursos, por lo que varios no lo tienen. Ahora es un problema el respeto de un horario...o los comentarios q hacen.. Si no los controlamos, si se distraen.. miran videos, escuchan música, juegan jueguitos.

¿Y qué solés hacer cuando los encontras distraídos con el celular?

Y llamar la atención...pero tbn dejar claro en qué clase se va a usar y para qué. Algunas maestras juntan los celus en una caja que tienen en el escritorio hasta el momento de usarlo.

O sea que en algunas clases si les dejan usar. ¿Me podrías dar un ejemplo de que tipo de uso le dan al celular en las clases?

El uso más frecuente que les permitimos es para buscar información, como por ejemplo fechas históricas, información de países y provincias para clases de geografía. Si salimos a hacer algún paseo educativo, como por ejemplo un museo, les dejamos tomar fotos para que después hagan un resumen de lo que vieron y lo que más les llamó la atención.

\section{Maestra 3}

Marta es maestra de cuarto año de una escuela pública de la provincia de Buenos Aires. Tiene un grupo de 32 alumnos/as. Da clases de lunes a viernes por la mañana. A sus clases asisten niños y niñas provenientes de distintas realidades sociales y la mantienen muy ocupada, intentando siempre el mejor aprendizaje posible dentro de las condiciones que se le plantean en su día a día. Dada su baja disponibilidad de tiempo, conversamos específicamente sobre la utilización de celulares en el aula.

\section{Registro de la entrevista}

Luego de contarme a qué se dedica, acerca de sus clases, sus alumnos, alumnas, le consulto acerca del uso del celular en las aulas. Le comento que tengo bien clara la política de utilización de celulares en las aulas.

¿Cómo es la política acerca del uso de celulares en el aula?¿Existe alguna reglamentación?

No hay un reglamento dentro de la escuela pública que permita o prohíba el uso. Es más una decisión desde la conducción de cada escuela. Y hasta a veces es la decisión de cada docente.

¿Cómo es en tu caso? ¿Les permitís su uso?

Pueden tener el celular en clase. Creo que es importante enseñarles como parte de la educación, a respetar los momentos en los que lo pueden usar y en los que no. Hasta ahora 
me maneje bien por suerte y coincidí con maestros que piensan igual que yo... hablarles a los chicos y tomar conciencia..Igualmente todavía son chicos... y "hacen caso"

Quizás es una estrategia mía...

¿Y como te va con las clases y el celular? ¿Qué medidas tomas para evitar las distracciones?

En general se comportan bastante bien y se controlan con el uso durante las clases. Pero como te comenté, son chicos y por supuesto que algunos por momentos se distraen. El tema de las fotos y usos de redes sociales durantes las clases es lo que más trato de evitar. En mi caso siempre les hable a los chicos y comente que si llegan a sacar fotos y las publican en redes sociales... y sale la foto de otro menor el problema era desde el celular que se tomó la foto ... más que nada era hacerles tomar conciencia.. nunca tuve inconvenientes... siempre lo entendieron y cuando han sacado hablando las borraron...

¿Les permitirías utilizarlo para algunas actividades?

Es un tema bastante complicado, porque siempre está el riesgo de que terminen utilizando el celular para cosas que no deben. Otros profesores si permiten para "buscar información" y han tenido problemas de que los pibes publican en horario escolar ... llaman a los padres para que vengan a buscarlos...Así que por el momento, intento permitirles el uso solamente fuera del horario de clases. 


\section{Padre 1}

\section{Contexto}

Pepe es padre de un niño de 10 años, cuyo hijo va a la escuela primaria pública. Lleva a su hijo todas las mañanas temprano a la escuela antes de ir a trabajar. Hace horario corrido y vuelve a su casa de noche, cuando es hora de cenar. Con mucha amabilidad y predisposición, nos cuenta cómo son los días escolares de su hijo y cómo lo acompañan en su aventura educativa.

\section{Registro de entrevista}

Todo arranca el domingo por la tarde. Mi hijo es muy responsable y hace la tarea para el día siguiente. El fin de semana es un caso especial, porque se divierte, sale a jugar con sus amiguitos y también salimos a pasear en familia. Esa tranquilidad y divertimento a veces se ve interrumpida cuando se acuerda, el mismo domingo por la noche, que tenía tarea para el lunes! Es en ese momento donde primero intentamos calmarnos, pero siempre terminamos corriendo para terminar a tiempo. Ya sea buscando material en internet, o construyendo maquetas hasta la medianoche. A veces lo encontramos relativamente fácil, otras nos cuesta bastante y nos lleva mucho tiempo. Son los menos, pero nos ha tocado lidiar con esas (sonríe). Siempre intentamos apoyarlo en todo.

El lunes por la mañana lo llevo a la escuela, y si tiene prueba, vamos repasando en el camino los temas que estuvo estudiando, para ayudarlo a despertar y para recordar o aclarar alguna duda de último momento que pueda surgir. Lo dejo en la escuela y la madre lo va a recoger.

¿Tu hijo lleva uno a la escuela?

Si, lo lleva. A nosotros nos da tranquilidad que él esté siempre comunicado. Si algún día se siente mal o nos quiere contar algo, que lo pueda hacer directamente con nosotros es muy importante. Incluso hay momentos en que nosotros también necesitamos hablar con él, ya sea porque por ejemplo tenemos alguna demora para ir a buscarlo, o para lo que sea que necesitemos, es muy importante.

\section{¿Qué opina del uso del celular en las aulas?}

Y mirá, creo que es un tema delicado. Las maestras no les dejan usarlo en clase y lo entiendo. El celular es un elemento muy distractivo y puede hacer que no presten atención en clase. Pero la realidad es que a veces lo usan igual. Suelo recibir mensajes por Whatsapp de mi hijo en horario de clase durante las clases de manualidades, contándome que se aburre (risas). Creo que el celular es algo que los va a acompañar durante toda la vida, es un elemento natural que la mayoría utilizamos. Nosotros intentamos ponerle límites a su uso en la casa, para que 
aprenda a usarlo lo más racionalmente posible. Cuando sale de la escuela y en momentos de relax, se lo dejamos usar. Le gustan mucho los juegos y se apasiona con el Fortinet o el de Pokemon. 
Journey Map Alumno
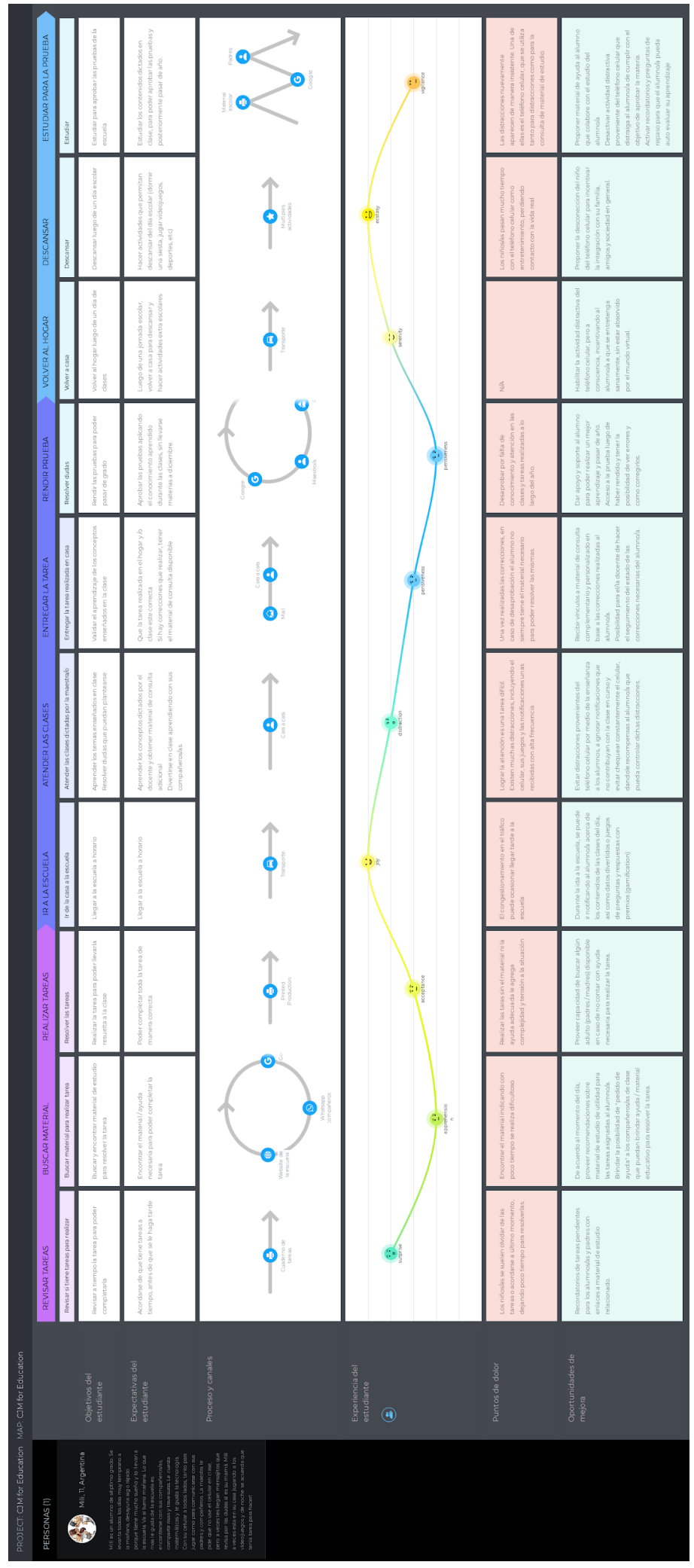
Concentrate: Journey Map Alumna/o

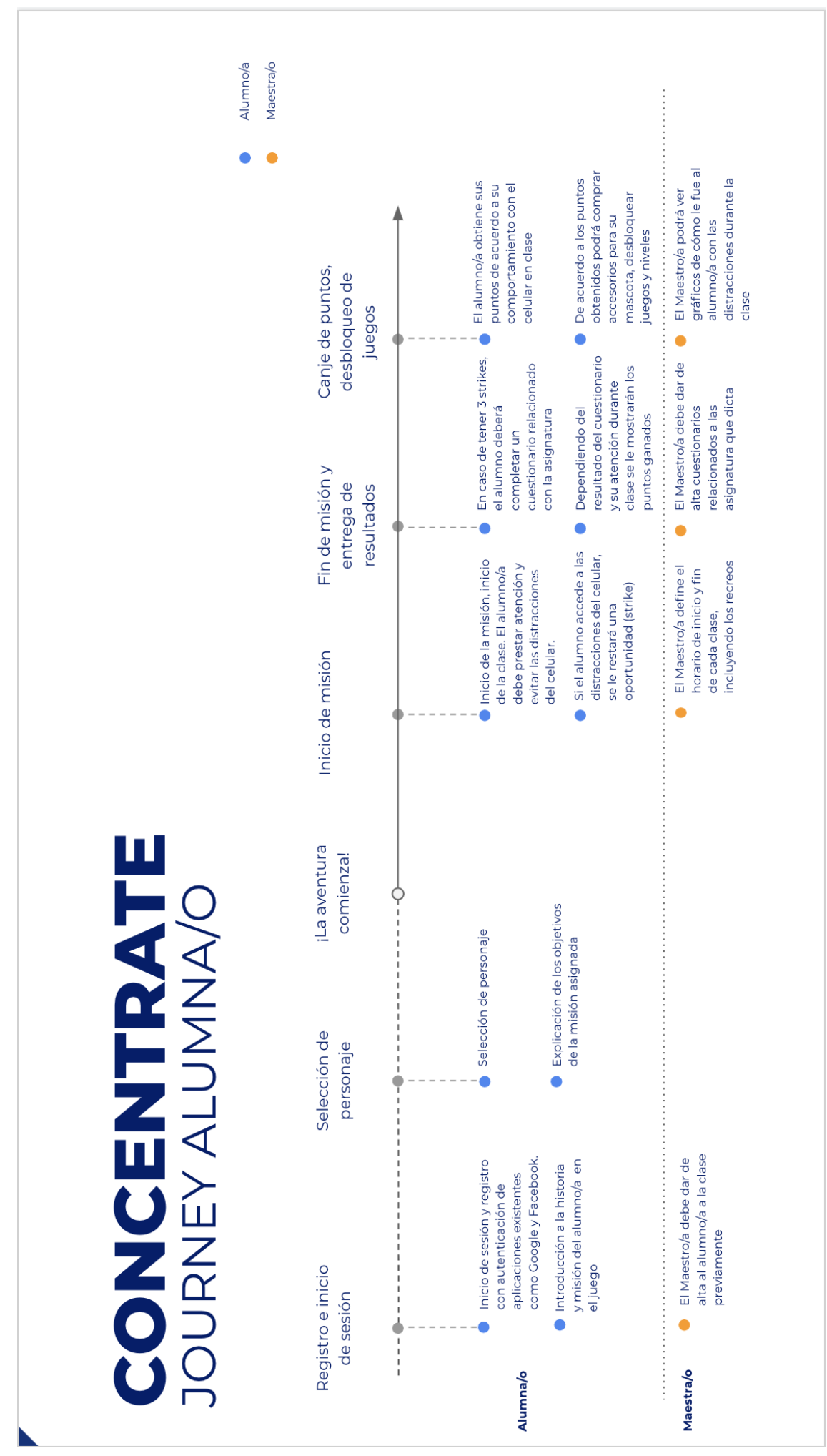


Concentrate: Journey map Maestro/a

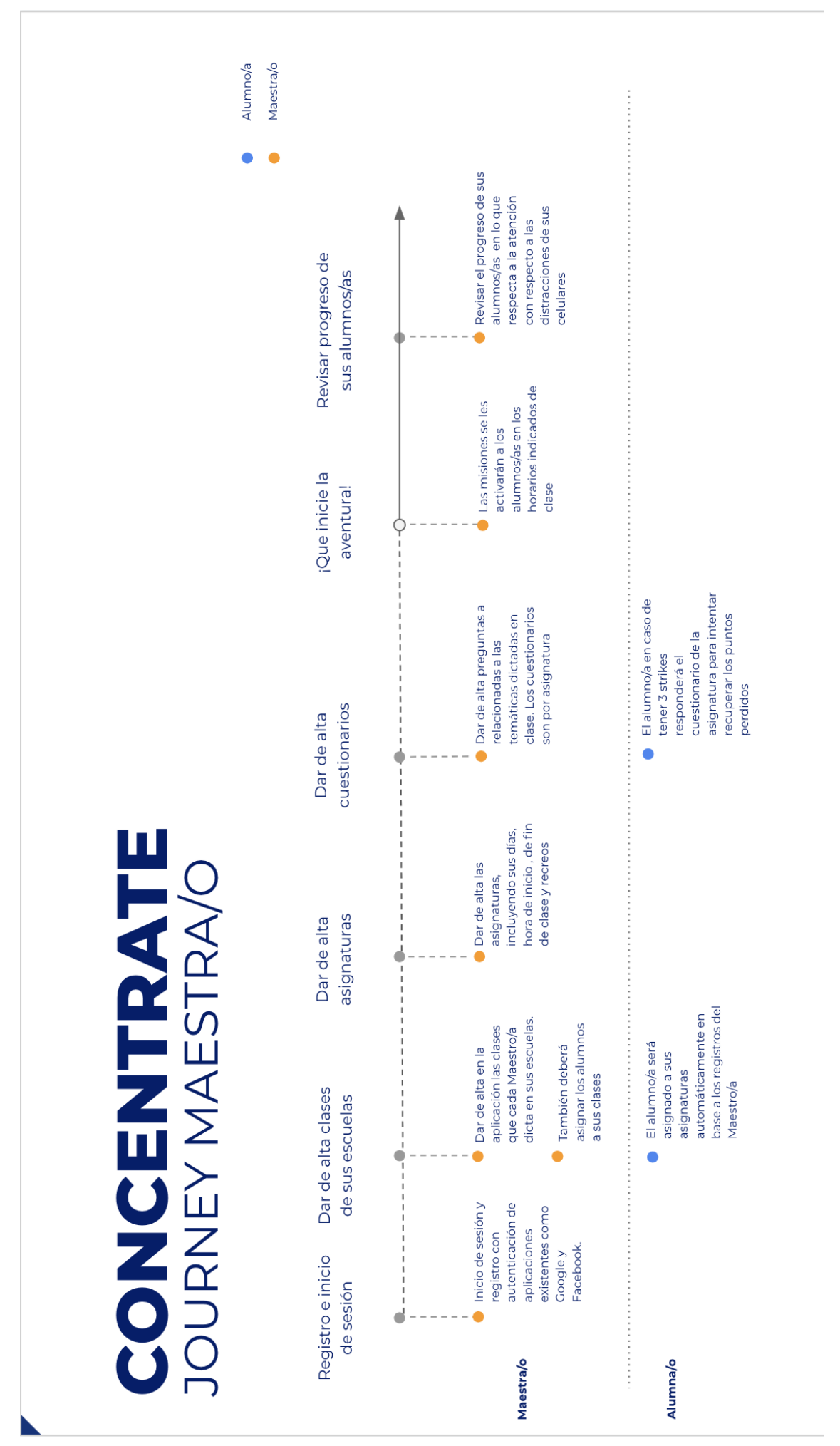

